\title{
The empirical effects of government spending
}

\author{
Citation for published version (APA):
}

van Gemert, T. J. J. (2021). The empirical effects of government spending. [Doctoral Thesis, Maastricht University]. Maastricht University. https://doi.org/10.26481/dis.20210622tg

Document status and date:

Published: 01/01/2021

DOI:

10.26481/dis.20210622tg

Document Version:

Publisher's PDF, also known as Version of record

\section{Please check the document version of this publication:}

- A submitted manuscript is the version of the article upon submission and before peer-review. There can be important differences between the submitted version and the official published version of record.

People interested in the research are advised to contact the author for the final version of the publication, or visit the DOI to the publisher's website.

- The final author version and the galley proof are versions of the publication after peer review.

- The final published version features the final layout of the paper including the volume, issue and page numbers.

Link to publication

\footnotetext{
General rights rights.

- You may freely distribute the URL identifying the publication in the public portal. please follow below link for the End User Agreement:

www.umlib.nl/taverne-license

Take down policy

If you believe that this document breaches copyright please contact us at:

repository@maastrichtuniversity.nl

providing details and we will investigate your claim.
}

Copyright and moral rights for the publications made accessible in the public portal are retained by the authors and/or other copyright owners and it is a condition of accessing publications that users recognise and abide by the legal requirements associated with these

- Users may download and print one copy of any publication from the public portal for the purpose of private study or research.

- You may not further distribute the material or use it for any profit-making activity or commercial gain

If the publication is distributed under the terms of Article $25 \mathrm{fa}$ of the Dutch Copyright Act, indicated by the "Taverne" license above, 


\title{
The Empirical Effects of Government Spending
}

\author{
Thomas van Gemert
}


(C) Thomas van Gemert, Maastricht, 2021

All rights reserved. No part of this publication may be reproduced, stored in a retrieval system, or transmitted in any form, or by any means, electronic, mechanical, photocopying or otherwise, without the permission in writing from the author.

This book has been typeset by the author using $\mathrm{ATEX}_{\mathrm{E}}$. 


\title{
The Empirical Effects of Government Spending DISSERTATION
}

\author{
to obtain the degree of Doctor at \\ Maastricht University, \\ on the authority of the Rector Magnificus, \\ Prof. dr. Rianne M. Letschert, \\ in accordance with the decision of the Board of Deans, \\ to be defended in public \\ on Tuesday, 22 June, 2021 at 10:00 o'clock \\ by \\ Thomas Jacobus Johannes van Gemert
}




\section{Promotors}

Prof. dr. Clemens Kool

Prof. dr. Tom van Veen

\section{Co-promotors}

Dr. Tania Treibich

Dr. Lenard Lieb

\section{Assessment Committee}

Prof. dr. Joan Muysken (chair)

Prof. dr. Bertrand Candelon

Prof. dr. Jonas Dovern, Friedrich-Alexander-Universität Erlangen-Nürnberg

Dr. Sinem Hacioğlu-Hoke, Bank of England 


\section{Acknowledgements}

This thesis is the end product of a long academic journey. It already began during my master's studies in 2014, when I first met Lenard Lieb, who taught Advanced Macroeconomics in the research master program. My interest for combining macroeconomics with econometrics turned into a fascination that kept me busy for years. Although Lenard and I are very different in many ways, we share the same passion for empirical macroeconomics, and we get along very well. I am very thankful to Lenard for providing me the opportunity to explore this field. He always ensured that I could follow my own interests, and challenged me to always think critically. I finished the master's program with a thesis on the categorization of government spending, of which Tania Treibich was the second supervisor. That was also the moment Lenard and Tania proposed that I should start a PhD project, where the three of us would work together intensively. I have enjoyed our cooperation over the last years very much. I really learned a lot from both of you. Your different perspectives and ways of working definitely contributed to the quality of my research. Also, thanks to my supervisors and the assessment committee for reading and evaluating the thesis.

I also want to thank my fellow $\mathrm{PhD}$ candidates, friends from the research master program, and colleagues from MILE and other SBE-departments at Maastricht University for your inspiration and support. I have really enjoyed working with you. For 8 years, Maastricht has felt as a second home to me. I especially want to thank Johannes, my office mate, who I could always count on. I really enjoyed our time together in Maastricht. I have very good memories to our trip to Cyprus. The interesting conversations that we had over there almost made me consider staying in academia. I wish you all the best with your future career. 
After all, I decided not to stay in academia. In 2020, I started working at Statistics Netherlands (CBS). I really appreciated the warm welcome that I received over there. Special thanks to my manager Hub, who has supported me in the last year, and encouraged me to finish the thesis. But of course, I would have never finished this thesis without the support from my family and friends. First of all, my girlfriend Fleur. Thanks a lot for all the patience, and confidence in me. I know that it has not always been easy to be with someone with a full-time job, a political career, and an ambition to finish a $\mathrm{PhD}$ thesis. I also want to thank my parents for providing me the opportunity to study. They have always encouraged me to follow my ambitions. Actually, it was my father who suggested to consider studying economics. If he had not suggested that, I would probably have studied law or political science. Finally, thanks to the rest of my family, friends, colleagues from CBS, the VVD and Natuurmonumenten, who always supported me during this long academic journey. 


\section{Contents}

\begin{tabular}{|ll}
\hline Acknowledgements & i
\end{tabular}

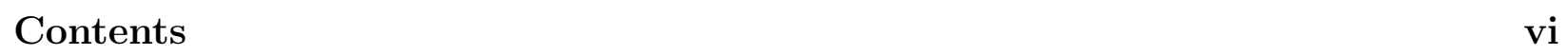

List of Figures $\quad$ viii

List of Tables $\quad$ ix

\begin{tabular}{lll}
\hline & Introduction & 1
\end{tabular}

1.1 Motivation . . . . . . . . . . . . . . . . . . . 2

1.2 Empirical identification problem . . . . . . . . . . . . . . . . . . 4

1.2 .1 Endogeneity of government spending . . . . . . . . . . . . . . . 4

1.2 .2 Government spending shocks . . . . . . . . . . . . . . . . . 6

1.2 .3 Current state of research $\ldots \ldots \ldots$. . . . . . . . . . . . . . . . . 7

1.3 Outline of the thesis $\ldots \ldots \ldots \ldots$. . . . . . . . . . . . . . . . . . . 8

1. A Appendix . . . . . . . . . . . . . . . . . . . . . . 12

1.A.1 Historical data

1. A.2 Empirical example . . . . . . . . . . . . . . . . . . 13

2 The Role of the Anticipation Horizon in Government Spending News 17

2.1 Introduction . . . . . . . . . . . . . . . . . . . . . . . . . . 18

2.2 Constructing fiscal foresight measures . . . . . . . . . . . . . . . . . . . . 21

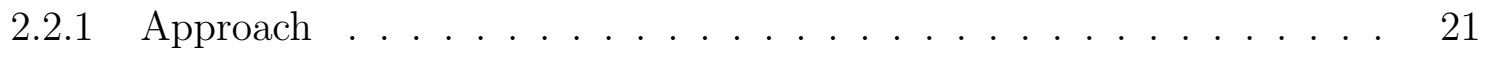


2.2 .2 Results . . . . . . . . . . . . . . . . . . . . . . . . . . . . . . . . . . . . 23

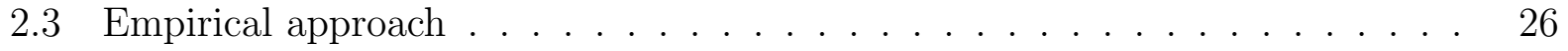

2.3 .1 Motivation . . . . . . . . . . . . . . . . . . . . . . 27

2.3 .2 Estimating Shocks $\ldots \ldots \ldots \ldots$

2.3 .3 Estimating Responses $\ldots \ldots \ldots \ldots$

2.4 Data and results $\ldots \ldots \ldots \ldots$

2.4 .1 Data $\ldots \ldots \ldots \ldots \ldots \ldots$

2.4 .2 Shock estimates . . . . . . . . . . . . . . . . . . . . . 34

2.4 .3 Impulse response estimates $\ldots \ldots \ldots \ldots \ldots$

$2.4 .4 \quad$ Discussion $\ldots \ldots \ldots \ldots \ldots$

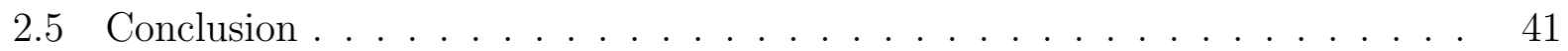

2. A Appendix . . . . . . . . . . . . . . . . . . . . . . . 42

2. A.1 Data description $\ldots \ldots \ldots \ldots \ldots \ldots$

2. A.2 Overview of all defense news $\ldots \ldots \ldots \ldots \ldots$

3 Local Fiscal Multipliers of Different Government Spending Categories 51

3.1 Introduction . . . . . . . . . . . . . . . . . . . . . . . . . . . 52

3.2 Local fiscal multipliers in the related literature . . . . . . . . . . . . . . 54

$3.2 .1 \quad$ Estimating local fiscal multipliers: Objectives and challenges . . . . . 54

$3.2 .2 \quad$ Estimating local fiscal multipliers: Possible solutions $\ldots \ldots \ldots . . .55$

3.3 Empirical approach $\ldots \ldots \ldots \ldots \ldots$

$3.3 .1 \quad$ Structure of government spending in the United States $\ldots . . . .58$

3.3 .2 Data $\ldots \ldots \ldots \ldots \ldots$

3.3 .3 Econometric model . . . . . . . . . . . . . . . . . . . . . . . . . . 61

3.4 Results . . . . . . . . . . . . . . . . . . . . . . . . . . . . . 67

3.4 .1 Baseline results . . . . . . . . . . . . . . . . . . . . 67

3.4 .2 Spillovers across states $\ldots \ldots \ldots \ldots$

3.5 Conclusion $\ldots \ldots \ldots \ldots \ldots \ldots$

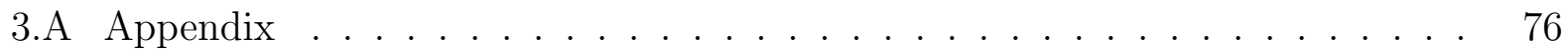


3. A.1 Static approach $\ldots \ldots \ldots \ldots \ldots \ldots \ldots$

3. A.2 $\quad$ Forecasting model for the dynamic approach . . . . . . . . . . . 79

3. A.3 Robustness checks . . . . . . . . . . . . . . . . . . . . . 81

4 Sectoral and Regional Spillover Effects of Government Spending $\quad 85$

4.1 Introduction . . . . . . . . . . . . . . . . . . . . . . . . . 86

4.2 Regional effects of government spending $\ldots \ldots \ldots$

4.2 .1 Existing literature $\ldots \ldots \ldots \ldots$

4.2 .2 Short-run policy consequences $\ldots \ldots \ldots$. . . . . . . . . . . . . . 92

4.3 Direct effects $\ldots \ldots \ldots \ldots \ldots$

4.3 .1 Estimation method $\ldots \ldots \ldots \ldots$

4.3 .2 Estimating region-specific shocks $\ldots \ldots \ldots$. . . . . . . . . 97

4.3 .3 Estimation results for direct effects . . . . . . . . . . . . . 100

4.4 Regional spillover effects $\ldots \ldots \ldots$. . . . . . . . . . . . . . . . . . . 104

4.4 .1 Constructing partner shocks ． . . . . . . . . . . . . . . . . . 104

$4.4 .2 \quad$ Estimation results for regional spillovers $\ldots \ldots \ldots \ldots$

4.5 Conclusion $\ldots \ldots \ldots \ldots \ldots$

4. A Appendix $\ldots \ldots \ldots \ldots$

4. A.1 Different EU funds . . . . . . . . . . . . . . . . . . . . . . . . . 113

4. A.2 Data description . . . . . . . . . . . . . . . . . . 115

4. A.3 Results sectoral responses _ . . . . . . . . . . . . . . . . . 116

4. A.4 Results regional spillovers _. . . . . . . . . . . . . . . . . . . . . . 119

4. A.5 Results employment . . . . . . . . . . . . . . . . . . . . . 122

$\begin{array}{llr}5 \text { Conclusion } & 125\end{array}$

5.1 Contributions and implications $\ldots \ldots \ldots \ldots$

5.2 Strengths and weaknesses $\ldots \ldots \ldots \ldots \ldots \ldots$

5.3 Future research $\ldots \ldots \ldots \ldots$

\begin{tabular}{lr}
\hline Valorisation addendum & 133
\end{tabular} 
CONTENTS

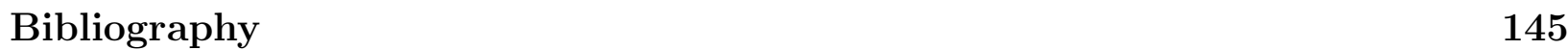

\begin{tabular}{ll}
\hline Summary & 147
\end{tabular}

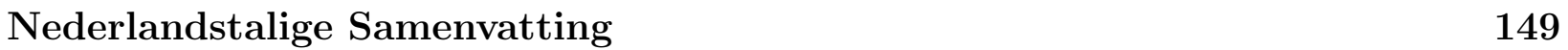

\begin{tabular}{ll}
\hline Curriculum Vitae & 153
\end{tabular} 


\section{List of Figures}

1.1 Government spending and debt in The Netherlands and the US . . . . . . . 2

1.2 Endogeneity of governments pending . . . . . . . . . . . . . . . . 5

1.3 Historical data for government spending and debt . . . . . . . . . . . . . . . 12

1.4 Time series plots of government spending and GDP . . . . . . . . . . . . . . 14

1.5 Scatter plots of government spending and GDP . . . . . . . . . . . . . . 15

2.1 Frequency of the length of the anticipation horizon . . . . . . . . . . . 24

2.2 Length of the inside lag over time . . . . . . . . . . . . . . . . . . . 24

2.3 News series with short and long anticipation horizon . . . . . . . . . . . . . 25

2.4 Responses with a short and long anticipation horizon . . . . . . . . . . . 36

2.5 Responses to a Ramey news shock . . . . . . . . . . . . . . . . . . . . . . . 37

2.6 Key macroeconomic variables . . . . . . . . . . . . . . . . . . . . 43

3.1 Fiscal policy flows in a federally organized state . . . . . . . . . . . . . 58

3.2 Impulse responses to defense spending and non-defense spending shocks . . . 68

3.3 Cumulative multipliers for defense spending and non-defense spending shocks 69

3.4 Impulse responses for the shocks to the opposite variables . . . . . . . . . . . 71

3.5 Impulse responses for cross-state spillovers . . . . . . . . . . . . . . . . . . . 74

$3.6 \quad$ Impulse responses and multipliers with quadratic trend . . . . . . . . . . . . 81

3.7 Impulse responses and multipliers with fiscal year data . . . . . . . . . . . . 82

3.8 Impulse responses and multipliers with NASBO vs Census data . . . . . . . 83 
$4.1 \quad$ Impulse responses shocks within and between programming periods . . . . . 99

4.2 Direct effects for a shock within and between programming periods . . . . . 100

4.3 Direct effects for less and more developed regions . . . . . . . . . . . . . . 101

4.4 Direct effects for the industrial and public sector . . . . . . . . . . . . . . 102

4.5 Direct effects for the construction and service sector . . . . . . . . . . . . . . 104

$4.6 \quad$ Regional spillovers within and between programming periods . . . . . . . . . 107

4.7 Regional spillovers for less and more-developed regions . . . . . . . . . . . . 108

4.8 Regional spillovers for the industrial and public sector . . . . . . . . . . . . . 109

4.9 Regional spillovers for the construction and service sector . . . . . . . . . . . 110

4.10 Relative sizes of EU structural and investment funds in 2010. . . . . . . . . . 113

4.11 EU structural and investment funds over time . . . . . . . . . . . . . . . . . 114

4.12 Development levels of NUTS-2 regions in the EU . . . . . . . . . . . . . . 115

4.13 Direct effects within and between programming periods . . . . . . . . . . . 116

4.14 Direct effects within a programming period for development levels . . . . . . 117

4.15 Direct effects between programming periods for development levels. . . . . . 118

4.16 Spillover effects within and between programming periods . . . . . . . . . . 119

4.17 Spillover effects within a programming period for development levels . . . . . 120

4.18 Spillover effects between programming periods for development levels . . . . 121

4.19 Direct effects within and between programming periods for employment . . . 122

4.20 Spillover effects within and between programming periods for employment . 123 


\section{List of Tables}

$1.1 \quad$ Estimation results for empirical example $\ldots \ldots \ldots$

$2.1 \quad$ Marginal F-tests for narrative series and shock estimates at future horizons . 34

2.2 Multiplier estimates for news shocks with a short and long anticipation horizon 38

$3.1 \quad$ Static results for defense and non-defense spending $\ldots \ldots \ldots 77$

3.2 Estimated multipliers and F-statistics for longer horizons using IV] . . . . . 78

3.3 Root mean squared forecast error $\ldots \ldots \ldots$. . . . . . . . . . . . . 79

3.4 Root mean squared forecast error using a 15-year window . . . . . . . . . . . 80

4.1 Description of EU funds $\ldots \ldots \ldots \ldots$

4.2 Data description $\ldots \ldots \ldots \ldots \ldots$ 
Chapter 1

\section{Introduction}




\subsection{Motivation}

The government has become an important player in the economy. Especially after the Second World War, the size of the government in the economy has increased substantially in many countries. Figure 1.1 shows two ways of measuring the size of the government, namely by government spending as a percentage of GDP, or government debt as a percentage of GDP The graphs show that the size of the government in the economy in both the United States and the Netherlands is quite substantial. Especially during the financial crisis in 2008, the size of the government increased. Nevertheless, this increase is probably incomparable compared to the increase in both spending and debt during the current Covid-19 pandemic.

Figure 1.1: Government spending and debt in The Netherlands and the US

(a) Government spending

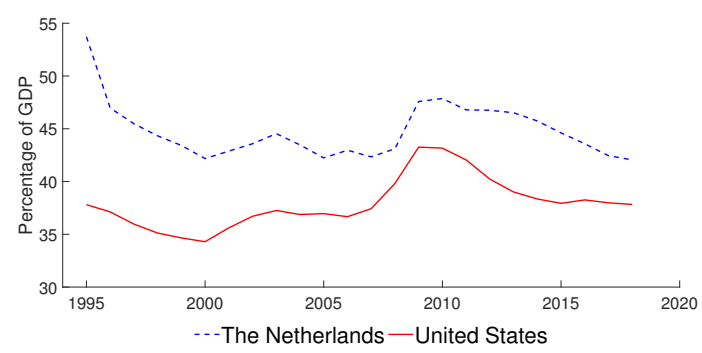

(b) Government debt

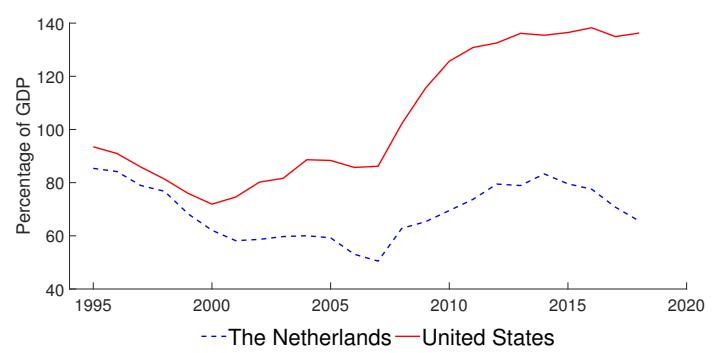

Note: Government spending (left) and government debt (right) in the Netherlands (dashed) and the US (solid) expressed in percentage deviation from the trend. Data source: OECD

There are several explanations why the government became such an important player in the economy. Governments have many economic goals, such as short-term stabilization, income and welfare redistribution, public goods provision and long-term economic growth promotion. It appears that governments increased their role in the economy to achieve these goals. Given the size of the government, it makes sense that economists pay special attention to it. There is a long tradition in macroeconomics to study whether governments effectively reach these policy goals. This thesis focuses on short-run stabilization policy.

More specifically, the thesis provides an empirical investigation into the underlying factors ${ }^{1}$ See also 1.A.1 for historical data for the United States and the Netherlands from Mauro et al. (2015). 
that play a role in the short-term macroeconomic consequences of government spending $2^{2}$ For quite some time, say between 1980 and 2010, there was little research interest into the role of the government in short-run stabilization policy. There was consensus in mainstream macroeconomics that stabilization policy was ineffective, due to the recognition of the rational expectations theory and the notion that many political barriers hindered policymakers from effectively conducting fiscal policy. Macroeconomists agreed that the central bank could possibly help the economy more by using monetary policy in an effective way, i.e. adjusting nominal interest rates.

However, after the financial crisis of 2008 , there was renewed interest in fiscal stabilization policy, because the nominal interest rate had reached the so-called zero lower bound. Many economists suggested that fiscal policy could be an effective tool in bringing the economy back to the long-run economic growth path. At that time, many countries developed discretionary fiscal stimulus packages. For example, in the US the American Recovery and Reinvestment Act (ARRA) was passed. In the Netherlands the Crisis and Recovery Act came into play, accelerating for example the construction of a motorway tunnel in Maastricht.

From a theoretical point of view, there is no consensus among macro-economists about the short-run effects of government spending. Keynesian theory predicts that additional government spending stimulates GDP, creating a government spending multiplier above 1, because private consumption is boosted, especially when the marginal propensity to consume is large. However, if the economy operates near full capacity, government spending raises the interest rate, which potentially creates a crowding-out effect on private investment through the negative relation between investment and the interest rate (Marglin and Spiegler, 2013). In contrast, Neoclassical theory claims that government spending crowds out private consumption, while raising private investment, associated with a multiplier of no more than 1. It predicts that government spending creates a negative wealth effect, because consumers anticipate on increases in future taxation. Therefore, consumers reduce consumption and leisure. However, they also increase labour supply, which raises the marginal product of

\footnotetext{
${ }^{2}$ The economic consequences of government deficits and debt are outside the scope of this thesis. The core analysis focuses on deficit-financed spending, without discussing the boundaries of deficits and debt.
} 
capital and stimulates private investment (Aiyagari et al., 1992; Baxter and King, 1993). Finally, New-Keynesian theory predicts that the government spending multiplier can only be above 1 under certain conditions, for example when wages are sticky and workers are off their labour supply curves (Ramey, 2019), when there are hand-to-mouth and/or liquidity constrained consumers (Galí et al., 2007; Auclert et al., 2018), or when monetary policy deviates from the Taylor rule (Woodford, 2011).

Since the main macroeconomic theories disagree about the income effects of government spending in the short-run, empirical research may provide useful insights. This introductory chapter motivates the empirical research conducted in this thesis. In section 1.2 , I explain the empirical identification problem that arises when studying the macroeconomic effects of government spending, and I discuss how this problem is tackled in the existing empirical literature. Section 1.3 provides the outline of the consecutive chapters in this thesis.

\subsection{Empirical identification problem}

\subsubsection{Endogeneity of government spending}

Empirical analysis can help to verify predictions from existing macroeconomic theories. Nakamura and Steinsson (2018) suggest that empirical research should focus on portable statistics that can be compared across models. An example could be the fiscal multiplier, which can be used for model evaluation, even though the fiscal multiplier is not a deep structural model parameter ${ }^{3}$ Nevertheless, empirical research can provide information on a block of model parameters or mechanism of a model, which allows to reject a set of models.

Empirical analysis typically consists of three stages: identification, estimation, and inference (or testing). In this thesis, I focus on the relation between government spending and other macroeconomic variables, such as GDP. However, in that case a severe identification problem arises. Government spending is inherently endogenous to other macroeconomic variables, because policies are not conducted as natural experiments. Instead, policymakers

\footnotetext{
${ }^{3}$ This recommendation goes to some extent against the Lucas critique that advises macroeconomists to only
} study deep model parameters to determine the behaviour of individual agents. 
endogenously react to the economic conditions. Policymakers are constantly analyzing the economic situation, and change their policies accordingly (Nakamura and Steinsson, 2018).

As shown by the diagram in figure 1.2 , there is possibly a direct causal effect of government spending on GDP, shown by the solid line. However, there are also external factors, that are possibly unobserved. An external shock may not only directly affect GDP, but also government spending, as shown by the dotted lines. As an example, consider an economic downturn caused by an external negative demand shock. This downturn in the business cycle lowers GDP, but also increases government spending, because more unemployment benefits have to be paid. Clearly, both government spending and GDP are simultaneously affected. Moreover, policymakers possibly react endogenously to a decrease in GDP by increasing counter-cyclical spending, which creates two-way causality, as shown by the dashed line.

Figure 1.2: Endogeneity of governments pending

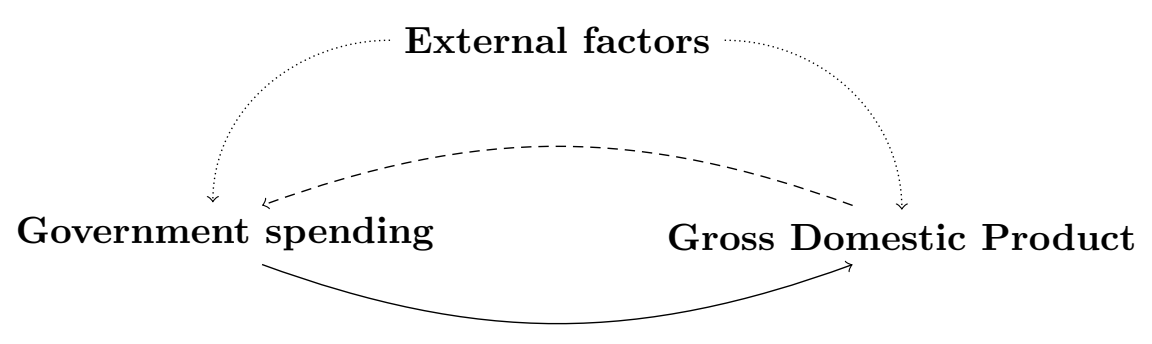

Due to the endogeneity of government spending, identifying the causal effect of government spending on the economy is complex. Formally, identification implies that if we would know the population where the data is drawn from, then we could know exactly the parameter(s) of interest (Lewbel, 2019). In modern terminology, this is called point identification, or frequentist identification. To achieve identification, one has to make restrictions on the data generating process (DGP), which means making assumptions on the model. However, identification fails in case of simultaneity or endogeneity, because we cannot uniquely identify the model parameters.

Since both government spending and GDP are simultaneously determined by external factors, it is impossible to make a causal statement using the estimated regression coefficients 
from a simple two-variable model with government spending and GDP 4 The identification problem goes beyond problems associated with estimation or inference, caused by possible autocorrelation, heteroskedasticity or non-normality in the residuals. Moreover, adding control variables, such as private investment, does not solve the endogeneity problem, because these variables are often colliding variables, i.e. these are endogenous themselves. In that case, adding control variables only amplifies the problem (Lewbel, 2019). In fact, a simple two-variable model is not suitable for identification of the causal relation, even though the model may be well-estimated, and does not suffer from any model specification errors. Consequently, another solution is needed.

\subsubsection{Government spending shocks}

In order to identify the causal effect of government spending on GDP, the government spending variable can be decomposed into an exogenous and endogenous component. The exogenous variation in government spending that is not influenced by the business cycle or GDP, can be used to study the causal effect of government spending on GDP. In the literature, the exogenous changes are usually called structural government spending shocks Nakamura and Steinsson, 2018). There are two general methods to obtain these shocks.

The first method is to estimate structural shocks based on a structural model. These models use economic theory to impose assumptions and restrictions to achieve identification. Usually, these models are used to identify deep model parameters, which can then be used to construct for instance fiscal multipliers. For example, Leeper et al. (2017) and Sims and Wolff (2018) estimate New-Keynesian DSGE models, and obtain structural government spending shocks to identify the causal effect of government spending. Typically, these models use strong assumptions to achieve identification of structural shocks.

The second method is to use reduced-form models to directly identify causal treatment effects. The models rely on natural or experimental randomisation in data. Typically, these models use 'proxies' or 'instruments' to achieve identification. Some examples of reduced

${ }^{4}$ In appendix 1. A.2 this is illustrated using data for the US and the Netherlands 
form models are discussed in the next subsection. In general, there are two problems associated with these models. First of all, Nakamura and Steinsson (2018) point out that natural experiments in data do not line up with policy questions, which creates an external validity problem. Secondly, Ramey (2019) states that many instruments used for causal identification are weak, i.e. not relevant in explaining government spending. Nevertheless, reduced form-models are very popular in the existing literature.

To conclude, although empirical research can help to verify predictions from macroeconomic models, identification of structural parameters or other portable statistics is difficult, since government spending is inherently endogenous to changes in variables like GDP. As a solution, structural or reduced-form models can be used to identify exogenous government spending shocks.

\subsubsection{Current state of research}

In the last two decades, reduced-form models have become very popular to identify the macroeconomic effects of government spending. The chapters in this thesis also follow this approach. Next to the structural vector autoregressive (SVAR) models, which have been popular for many years in empirical macroeconomics, instrumental variable (IV) analysis has gained popularity. In recent years there have been many applications using either time series or panel data, at the national and sub-national level. As Ramey (2019) and Chodorow-Reich (2019) show, the estimated fiscal multipliers obviously differ substantially across studies. However, these differences cannot be explained only by differences in methodology.

Many factors possibly affect the way government spending affects the macro-economy, such as the degree of anticipation, implementation horizon, persistence of shocks, category of spending, financing method, distribution across agents, state of the business cycle, exchange rate regime, level of development, and interaction between monetary and fiscal policy. Of course, this list is far from exhaustive and many factors are deeply interconnected. Definitely, more theoretical and empirical research into the underlying factors is needed.

In the remainder of this thesis, several underlying factors that play a role in the way 
government spending affects the macro-economy are empirically assessed, i.e. the role of anticipation, categories of spending, and sectoral and regional spillover effects. In general, this thesis takes a disaggregated approach to study the conditions that affect the macroeconomic effects of government spending. Disaggregation implies breaking down aggregate macroeconomic variables, on the spending or receiving side, into smaller components. A disaggregated approach makes it possible to study the underlying factors that affect the macroeconomic effects of government spending in greater detail. Disaggregation can help with identification, but it often also requires more restrictions on the model. Identifying the underlying factors can help to discriminate between macroeconomic theories on the effectiveness of government spending. The next section provides an outline of the chapters that follow.

\subsection{Outline of the thesis}

\section{Chapter 2}

Chapter 2 focuses on the anticipation horizon of government spending news ${ }^{5}$ The chapter investigates to what extent the response of a small set of macroeconomic variables to a government spending news shock is affected by the length of the anticipation horizon. Following Leeper et al. (2012) and Leeper et al. (2013), the chapter exploits the lag structure that governs the information flow of government spending policies. It therefore differentiates news shocks according to the length of the so-called inside lag, which is the time between the initial policy announcement and the legal implementation. This time lag is the most substantial part of the anticipation horizon. When the inside lag is shorter than 90 days, then the anticipation horizon is classified as being short.

In this chapter the defense news narrative from Ramey (2011) is decomposed into news with a short versus long anticipation horizon. The chapter differentiates news according to

\footnotetext{
${ }^{5}$ This chapter uses only data about US defense spending. It is common in the literature to focus on defense spending, since this is regarded as the most exogenous category of government spending. In the US, the share of defense spending lies currently around $60 \%$ of total federal consumption and investment expenditures (NIPA Tables, US Bureau of Economic Analysis).
} 
the implied anticipation horizon by linking the narrative records on defense spending news to the implementation dates in the legislative decision process. The anticipation horizon is estimated by connecting the announcement dates in the narrative to the signing dates of the defense appropriation bills. Using a proxy-VAR methodology, the effects of news shocks with a long anticipation horizon and a short anticipation horizon respectively are studied on macroeconomic variables like GDP, private consumption and private investment.

The main finding is that news indicating policy changes in the (more distant) future results in higher multiplier effects. News with a longer anticipation horizon leads to expansionary effects on GDP, private consumption and investment, while news with a shorter anticipation horizon creates crowding-out effects on these variables. The findings can be explained by the notion that news with a long anticipation horizon has a strong forward guidance effect, implying that agents experience a positive wealth effect, which outweighs possible negative crowding-out effects. Macroeconomic theories that predict large expansionary effects of fiscal policy, are consistent with defense news with long anticipation horizons.

\section{Chapter 3}

In chapter 3, the macroeconomic effects of different categories of government spending are investigated. Specifically, the chapter focuses on the effects of defense versus non-defense spending in the US. The identification strategy exploits the cross-sectional variation in federal spending. Exogenous federal government spending shocks are estimated for different spending categories at the state-level. For defense spending, these shocks are estimated from data on state level defense contracts and for non-defense spending these are based on data on intergovernmental transfers from the federal to the state-level government. ${ }^{6}$ For both spending categories, the exogenous part of federal spending allocated to states is isolated by removing the common component of spending across states and the endogenous state-level component. The identification relies on the notion that part of federal spending to states is allocated independently of the state-level economic conditions, and the spending decision

\footnotetext{
${ }^{6}$ These federal transfers to state governments are an important source of revenue for state governments: in
} 2019 the share was $31 \%$ of total state government receipts (NIPA Tables, US Bureau of Economic Analysis). 
lies outside of the control of the state. This approach has two main advantages, namely that the estimated shocks outperform instruments from the existing literature, and that it is suitable for any federal spending category, since it does not rely on specific instruments.

The main finding is that defense spending results in smaller fiscal multipliers than nondefense spending, which is in line with previous findings on non-defense state-level multipliers. This finding can be explained with three arguments that are used in the related literature. First, it is argued that military build-ups create large Ricardian responses for

consumers. Second, defense contracting industries are less connected with other industries, which implies smaller positive spillovers. Third, defense spending has a strong reallocation effect on production factors, which is costly.

The finding that defense spending results in lower multipliers than non-defense spending implies that empirical studies that focus only on defense spending typically underestimate the fiscal multiplier. Of course, this observation also holds for the results obtained in chapter 2. Therefore, thorough empirical analysis of fiscal multipliers always requires the correct usage of spending categories. Moreover, theoretical predictions for fiscal multipliers can only be assessed empirically when both the theoretical and empirical model use the same mix of spending categories.

\section{Chapter 4}

In chapter 4, sectoral and regional spillover effects of government spending are investigated, with a specific application to the European Union (EU). The chapter uses a panel analysis to study the effects of EU Structural and Invstment Funds across NUTS-2 regions in EU member states. Unlike existing studies that evaluate whether EU funds stimulate long-term convergence, this chapter studies the short-run economic effects of EU funds. It is important for policymakers to not only be aware whether the long-term objectives are achieved, but also whether unintended short-run policy consequences arise.

The methodology to obtain region-specific shocks in EU funds is similar to chapter 3 . Region-specific shocks in EU funds are estimated both within and between programming 
periods. The empirical approach covers more variation in EU funds than existing papers, because all EU regions are used and both the variation within and between programming periods are exploited. Including more variation not only helps for estimation precision, but also allows to estimate effects in more-developed regions versus less-developed regions. The shocks are used to study the dynamic effects of EU funds over a 4-year horizon. The responses of production across sectors in a region are used to examine heterogeneity in responses across sectors. Since EU funds effectively stimulate specific sectors, it is possible that sectoral substitution effects arise. Moreover, spillover effects across regions are estimated to investigate how the effects in one region spill over to other regions. To measure the spillovers, a spatial approach is used, with weights based on intra-EU trade between regions.

The results indicate that in general the effects of EU funds are rather limited, but there are several relevant policy conclusions. In line with the literature, this chapter finds a mild positive direct effect from a shock between programming periods in less-developed regions, driven by the industry and public sector. The same shock has a slight negative effect in moredeveloped regions, due to sectoral substitution effects between mainly the construction and services sector. The regional spillover effects are very limited at the regional level, although some sectors experience spillovers, which are in general opposite to the direct effects. This finding is consistent with a view that the supply-side effects through increased competition for production factors outweigh demand-side effects. Policymakers should be aware that even though government spending might have positive aggregate effects, there can still be crowding-out effects at the sectoral level, or between regions. Therefore, macroeconomic models that are used for policy evaluation should take these aspects into consideration.

\section{Chapter 5}

Finally, chapter 5 reflects on the conclusions and contributions of the chapters, and provides recommendations for future research. 


\section{A Appendix}

\section{A.1 Historical data}

Figure 1.3: Historical data for government spending and debt

(a) Government spending

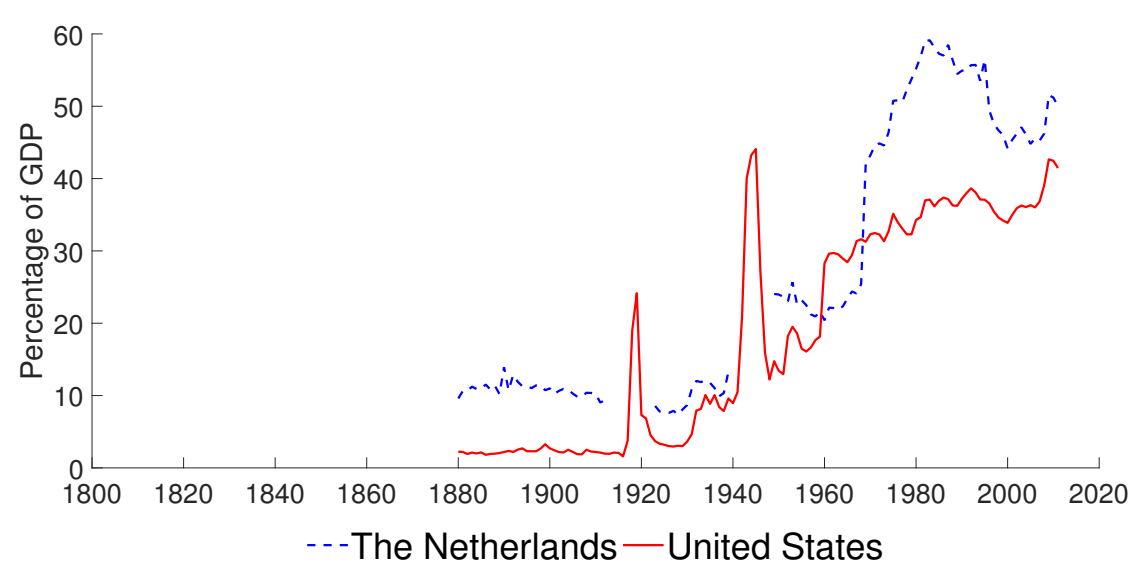

(b) Government debt

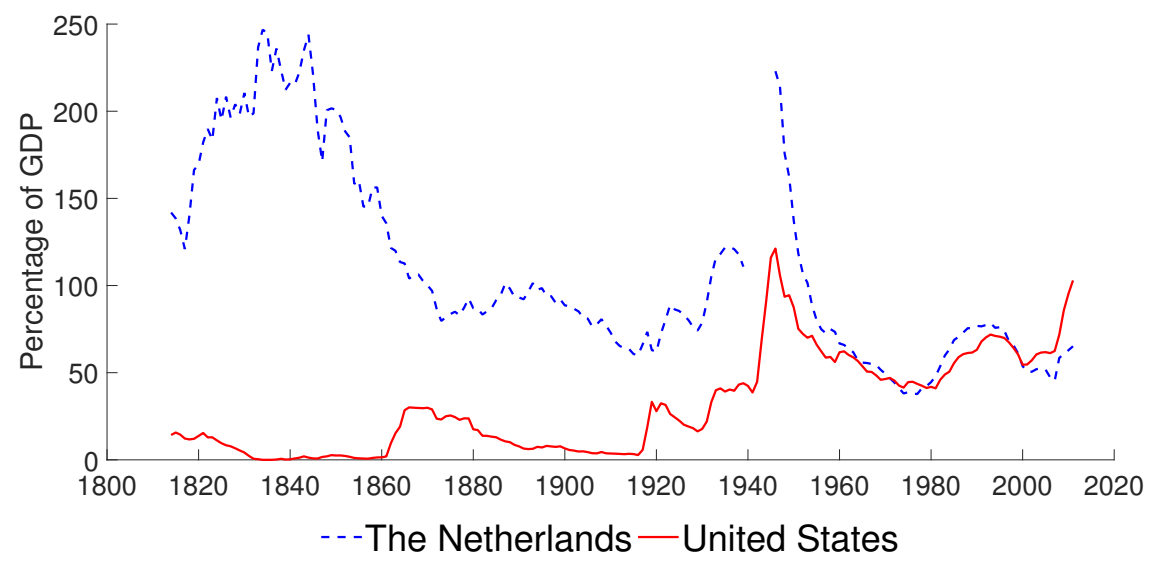

Note: Historical data for government spending (upper) and government debt (lower) expressed in percentage of GDP in the Netherlands (dashed) and the United States (solid). Data source: Mauro et al. (2015). 


\section{A.2 Empirical example}

The following empirical example is based on quarterly data from the OECD on government consumption and GDP for both the Netherlands and the US between 1960 and 2018 in US dollars. The time series plots are shown in figure 1.4. For both countries, the series are seasonally adjusted, deflated with the GDP deflator, transformed with the natural logarithm before detrending with the HP filter (where the smoothing parameter is 1600). Since the series are log-detrended, they can be interpreted as the percentage deviation from the trend. If I analyze the relation between the variables with a simple linear regression model, then the following estimates are obtained, as shown in table 1.1. The model has been estimated with ordinary least squares (OLS) for both countries separately with 236 observations per country for the whole sample and 117 before 1990 and 119 after 1990. The scatter plots are shown in figure 1.5 .

Table 1.1: Estimation results for empirical example

\begin{tabular}{l|l|l|l}
\hline \hline Coefficient & Entire sample & Pre 1990 sample & Post 1990 sample \\
\hline$\beta$ The Netherlands & $\begin{array}{l}0.53^{* * *} \\
(0.05)\end{array}$ & $\begin{array}{l}0.52^{* * *} \\
(0.06)\end{array}$ & $\begin{array}{l}0.54^{* * *} \\
(0.10)\end{array}$ \\
$\beta$ United States & $\begin{array}{l}-0.10 \\
(0.07)\end{array}$ & $\begin{array}{l}0.04 \\
(0.36)\end{array}$ & $\left(0.37^{* * *}\right.$ \\
& Note: Table with estimated coefficients and standard errors in parenthesis, \\
$* * *$ & indicates that the coefficient is significant at the 1\% level
\end{tabular}

One could think that the findings from this simple empirical example indicate that there is a stable significant positive effect of government spending of GDP in the Netherlands across the two sample periods, and that the effect is negative significant effect in the US after 1990. However, as discussed in the main text, it is impossible to make a causal statement using the estimated regression coefficients, due to the endogeneity problem of government spending. The bottom line is that this identification problem cannot be inferred from the estimation results, because it goes beyond problems associated with estimation or inference, caused by possible autocorrelation, heteroskedasticity or non-normality in the residuals. 
Figure 1.4: Time series plots of government spending and GDP

(a) The Netherlands

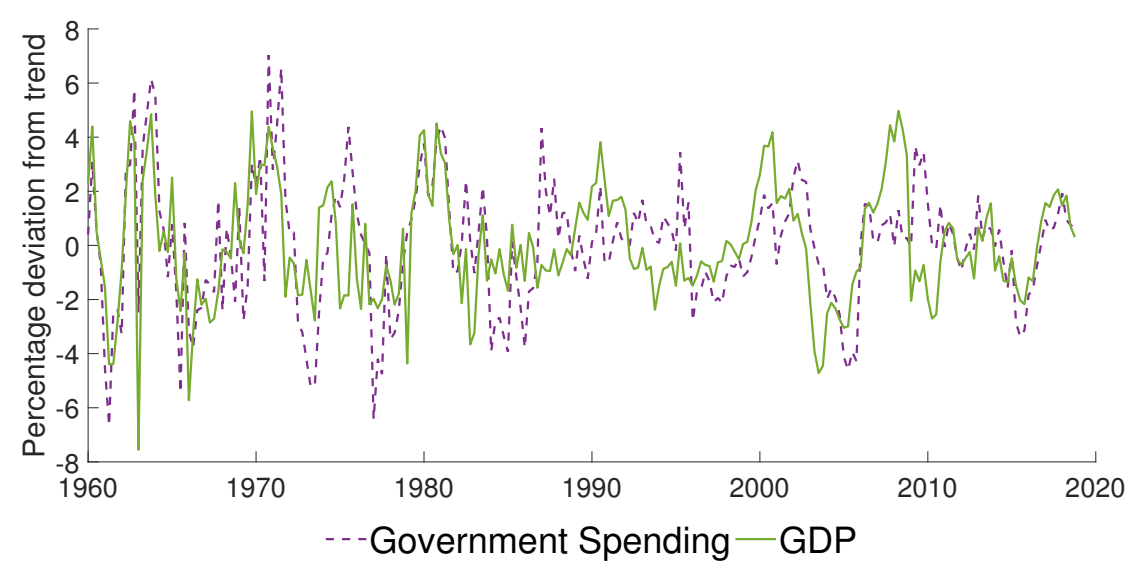

(b) United States

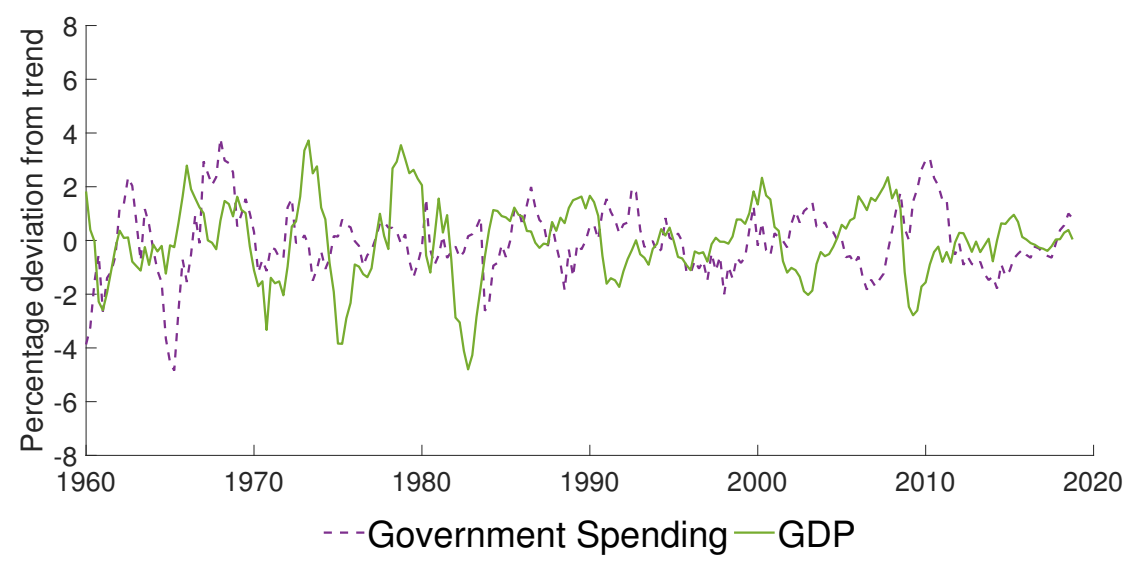

Note: Government spending (dashed) and GDP (solid) in the Netherlands (left) and the US (right), expressed in percentage deviation from their trends. Data source: OECD. 
Figure 1.5: Scatter plots of government spending and GDP

(a) The Netherlands

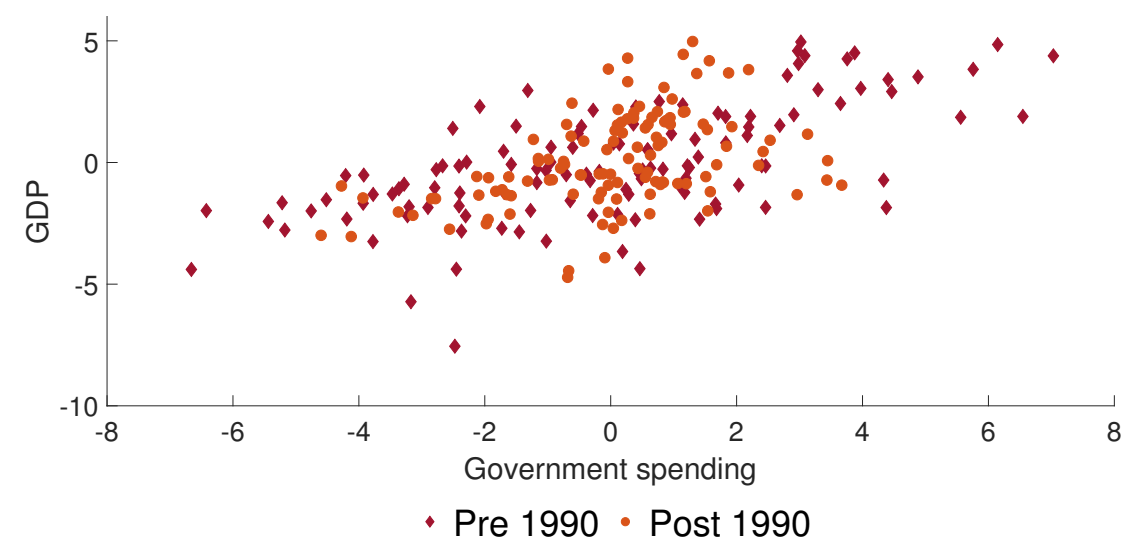

(b) United States

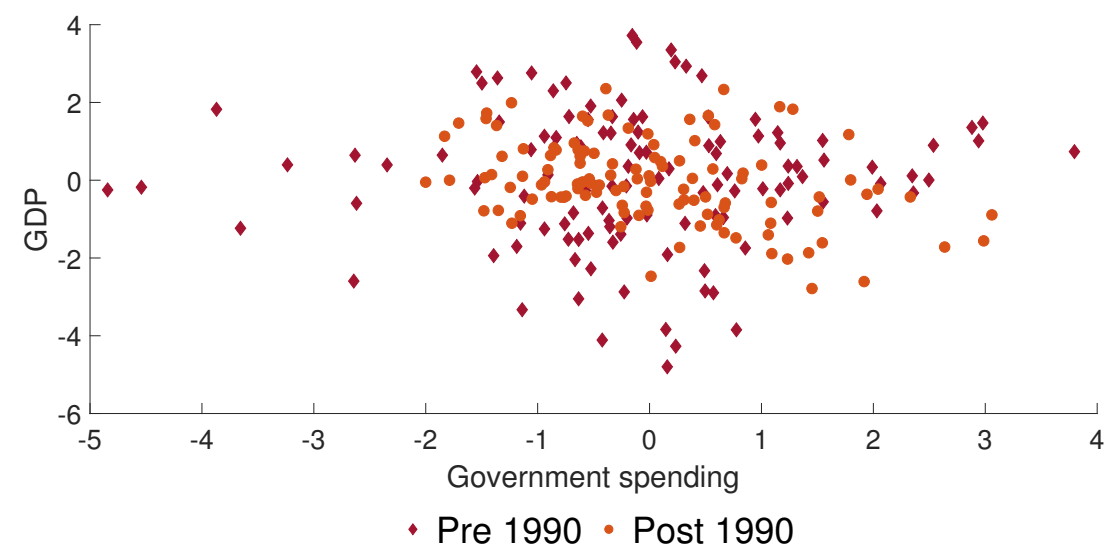

Note: Scatter plots for GDP against government spending in the Netherlands (upper) and the United States (lower), both expressed in percentage deviation from the trend. The diamonds are the observations before 1990 and the circles are post 1990. Data source: OECD. 
1.A. APPENDIX 


\section{Chapter 2}

\section{The Role of the Anticipation Horizon in Government Spending News ${ }^{\boxplus}$}

This chapter investigates the dynamic effects of government spending news in the United States. In contrast to the literature, the chapter differentiates news according to the implied anticipation horizon. To this aim, narrative records on defense spending news are linked to the legislative decision process. This makes it possible to distinguish between news with a short(er) and long(er) anticipation horizon. The chapter provides empirical evidence that news indicating policy changes in the (more distant) future results in higher multiplier effects. Private consumption and investment are crowded-out when the anticipation horizon is short.

\footnotetext{
${ }^{1}$ This chapter is based on Van Gemert and Lieb (2020).
} 


\section{$2.1 \quad$ Introduction}

The enactment of laws with significant budget impact is regularly preceded by lengthy debates and discussions among politicians and public commentators. For example, the bill for the Affordable Care Act ('Obamacare') was signed by then president Obama in March 2010, with most major provisions only phasing in starting 2014. The legislative history of the act, however, dates back to early 2009 when committees in both houses started to hold meetings and negotiations between parties began. The draft of the bill changed repeatedly during this process. Even before the election of Barack Obama in November 2008, the reform of the health care system in the US was a pillar of his presidential campaign, and hence a subject to public debate and scrutiny. All of this indicates that the reform of the health care system was (to a large extent) anticipated by the public long before it took effect in January 2014.

While not all fiscal policy decisions are subject to such a lengthy political and legislative process, (possibly noisy) information on future policy directions is often available to the public throughout the period between the first mentioning or announcement of the policy and effective implementation. In the previous example, this is the period between 2008 and 2014. Since economic agents are forward-looking, such information, or news, are likely to influence decisions through changes in expectations throughout this period.

It is indeed widely established that news - about future economic events in general is a key driver of economic fluctuations (Beaudry and Portier, 2006, 2014; Jaimovich and Rebelo, 2009; Barsky and Sims, 2011; Forni et al., 2013). The role of anticipated fiscal policy shocks has also been extensively analyzed in the literature, both from a theoretical perspective (Schmitt-Grohé and Uribe, 2012; Leeper et al., 2012, 2013) and an empirical perspective (Fragetta et al., 2014; Ricco et al., 2016; Ben Zeev and Pappa, 2017). Most studies confirm the importance of fiscal foresight, that is fiscal policy news having an effect on macroeconomic variables before the fiscal policy variable actually adjusts.

The theoretical literature, such as Schmitt-Grohé and Uribe (2012); Leeper et al. (2012, 2013), emphasizes how different types of (noisy) signals (i.e. news) are processed by agents and, importantly through which mechanisms. Existing studies usually compare the effect of 
anticipated fiscal policy shocks to those of unanticipated (or surprised) shocks. However, the impact of different "kinds" of anticipated fiscal policy shocks could also differ. For example, one may expect that the anticipation horizon and the amount of noise in the news signal affects the way agents process information. Nonetheless, a more differentiated treatment is often missing in empirical studies. One exception is Ricco et al. (2016), who find that a larger amount of noise (disagreement of policy makers) in the news decreases the stimulating effect on economic activity.

This chapter investigates to what extent the response of a small set of macroeconomic variables to a government spending news shock is affected by the length of the anticipation horizon. To that purpose, we distinguish between news shocks with a long anticipation horizon and news shocks with a short anticipation horizon. By controlling for the possible noise in the news, we ensure that the difference between the two types of news is only due to the difference in length of the anticipation horizon.

Identifying news signals about future government spending policies from macroeconomic data is difficult. Consequently, much of the related literature has focused on extracting relevant information from auxiliary sources (Ramey, 2011, 2015; Fragetta et al., 2014; Alesina et al., 2017; Ben Zeev and Pappa, 2017). We follow a similar approach to retrieve information on long- and short-horizon anticipation. To this aim, we exploit the lag structure that governs the information flow of government spending policies (Leeper et al., 2012, 2013). More specifically, we use the defense news series from Ramey (2011) to obtain announcement dates of the main events that drive public expectations in defense spending. In order to measure the length of the anticipation horizon, we connect the announcement dates to the legislative decision process, and obtain the signing dates of the defense appropriation bills. With this procedure, we decompose Ramey's original narrative into one series carrying information on news with a short(er) anticipation horizon and another series with a long(er) one. Using this decomposition we estimate news shocks that differ in their anticipation horizon.

The distinction between the inside lag and outside lag is key to how Leeper et al. (2012, 2013) characterize the information flow. This lag structure is shown in the following diagram: 


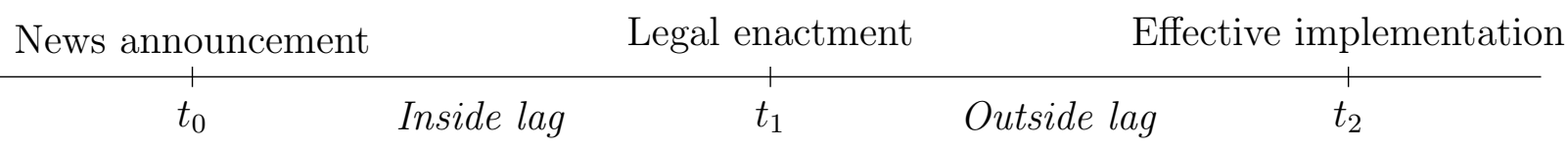

The inside lag represents the period between announcement ${ }^{2}$ at $t_{0}$ and the legal enactment at $t_{1}$. Since the policy is not legally enacted during the inside lag, new announcements or 'news updates' can still arrive. This period is characterised by (potentially) imprecise fiscal foresight and, often, by a long anticipation horizon. Once the policy has been legally enacted at $t_{1}$, it may take some time before the policy is effectively implemented. This means that the budget is approved, but the actual spending has not yet taken place. The time between $t_{1}$ and the effective implementation dat $5^{3} t_{2}$ is the outside lag. This is a period of more precise fiscal foresight, as the amount and type of the spending would have already been agreed on. Some federal statutes are swiftly implemented after enactment but are preceded by a long inside lag, while others have a short legislative history but a long outside lag.

Both the inside and outside lag constitute periods of anticipation. In general, both are necessary to identify the total anticipation horizon. By disregarding one of these periods, we may underestimate the length of anticipation $\left(t_{0}\right.$ to $\left.t_{2}\right)$. The outside lag is, however, difficult to determine accurately for some spending policies. In the case of defense spending the outside lag is relatively homogeneous and short compared to other public policies, e.g. taxation (Mertens and Ravn, 2012). Therefore, the inside lag is likely the key driver of the length of the anticipation horizon for defense spending. Identifying the inside lag, thus, allows us to distinguish between news with long(er) and short(er) anticipation horizons.

In the next section, we give a detailed overview how we construct these two measures for fiscal foresight, by identifying the length of the inside lag. To investigate the effect of various types of spending news shocks, we propose a methodological framework able to cope with the 'granular' nature of structural shocks in section 2.3. We find that the

${ }^{2}$ The announcement can be a presidential speech, or just the starting point of debates in Congress. It is not always a formal moment.

${ }^{3}$ This is the moment when the first dollar is spent, which is the effective implementation of the announced change in policy at $t_{0}$. 
estimated news shock with the shorter anticipation horizon has more predictive power on government spending than the 'short-horizon component' of Ramey's narrative, and that the 'long-horizon component' drives the predictive power of the original narrative. Furthermore, the impulse response estimates suggest that the anticipation horizon matters. We find that news with a longer horizon can act as a strong fiscal forward guidance tool, by increasing expected output levels, which outweighs the negative crowding-out effect. Consequently, we find positive hump-shaped responses of output, private consumption and investment for news with a long anticipation horizon. Instead, for news with a short anticipation horizon, the negative crowding-out effect dominates, because of coordination problems between economic agents who cannot quickly adjust to the news. This explains why we find a negative response output, private consumption and investment when the anticipation period is relatively short, which is in line with Ramey (2011, 2015), Ellahie and Ricco (2017) and Ben Zeev and Pappa (2017).

\subsection{Constructing fiscal foresight measures}

This section provides a detailed description how we construct two distinct fiscal foresight measures based on the length of the anticipation horizon. In the next section, we explain how we use these measures to construct structural shocks and estimate structural responses.

\subsubsection{Approach}

We use the defense news narrative series in the online appendix of Ramey (2011, 2015) to construct two distinct measures of fiscal foresight $5^{5}$ News on defense spending is particularly well suited to identify the effects of government spending news with different anticipation horizons. Defense spending in the US is appropriated by bills that set the defense budget

\footnotetext{
${ }^{4}$ The defense narrative is available on the website of Valerie Ramey (University of California): http://econweb.ucsd.edu/ vramey/research/Defense_News_Narrative.pdf.

${ }^{5}$ The narrative provides information on the main news that drives public expectations of future defense spending in the US. We focus on defense spending news, because defense spending is mainly driven by non-economic factors, such as foreign political events, which makes it suitable to analyze the impact of government spending news on macroeconomic variables (Barro and Redlick, 2011, Ramey, 2011).
} 
once every fiscal year. Once such spending has been approved $80 \%$ of that amount must be spent in the first ten months of that fiscal year. Spending is carried out fast also when appropriated by supplementary spending bills. Thus, defense spending policies usually have a short and homogeneous outside lag. Hence, whether spending news have a short(er) or long(er) anticipation horizon is largely determined by variation in the inside lag.

Ramey's defense news narrative captures announcement dates of major implemented changes to defense spending and thus gauges the public's anticipation (or expectation) of future defense spending. We use this to identify $t_{0}$, i.e. the start of the inside lag. To assess the anticipation horizon of defense news, we link every news announcement in Ramey's narrative series to the date when the associated appropriation bill was signed by the president (legal enactment). We therefore follow the legal implementation (regular and supplementary appropriation bills ${ }^{6} 7$ of the announced policy changes in Ramey's narrative series $8^{8}$ The inside lag is the time difference between the announcement date from the Ramey's narrative and the date of the appropriation bill.

Based on the lag structure outlined above, we classify the news in the narrative according to the following timing convention. When the estimated inside lag is less than 90 days, the news is classified as having a short-horizon anticipation; if the inside lag is longer, we classify the news as having a long-horizon anticipation. When the inside lag is shorter than 90 days, the effect on macroeconomic data sampled at quarterly frequency will not be visible. Therefore, the 90-days rule that we use for classification is not an arbitrary assumption, but an automatic consequence of the frequency of the responding variables.

We base the classification strategy on several assumptions. First, we assess defense spending news at daily frequency, but only count the days once the month in which the announcement takes place is over. Although Ramey's defense narrative series relies on gran-

\footnotetext{
${ }^{6}$ Regular appropriation bills allocate funding for the $\mathrm{DoD}$ in a fiscal year. Supplementary appropriation bills fund spending above and beyond the regular appropriation and are often proposed in war times or after a natural disaster. Appropriation via continuing resolutions cannot implement the news previously announced and are therefore disregarded.

${ }^{7}$ Other sources of funding are also used to finance spending, especially in war times, but in that case the anticipation horizon is anyhow short (Miller, 2007).

${ }^{8}$ The only exception is the (automatic) sequester cuts in on March 1, 2013, which resulted into immediate budget cuts to discretionary spending parts of the Federal budget, including the spending for the DoD.
} 
ular news sources, it is not always clear whether the specified date is the first time that this specific (yet to be implemented) policy change was ever mentioned. Other papers raise the same concern and use a similar approach. For example, Mertens and Ravn (2012) focus on the announcement quarter (a less precise dating strategy than ours) $!^{9}$

Second, we assume that each news announcement at $t_{0}$ can be linked to a unique enactment date $t_{1}$. Furthermore, since it follows from the narrative by Ramey (2011) that most news carry information about the current or upcoming fiscal year only, the enactment horizon (i.e. the time until the associated bill is signed) is the current and upcoming fiscal year. Yet, it is allowed in our set up that the effective implementation does not take place in the current or next fiscal year, but in the fiscal year thereafter. This occurs only once, namely in January 1967, when there is news about the fiscal year 1969.

The third and final assumption is that we allow for news updates during the inside lag. We include this possibility by allowing to link multiple announcements to the same legal enactment date. An example is the budget cut in September 1970, which updated the announcement from February 1970, while both are enacted in December 1970.

\subsubsection{Results}

The appendix 2.A.2 provides an overview of all defense news announcements, including their classification. Figure 2.1 shows the distribution of the length of the identified inside lags. 36 news announcements (47\%) are classified have a short-horizon anticipation, while 40 news announcements $(53 \%)$ are classified as having a long-horizon anticipation. Furthermore, Figure 2.2 shows the length of the inside lag for every news announcement.

Figure 2.3 depicts the two series: news with a short and a long anticipation horizon. The amounts mentioned in the news announcements are scaled to a percentage of nominal GDP in the quarter before announcement date 10 We find that the legislative procedure is shorter during war times, especially at the start of a military conflict. For example, at the

\footnotetext{
${ }^{9}$ If we would not count the days in the quarter, this would mean that four announcements would have a long horizon: 1948 January, 1953 February, 2005 January and 2011 August.

${ }^{10}$ We use 1955 Q1 as the starting date for the empirical analysis, which is is right after the scale-down of the Korean War.
} 
Figure 2.1: Frequency of the length of the anticipation horizon

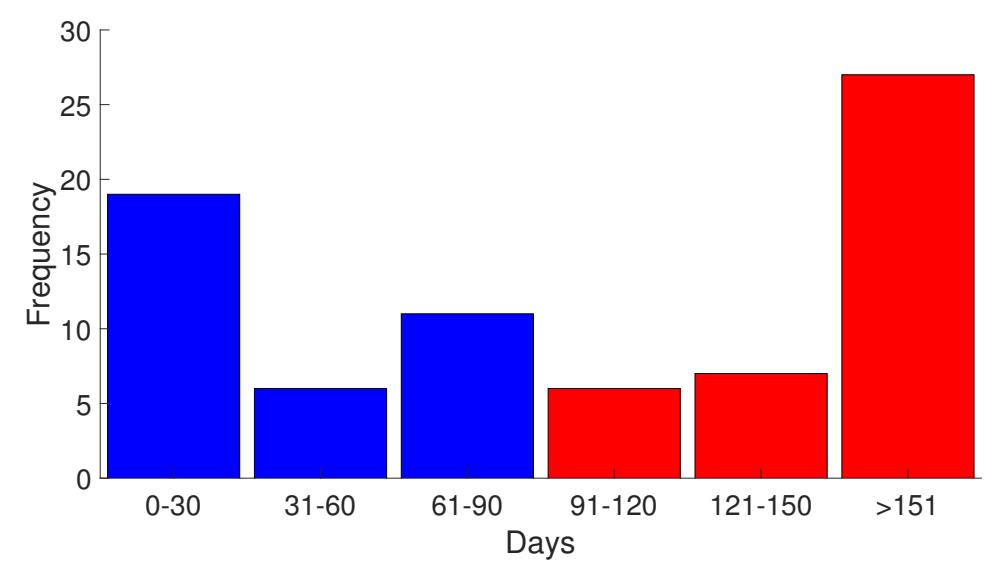

$\square$ Short Anticipation Horizon $\square$ Long Anticipation Horizon

Figure 2.2: Length of the inside lag over time

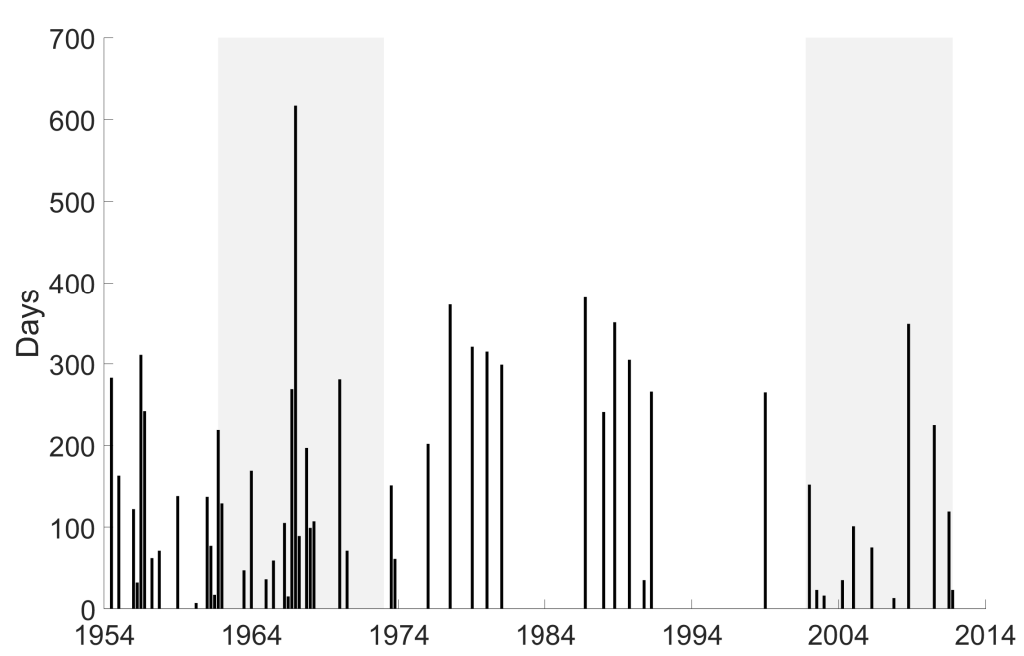

Note: The length of the inside lag is measured in days over time after the Korean War. The shaded areas correspond to the Vietnam War and the War on Terror (Afghanistan and Iraq).

start of the Vietnam War a $\$ 700$ million request to congress was signed into law only three days later (Pub. L. 89-18). Another example is the response after the terrorist attacks on September 11 in 2001. President Bush sent his request for emergency defense appropriations on September 14, which were signed into law just four days later (Pub. L. 107-38). Similar patterns (short anticipation horizons) are present in other war time episodes, e.g. the Gulf 
Figure 2.3: News series with short and long anticipation horizon
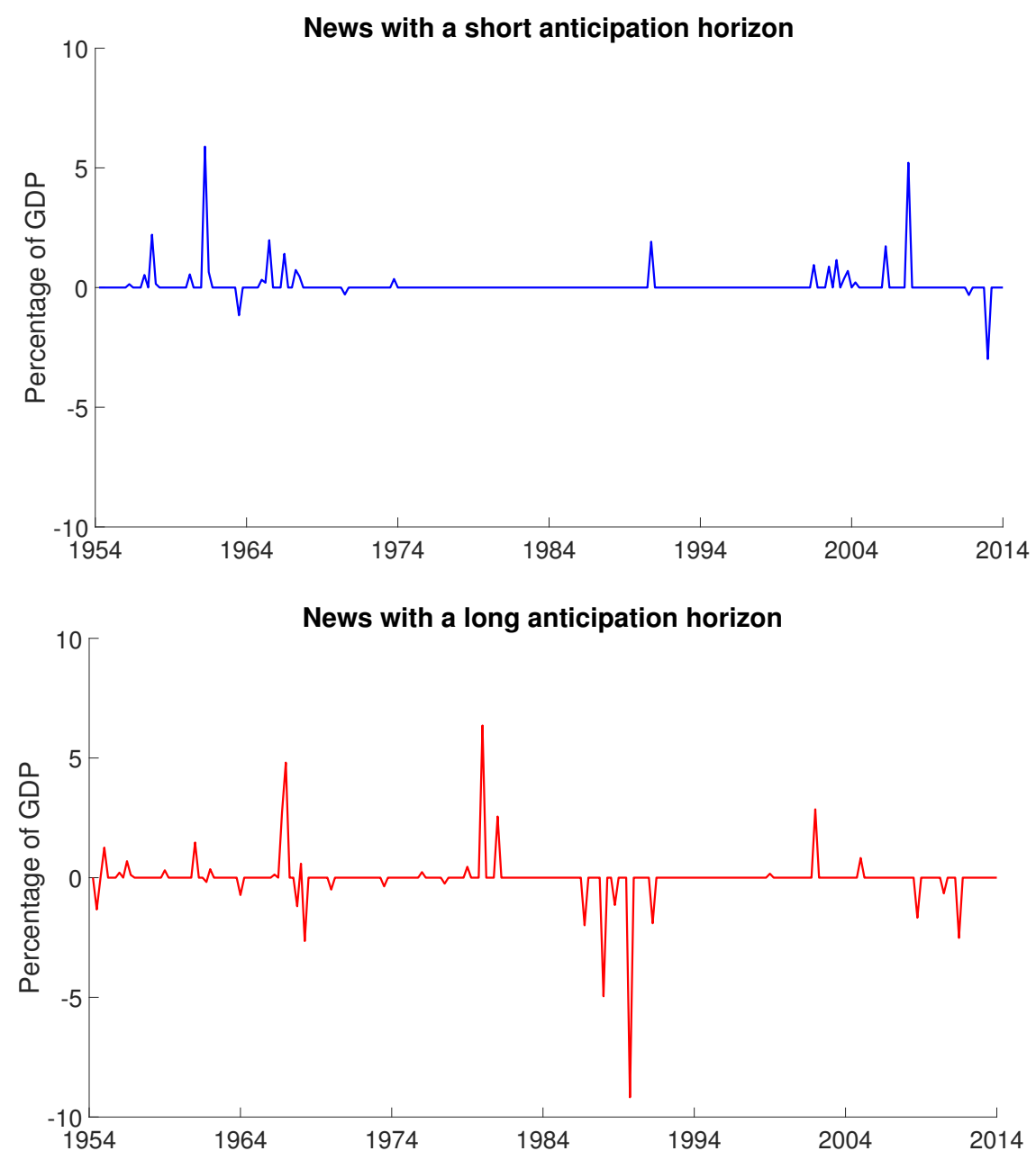

War (1990), and the War on Terror (2001-2008).

On the other hand, longer anticipation horizons are more common in 'peaceful times' such as the Reagan-Carter build-up (1979-1980), near the end of the Cold War (1987-1989) and during the first term of President Obama (2008-2011). In war times, administrations regularly request (emergency) supplementary budgeting to finance the costs of a war (Miller, 2007). The total cost of war are usually hard to estimate especially at the beginning of a military conflict, resulting in more supplementary budget requests to Congress. There is a gradual transition from supplementary budgeting to regular budgeting as war progresses. We see this, for example, during the Vietnam War (1965-1967). At its start, almost all defense 
spending news is swiftly enacted, while near the end (1967-1970) most news announcements are followed by a longer anticipation horizon 11

It is important to note that all news considered here refers to news that is effectively implemented. The narrative by Ramey (2011) is constructed such that it reflects all implemented defense news announcements. Therefore, all news announcements in the series result in actual changes in defense spending. Even though we do not provide an estimate of the effective implementation date - and therefore the outside lag - we know that all announcements were effective implemented and affected defense spending by the federal government.

After decomposing Ramey's narrative into two series, we proceed to identify fiscal policy news shocks. The two series obtained in this section carry valuable information which may be helpful for identifying government spending news shocks with different anticipation horizons 12

In the next section, we discuss how to estimate structural shocks based on these measures. The underlying assumption is that the series are a reasonable proxy for the unobserved structural government spending shocks. They contain information on (specific forms of) anticipation that is hard to directly identify from typical aggregated macroeconomic variables.

\subsection{Empirical approach}

In this section, we discuss the empirical strategy. We first motivate our approach to estimate structural government spending shocks based on the measures that we obtained in the previous section. Then, we present in detail the underlying model and estimation method that we use obtain estimates for the two shocks. Finally, we discuss how the estimated shocks are used to obtain impulse response functions.

\footnotetext{
${ }^{11}$ During the War on Terror (in Iraq and Afghanistan) the large amount of supplementary appropriations met pushback in Congress. When preparing the budget for the fiscal year 2006, Congress explicitly demanded to include the war expenses from now onward into the regular budgeting process (Miller, 2007).

${ }^{12}$ Ramey's narrative captures changes in public expectations regarding future government spending. This property logically carries over to the two fiscal foresight measures, and also to the shocks estimated in the next section. By construction, these shocks do not relate to changes in current government spending.
} 


\subsubsection{Motivation}

In order to have a causal interpretation, structural shocks have to be: i) exogenous with respect to the economic agents' information set; and ii) uncorrelated among each other. Identification in empirical macroeconomics means translating errors from the linear projection of a vector of variables onto their past values into mutually uncorrelated (economically interpretable) structural shocks. Thus, i) requires that the information set of the econometrician (i.e. the conditioning variables) contains the information available to economic agents. Condition ii) requires a sensible approach to (linearly) translate reduced-form errors into structural shocks. The identification of (fiscal policy) news shocks (i.e. shocks relating to expectations of agents) is particularly difficult, since the small set of variables typically included in an empirical macroeconomic analysis carries less information than accessible to forward-looking economic agents (see e.g. Leeper et al., 2013). A pragmatic response to this problem is to add more information (i.e. more variables), such that condition i) is more likely to hold. Which information (and thus which variables) should be added is, however, unclear in many situations. Augmenting the analysis with factors compressing a large amount of information into a few variables is a potential solution for information insufficiency (see e.g. Forni et al. 2013). This approach provides in addition a safeguard against the "curse of highdimensionality" in an information-rich environment. An alternative approach is to include a measure of expectations (constructed from auxiliary sources) directly into the analysis (see e.g. Romer and Romer, 2010; Ramey, 2011; Leeper et al., 2012).

In order to include relevant information on fiscal foresight, Ramey (2011) augments a vector autoregressive model (VAR) consisting of standard macro variables with her series on narrative records. She interprets a (scaled) prediction error of her narrative series as an ("anticipated") defense news shock. This approach corresponds to a "Cholesky-identified" structural VAR (SVAR) with the narrative series ordered first - often referred to as "expectational VAR" (EVAR) in the literature. Hence, the identification of structural impulse responses relies on both the information contained in the narrative and short-run identification restrictions. To avoid imposing SVAR-type identification restrictions, Stock and 
Watson (2012) and Mertens and Ravn (2013) have suggested to interpret such narrative records as external instruments (or proxy variables) for the structural shock of interest. If indeed a specific proxy variable is correlated with the (unknown) structural shock of interest (but uncorrelated with all other structural shocks), this structural shock is identified as the predicted value in the population regression of the proxy variable on the VAR errors. Identification is however conditional on the information sufficiency of the VAR, which is, as mentioned before, unlikely to hold in the presence of fiscal foresight.

The role of information sufficiency - or rather the problem of information deficiency - is amplified in the structural identification exercise we want to solve here. An additional complication is implied by our view of structural (government spending) news shocks. The decomposition of the Ramey's narrative follows the idea that fundamental structural shocks can often be split up into various (sub-)components (Schmitt-Grohé and Uribe, 2012 , Ben Zeev and Pappa, 2017; Alesina et al., 2017) and are hence more "granular" in nature. This increases the number of shocks driving macroeconomic dynamics. In a standard SVAR setting with a small number of variables, one could easily arrive in a situation where there are more structural shocks than variables. Identification in this case fails, since the informational content in the reduced-form errors is insufficient to recover (all) structural shocks. In other words, the VAR is not invertible and the reduced-form errors do not span the space of structural shocks 13

To tackle these issues, we proceed in two steps. First, we attempt to solve the issue of information deficiency by estimating the two components of our government spending news shock from a high-dimensional VAR model, hence, following the idea put forward by the literature on proxy-VARs. In a second step, these estimates are included in a small scale SVAR consisting of key macro variables of interest. Our final goal is to estimate structural impulse responses of these key macro variables to spending news shocks with different anticipation horizons.

\footnotetext{
${ }^{13}$ Analysing structural dynamics based on factor (augmented) models would still require to map low(er)dimensional reduced-form errors onto high(er)-dimensional structural shocks and, hence, hinder causal inference.
} 


\subsubsection{Estimating Shocks}

To estimate the shocks, we use a large $K$-dimensional vector $Y_{t}=\left[y_{1, t}, y_{2, t}, \ldots, y_{K, t}\right]^{\prime}$ of macroeconomic variables, including the key variables of interest (say $X_{t}$ as a subset of $Y_{t}$ ) as well as other possibly relevant variables reflecting agents' available information. Assume $Y_{t}$ is generated by a stationary VAR process:

$$
Y_{t}=\sum_{j=1}^{p} A_{j} Y_{t-j}+V_{t}
$$

where $U_{t}$ is a vector of reduced-form error terms ${ }^{14}$. Since number of parameters is too large relative to the observed sample, it is impossible to obtain OLS estimates of $U_{t}$.

Due to the high dimensionality of $Y_{t}$ it is likely that the VAR parameter matrices are sparse. Therefore, a regression shrinkage method might be a solution. However, since it is likely that there is relatively strong correlation among (groups) of regressors, the least absolute shrinkage and selection operator (LASSO) - most commonly used for feature selection - may not be an optimal choice. Model selection via $L 1$ penalisation tends to select one variable from a group of correlated covariates and ignores the others (Zou and Hastie, 2005). In our set-up we need a larger set of variables, because we want to measure two distinct components of government spending news.

Thus, we opt instead for a variation more suited to our situation. From a sparsity point of view, we are interested in finding a small number of sets of correlated regressors. Elastic net offers exactly that (Zou and Zhang, 2009). More precisely, we estimate the high-dimensional VAR above equation by equation by minimizing the following objective function:

$$
\arg \min _{\mathbf{A}_{i} \in \mathbb{R}^{K p}}\left(y_{i, t}-\mathbf{A}_{i} Z_{t}\right)^{2}+\lambda_{i}\left[(1-\alpha) \sum_{j=1}^{K p} \mathbf{A}_{i, j}^{2}+\alpha \sum_{j=1}^{K p}\left|\mathbf{A}_{i, j}\right|\right],
$$

where $\mathbf{A}_{i}$ is the $i$-th row of the $K \times K p$ dimensional matrix $\mathbf{A}=\left[A_{1}, A_{2}, \cdots, A_{p}\right]$ and $Z_{t}=\left[Y_{t-1}^{\prime}, Y_{t-2}^{\prime}, \cdots, Y_{t-p}^{\prime}\right]^{\prime} . \alpha \in[0,1]$ represents the trade-off between ridge regression and

\footnotetext{
${ }^{14} \mathrm{We}$ assume all $y_{i, t}$ 's are transformed to stationarity (if necessary) and normalized to have zero mean and unit variance.
} 
the LASSO and $\lambda_{i}$ corresponds to the magnitude of penalisation 15 We fix $\alpha=0.5$, which gives equal weight to ridge regression and LASSO to benefit both from the feature selection capability of LASSO and the ability of ridge regression to handle correlation in the data. The reason is that LASSO relies on $L 1$ penalization and therefore it shrinks some coefficients to zero, while ridge regression will not shrink the coefficients to exactly zero, because it relies on quadratic penalization. The lag length $p$ is set to 4 . We leave the autoregressive blocks associated to the key macro variables unpenalised. Furthermore, inspired by the Bayesian literature, we do not impose a penalty on the individual autoregressive coefficients of all other variables included in the VAR. To determine $\lambda_{i}$ we use the BIC as in Kock and Callot (2015).$^{16}{ }^{17}$

Since the estimated parameters of the VAR obtained from minimizing (2.2) may suffer from regularization bias ${ }^{18}$, we estimate in a second stage the model from equation 2.1 by OLS post elastic net (Belloni and Chernozhukov, 2013) on the active set of the (demeaned and de-trended levels) sample. The active set consists of the variables with an estimated non-zero coefficient in the first stage. The aim is to estimate the vector $\hat{V}_{t}$ containing the residuals.

Following arguments of the proxy-VAR literature (Stock and Watson, 2012; Mertens and Ravn, 2013), we regress the two series of our narrative records on the residuals $\hat{V}_{t}$. The estimated predicted value in that regression, say $\hat{W}_{t}$, constitute an (initial) estimate of the structural shocks we aim to recover. This procedure essentially corresponds to the proxyVAR methodology with a large number of added controls $\sqrt{19}$ Since estimation corresponds

\footnotetext{
${ }^{15}$ Since sparsity patterns and persistency may vary across data series contained in $Y_{t}$, we allow the penalty parameter $\lambda_{i}$ to be different across equations.

${ }^{16}$ That is, $\lambda_{i}$ is chosen by minimizing $I C\left(\lambda_{i}\right)=\log \left(R S S\left(\lambda_{i}\right)\right)+D F\left(\lambda_{i}\right) \frac{\log (T)}{T}$ over a suitable grid of values for the penalty parameter. $R S S$ corresponds to the residual sum of squares and $D F$ represents the effective degrees of freedom.

${ }^{17}$ The effective degrees of freedom are estimated by the number of non-zero coefficients in $\widehat{\mathbf{A}}_{i}^{\text {ENet }}$, the parameter vector estimated by the elastic net. While this does not correspond to an unbiased estimator for the elastic net (Tibshirani and Taylor, 2012), we have found in unreported simulations that it provides a "robust compromise" if $\alpha$ is held fixed.

${ }^{18}$ Due to the penalization, it is likely that too few variables are non-zero, and this active set of variables is too small to obtain an unbiased estimate of the true relations.

${ }^{19}$ In finite samples the estimated structural shocks will always have a non-zero correlation coefficient. We address this issue when discussing the estimation of structural impulse responses below.
} 
to solving a high-dimensional regression problem, we use the two-stage elastic net procedure outlined above ${ }^{20}$

\subsubsection{Estimating Responses}

Our aim is to obtain structural responses of the macroeconomic variables to the estimated shocks. We could in principle base our further analysis on the high-dimensional (post elastic net) (proxy-)VAR. However, inference for regularised models with temporal and crosssectional dependent data is no trivial task and has only most recently been properly investigated in the literature (Chernozhukov et al., 2018). Also, we are mainly interested in the reaction of a few macroeconomic variables, say $X_{t}$, and not the full set of variables contained in $Y_{t}$. We therefore take a different approach and estimate a small scale SVAR in $X_{t}$ augmented with the estimated (initial) shock series $\hat{W}_{t}$. More specifically, we estimate the following model:

$$
X_{t}=\Gamma D_{x, t}+\sum_{j=1}^{p} \Theta_{j} X_{t-j}+\sum_{j=0}^{p} \Pi_{j} \hat{W}_{t-j}+U_{t}
$$

where $X_{t}$ is a (small) set of macro variables (in levels), $\hat{W}_{t}=\left[\hat{W}_{1, t}, \hat{W}_{2, t}\right]$ contains (initial) estimates of the two structural shocks. With $\hat{W}_{1, t}$ capturing news of fiscal policy with short anticipation horizon and $\hat{W}_{2, t}$ news with long(er) anticipation. Finally, $U_{t}$ is a vector of reduced-form disturbances. We set $p=4$. $D_{x, t}$ contains deterministic components. ${ }^{21}$.

To cope with the time structure of policy implementation discussed in previous sections, we explicitly allow the structural shocks $\hat{W}_{t}$ to have lagged effects on $X_{t}$. While $\hat{W}_{t}$ is orthogonal to lagged $X_{t}$ 's included as regressors (due to the estimation procedure in the first step), it may still be an imprecise estimate of the shocks of interest. In particular, estimating $W_{t}$ does not guarantee that the two components $\hat{W}_{1, t}$ and $\hat{W}_{2, t}$ are uncorrelated in finite sample. To obtain more precise estimates of the structural shocks, we estimate (2.3) in VAR formulation and impose additional covariance restrictions.

More specifically, let $G_{t}$ be our measure of government spending (contained in $X_{t}$ ) and

${ }^{20}$ We fix $\alpha=0.5$, and use the BIC to determine $\lambda$.

${ }^{21}$ More specifically, $D_{x, t}$ includes an intercept, a linear, and a quadratic trend. 
$X_{-G, t}$ all remaining variables in $X_{t}$. We can express 2.3) in (restricted) VAR form as (neglecting deterministic terms for simplicity)

$$
\left[\begin{array}{c}
G_{t} \\
\hat{W}_{1, t} \\
\hat{W}_{2, t} \\
X_{-G, t}
\end{array}\right]=\sum_{j=1}^{p}\left[\begin{array}{c}
\Omega_{G, j} \\
0 \ldots 0 \\
0 \ldots 0 \\
\Omega_{-G, j}
\end{array}\right]\left[\begin{array}{c}
G_{t-j} \\
\hat{W}_{1, t-j} \\
\hat{W}_{2, t-j} \\
X_{-G, t-j}
\end{array}\right]+\left[\begin{array}{c}
U_{1, t} \\
\hat{W}_{1, t} \\
\hat{W}_{2, t} \\
U_{-1, t}
\end{array}\right]
$$

Where $\Omega_{G, j}$ are row vectors and $\Omega_{-G, j}$ are matrices of appropriate dimensions capturing the autocorrelation in $X_{t}$ and the lagged dependency of $X_{t}$ on $\hat{W}_{t}$. We use a Cholesky decomposition to identify the contemporaneous effect of $\hat{W}_{t}$ on $X_{t}$. That is, the structural model based on the above VAR is identified by a Cholesky decomposition using the ordering in 2.4 . i) government spending first; ii) the component of $\hat{W}_{t}$ containing information on news with a short anticipation horizon second; iii) and the estimated series with information on news with a long anticipation horizon third. This ordering reflects the theoretical properties of our two shocks related to anticipated government spending. Both shocks relate to expectations on future policy directions and hence, must not have an instantaneous effect on government expenditure. Similarly, sudden changes in anticipation about future spending policies cannot affect already enacted (but not yet implemented) policy decisions.

We use a simple residual-based bootstrap to construct inference for impulse responses. Since $\hat{W}_{t}$ is exogenous to $X_{t}$ by construction ${ }^{22}$, we jointly draw (with replacement) from the reduced-form VAR residuals and the estimated external variables $\hat{W}_{t}$. We construct the bootstrap sample of $X$ and recursively based on the estimated autoregressive coefficients in (2.3) 23

${ }^{22}$ The estimated shocks in $\hat{W}_{t}$ are a linear combination of the residuals $\hat{V}_{t}$ from model 2.1, which are by construction orthogonal to $Z_{t}$.

${ }^{23}$ Note that $\hat{W}_{t}$ can be viewed as generated regressors. Showing that $\hat{W}_{t}$ is a precise enough estimate for $W_{t}$ such that it can be treated as data without a "generated regressor" problem is beyond the scope (of the applied nature) of this chapter. 


\subsection{Data and results}

In this section we explain how we implement the methodology outlined in the previous section. We first describe the two data sets that we use to estimate the two structural shocks and the impulse response functions. Then, we test how well the estimated shocks predict future government spending. Thereafter, we show the estimated responses for the set of key macroeconomic variables to the two estimated government spending shocks. Finally, we give an interpretation of our results and link it to the findings in the related literature.

\subsubsection{Data}

We use two data sets in our analysis, namely a high-dimensional data set and a set of key macroeconomic variables. In the previous section the high-dimensional data set was denoted as the vector $Y_{t}$. This data set is used to estimate the two anticipated shocks with with different anticipation horizons. We use an updated version of the Stock and Watson (2012) data, which consists of 131 series of quarterly data for the period 1948 - 2008. ${ }^{24}$ Our differencing and detrending procedure is identical to Stock and Watson (2012). In appendix 2.A.1, we discuss this procedure in more detail.

However, for the structural responses, we use a smaller subset of $Y_{t}$, denoted as $X_{t}$. This vector contains the following key macroeconomic variables: Federal Government Spending, GDP, Private Consumption, Private Non-residential Investment, Hours Worked, Government revenue and the interest rate. This set of main macroeconomic variables displays the main fluctuations in the economy. A similar set is used in related studies (Ramey, 2011, 2015, Ben Zeev and Pappa, 2017). The data are taken from the NIPA tables provided by the Bureau of Economic Analysis (BEA) and the Bureau of Labor Statistics (BLS). The time series are converted into log real per capita if applicable. We deflated the variables using the GDP deflator. More details about the data sources and transformations are provided in appendix 2.A.1, as well as time series plots of the variables.

\footnotetext{
${ }^{24}$ We add the time period 1948 - 1952 using the original references to the McCracken Quarterly Economic Data (FRED-QD).
} 


\subsubsection{Shock estimates}

Using the methodology described in the previous section, we obtain two estimates for the structural shocks of government spending news. Before turning to the impulse response analysis, we test the predictive power of these shocks for future government spending growth, in comparison to the original Ramey narrative and the sub-components. Therefore, we perform a marginal F-test on the coefficients for the shocks in a predictive regression model with government spending growth (i.e. first difference of logs) as the dependent variable and as control variables four lags of GDP growth, the interest rate and government spending growth.

Table 2.1 below shows the F-statistics for Ramey's original series, the sub-components of the narrative and our shock estimates. As a rule of thumb, an F-statistic above 10 is regarded as sufficient predictive power. The first row shows that the Ramey narrative has an F-statistic above 10 in horizons 2 until 5, and no predictive power in the first horizon. The second row shows that the component of the Ramey narrative with a short anticipation horizon only has weak predictive power in the short run.

In contrast, our estimated news shock with a short anticipation horizon has high predictive power one quarter ahead. For the long horizon, both the narrative component as well as our news shock estimate have high predictive power for policy changes 3 to 4 quarters ahead. Not surprisingly, the long-horizon component drives the predictive power of the original Ramey narrative.

Table 2.1: Marginal F-tests for narrative series and shock estimates at future horizons

\begin{tabular}{l|rrrrrrrrrr} 
Series & 1 & 2 & 3 & 4 & 5 & 6 & 7 & 8 & 9 & 10 \\
\hline \hline Ramey narrative & 1.67 & 62.91 & 89.46 & 71.07 & 27.15 & 0.09 & 2.52 & 0.50 & 0.62 & 0.01 \\
Short-horizon narr. & 6.31 & 0.30 & 0.00 & 1.32 & 0.29 & 0.55 & 0.03 & 3.07 & 0.06 & 0.18 \\
Short-horizon shock & 31.73 & 0.07 & 0.11 & 0.75 & 0.07 & 1.30 & 2.75 & 0.80 & 3.37 & 0.99 \\
Long-horizon narr. & 0.66 & 64.74 & 96.40 & 70.29 & 27.01 & 0.01 & 2.76 & 1.39 & 0.74 & 0.04 \\
Long-horizon shock & 0.06 & 12.42 & 28.65 & 7.05 & 0.21 & 1.69 & 1.39 & 2.10 & 0.79 & 0.01
\end{tabular}

Note: The narrative series and shock estimates are included in a predictive regression model for government spending growth at different future horizons. 


\subsubsection{Impulse response estimates}

Figure 2.4 shows estimated impulse responses of the key macroeconomic variables together with bootstrap $68 \%$ confidence intervals ${ }^{25}$ The left column displays the responses to a news shock with a short anticipation horizon, and the right column shows the responses to a shock with a long anticipation horizon. In the first row, the effect of the shocks on government expenditure is shown. Clearly, both shocks affect government spending positively, although the peak in the response is already after 4 quarters for the shock with a short anticipation horizon, while the peak is around 8 quarters for the shock with a long anticipation horizon. For the other macroeconomic variables, we estimate opposite responses to the two shocks. We find expansionary effects for the long anticipation horizon, and contractionary effects when the anticipation horizon is short.

This impulse response analysis can be primarily used for the analysis of the short run impact. Since the underlying model relies on stationarity, we cannot make any claims on medium or long-run impact of the shocks. Hence, the responses after 10 to 15 quarters should be interpreted with caution. In most of the cases these responses go back to zero after a while, or turn insignificant. Even though the long-run impact of the different shocks is an interesting avenue for empirical research, it lies outside the scope of this chapter.

Next, we compare our results to the original findings from Ramey (2011). Figure 2.5 provides this comparison in two different ways. The left column shows the responses to a shock estimated from Ramey's narrative series using the method outlined in section 2.3 . Intuitively, this shows the response to an "aggregated" news shock, which is a combination of shocks that have a long and a short anticipation horizon. In the right column, we include for comparison the impulse responses to a news shock identified as in Ramey (2011), using her EVAR methodology. Analysing impulse responses in figure 2.5 indicates that the estimated reaction to Ramey's "aggregated" news shock is comparable across methodologies (the methodology put forward in this chapter and the EVAR).

\footnotetext{
${ }^{25}$ The responses start at time $t_{0}$, i.e. the moment the news is announced. Hence, there can be already a response in the macroeconomic variables before the effective implementation.
} 
Figure 2.4: Responses with a short and long anticipation horizon

Short anticipation horizon

Gov. Exp.
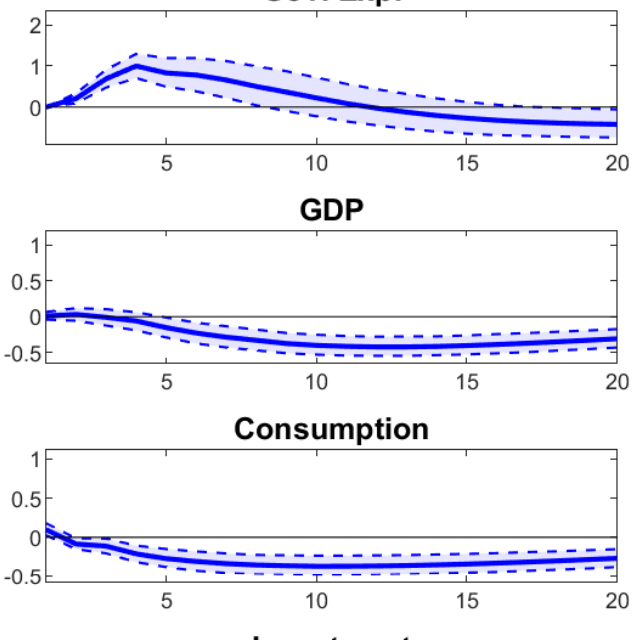

Investment

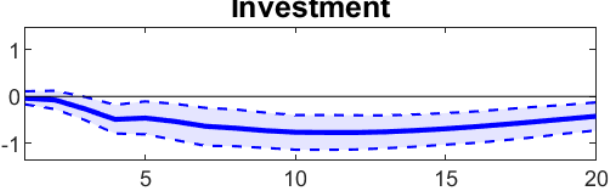

Hours

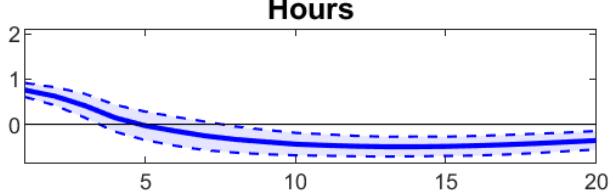

Gov. Rev.

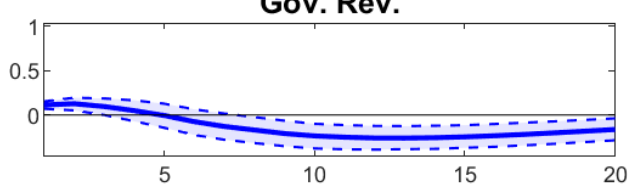

Interest rate

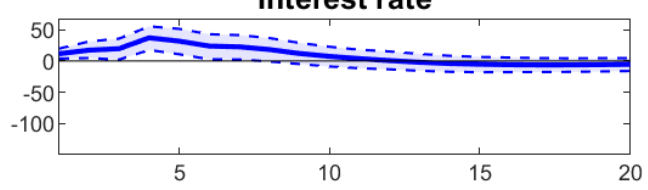

Long anticipation horizon

Gov. Exp.
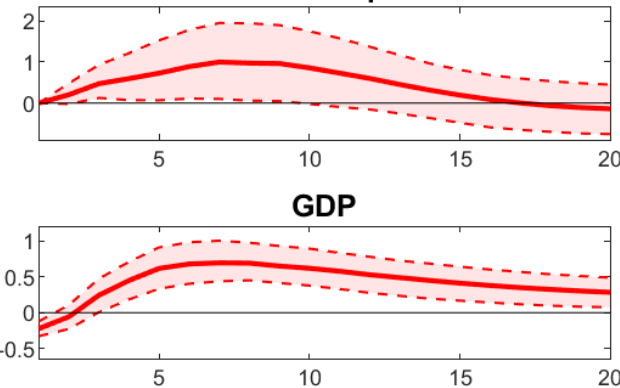

Consumption
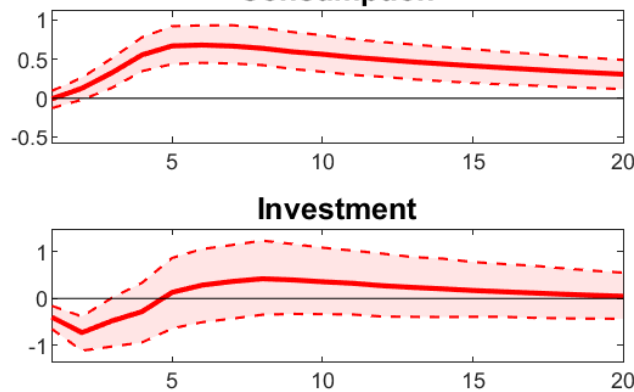

Hours

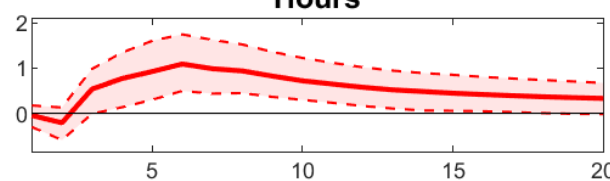

Gov. Rev.

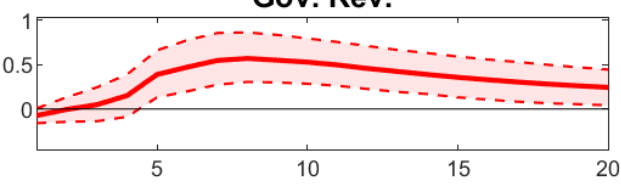

Interest rate

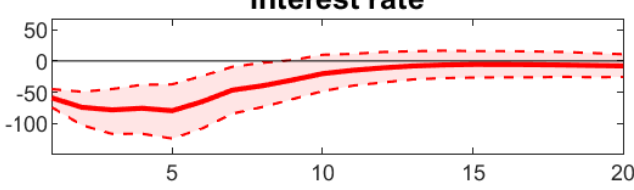

Note: The point estimates are shown together with the bootstrapped $68 \%$ confidence intervals. Impulse responses are normalised such that the maximum positive response of government spending is unity. 
Figure 2.5: Responses to a Ramey news shock

\section{Ramey news (our method)}

Gov. Exp.
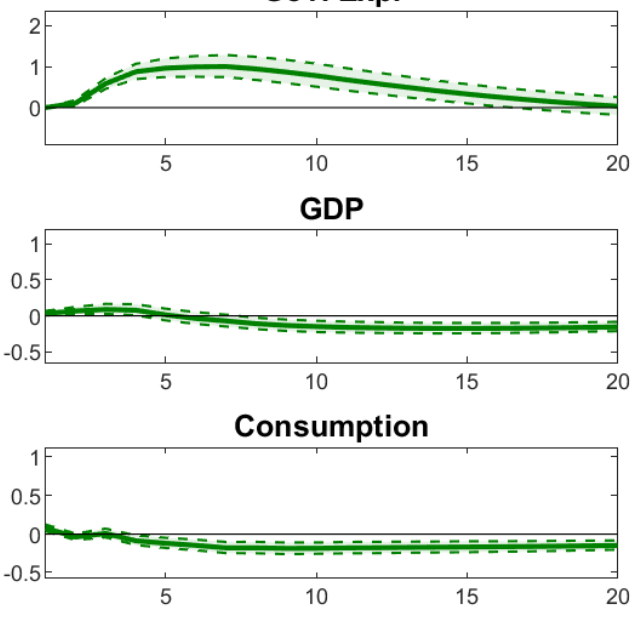

Investment

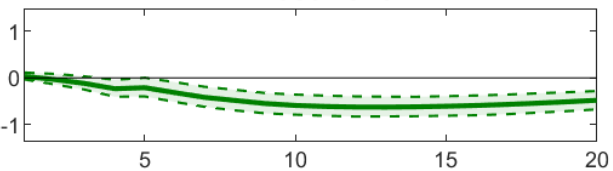

Hours

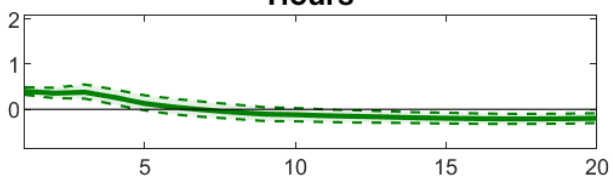

Gov. Rev.

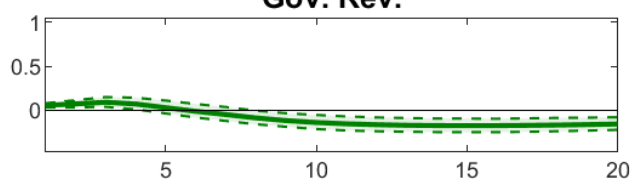

Interest rate

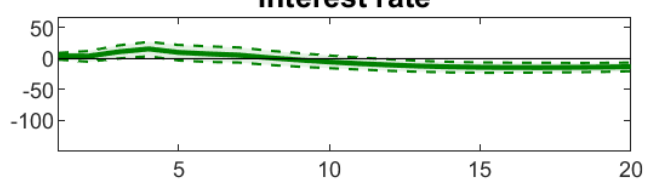

Ramey news (EVAR)

Gov. Exp.
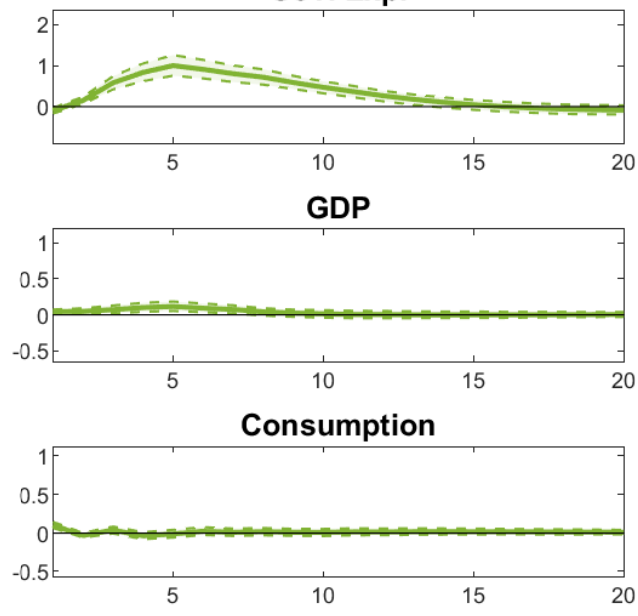

Investment

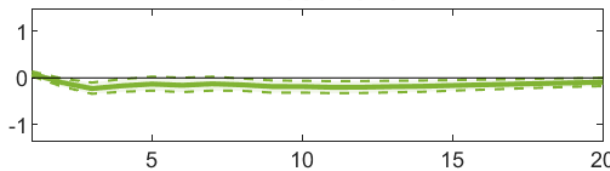

Hours

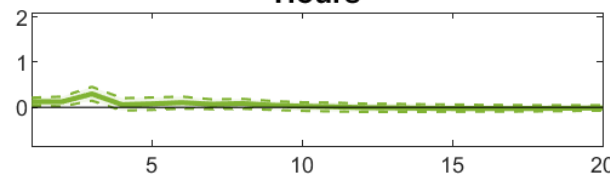

Gov. Rev.
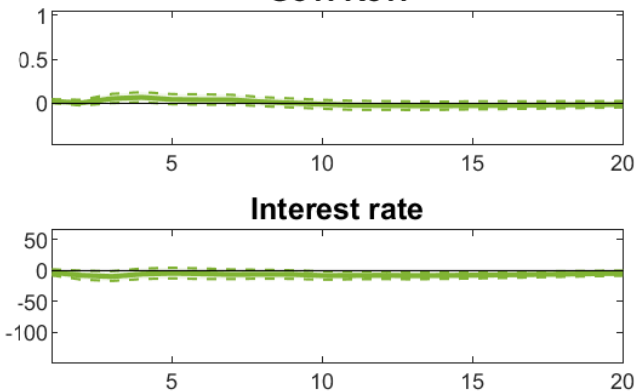

Note: Responses to a Ramey news shock using our methodology in the left column and using the EVAR methodology of Ramey (2011) in the right column. The point estimates are shown together with the bootstrapped $68 \%$ confidence intervals. Impulse responses are normalised such that the maximum positive response of government spending is unity. 
Our results, using our methodology and therefore a possibly more accurate estimate of spending news shocks, confirm the conclusion drawn by Ramey (2011): "Aggregated" government spending news seem to trigger - if at all - a rather short-lived boost in economic activity and cause persistent contractionary effects in main economic aggregates in the medium-run. These contractionary effects appear to be driven by news about government spending due to be implemented in the near(er) future: government spending peaks shortly after the arrival of the news (see first column of Figure 2.4). While positive (yet insignificant) at impact, impulse responses of GDP and its main components are persistently negative after a year.

In contrast, when news incorporates signals about spending changes in the more distant future, the effects on GDP and consumption are positive and persistent. Government expenditures now peak only about two years after impact. While initially GDP responds negatively, aggregate activity increases steadily for the first two years, peaking simultaneously with government spending. The growth in output is mainly driven by a rise in consumption. Interestingly, private investment is crowded out in the first half year despite falling interest rates. Overall, our results confirm the importance of fiscal foresight, in particular the foresight horizon, when conducting government spending policies.

Table 2.2 shows the cumulative, impact and peak multiplier estimates for news shocks, according to anticipation horizon. The multiplier is calculated as the (cumulative) response of GDP divided by the (cumulative) response of government spending, and scaled by the mean nominal GDP-government spending ratio in our sample.

Table 2.2: Multiplier estimates for news shocks with a short and long anticipation horizon

\begin{tabular}{l|rrr} 
Horizon & Cumulative & Impact & Peak \\
\hline \hline Short & -0.13 & 1.53 & 1.53 \\
Long & 6.28 & -2.76 & 8.60
\end{tabular}

We calculate the cumulative multiplier until the peak response of government spending, which is at 4 quarters for the short horizon and 7 quarters for the long horizon. The impact multiplier is always calculated at a horizon of 2 quarters, because government spending 
is restricted not to react to any anticipated government spending shock on impact. The results in table 2.2 indicate that news with a short(er) anticipation horizon has a negative cumulative effect and that only the initial impact is positive. In contrast, if spending policies are anticipated for a long(er) time multiplier effects are positive and large, as shown by the cumulative multiplier estimate. These results confirm that the impact multiplier is not always very informative when investigating anticipated fiscal shocks with significant inside lags, because the response to shocks with longer anticipation horizons can switch sign.

As mentioned before, news with short(er) anticipation horizons are more prominent in war periods, whereas news with long(er) anticipation horizons are more concentrated in peaceful periods. This indicates that our results may be driven by differences in type of spending in war and peaceful periods. However, including a war dummy as exogenous variable does not affect our findings. Also, we further investigate the robustness of our results by including different variables, such as the oil price or total factor productivity. Again, our results seem to be robust across various specifications of the model.

In summary, our findings indicate that the anticipation horizon affects the response of key macroeconomic variables to a government spending news shock. The contractionary effects of government spending news found by for example Ramey (2011) are clearly driven by news shocks with a short anticipation horizon. We show that when we split the news shocks according to the anticipation horizon, we find expansionary effects for news with a long anticipation horizon. In the next subsection, we provide some intuition on how to interpret these empirical results.

\subsubsection{Discussion}

In our empirical set-up, we distinguish between government spending news with a short and long anticipation horizon. We have already argued that the outside lag plays a less important role for government spending. Therefore, the inside lag effectively determines the anticipation horizon. In order to investigate the role of the length of the anticipation horizon, the two components of fiscal news should be comparable. Leeper et al. (2010, 2013) 
argue that the inside lag is characterized as a period of high uncertainty, because news is possibly noisy and subject to changes. Hence, we have to ensure that the news with a long inside lag is not more noisy than the news with a short inside lag. Since we exclusively focus on news that is effectively implemented, we ignore noisy news during the inside lag. Consequently, both news with a short and long anticipation horizon reduce uncertainty, noise and disagreement among agents, which is an important condition for fiscal policy news to be effective (Ricco et al. 2016).

There are potentially two contradicting effects of fiscal policy news on private consumption and investment. On the one hand, additional government spending can crowd out private consumption and investment. The additional demand by the government possibly increases interest rates, which negatively effects private investment and consumption $\sqrt{{ }^{26}}$ On the other hand, news about additional productive capital provided by the government can also positively affect expected (potential) output, especially when economic agents are non-Ricaridan and expect no increase in future taxation. Since private investment and consumption are forward-looking variables, the positive wealth effect due to the increase in expected future production can already have a positive effect in the short run when the positive wealth effect outweighs the negative crowding-out effect (Leeper et al., 2010; Ricco, 2015).

In the previous subsection, we provided empirical evidence that government spending news with a long anticipation horizon has a positive effect on output, private consumption, and investment, while news with a short anticipation horizon has a negative effect on these macroeconomic variables. Our results therefore indicate that news with a long anticipation horizon can act as a strong fiscal forward guidance tool, by increasing expected potential output levels, which outweighs the negative crowding-out effect.

Instead, for news with a relatively short anticipation horizon, we find that the crowdingout effect dominates the wealth effect. This result can be explained by the adjustments that economic agents have to make in their inter-temporal decision making process. The crowdingout effect is stronger when the anticipation horizon is shorter, because there is insufficient

\footnotetext{
${ }^{26}$ However, in the neoclassical view only private consumption is negatively affected, because households increase labour supply, which increases private investment (Baxter and King, 1993).
} 
time for adjustment for the economic agents between announcement and implementation. Since agents are forward looking, they cannot immediately adjust adequately to the news. (Fève and Pietruni, 2016) discuss that since private investment is a forward-looking variable, it is costly to adjust to news, and therefore it is likely that investment responds negatively to news that is implemented soon after the announcement. Our results indicate that this

effect is both present for private consumption and investment. In line with Ellahie and Ricco (2017) and Ricco (2015), we find that if news creates a short-run mistake in expectations of economic agents, then it results in strong crowding-out effects.

\subsection{Conclusion}

This chapter offers new insights into the importance of anticipation in the transmission mechanism of fiscal policy. We investigate the role of the anticipation horizon by distinguishing anticipated government spending shocks with short(er) and long(er) periods of foresight. The key idea is that a longer planning horizon may intensify the role of expectations in agents' reaction to policy changes.

We find evidence that fiscal policy has indeed stronger effects when anticipated for a longer period, resulting in large multiplier effects. In contrast, when the foresight horizon is short, effects of anticipated spending shocks are contractionary. From a policy perspective, our findings could provide important insights into how to effectively steer fiscal policy when used as a forward guidance tool. If policymakers aim to provide an economic stimulus, then economic agents should have sufficient time to anticipate on the policy change. Otherwise, the stimulus could do more harm than good. 


\section{A Appendix}

\section{A.1 Data description}

\section{Key macroeconomic variables}

The table below shows the main macroeconomic variables that we use to estimate the impulse responses. Some remarks:

- BEA refers to the US Bureau of Economic Analysis.

- BLS refers to the US Bureau of Labor Statistics

- SA means seasonally adjusted, NSA means not seasonally adjusted. For more information about seasonal adjustments, see the corresponding source.

- For Federal government spending, we use only total consumption and investment, which means that we exclude for example expenditures related to social security and interest payments.

\begin{tabular}{|c|c|c|c|}
\hline Name & Source & Units & Transformation \\
\hline Gov. Spending & $\begin{array}{l}\text { BEA, NIPA } \\
\text { 1.1.5, line } 22\end{array}$ & Billions of dollars (SA) & $\begin{array}{l}\text { Logarithmic and di- } \\
\text { vided by population } \\
\text { and GDP deflator }\end{array}$ \\
\hline GDP & $\begin{array}{l}\text { BEA, NIPA Table } \\
\text { 1.1.5, line } 1\end{array}$ & Billions of dollars (SA) & $\begin{array}{l}\text { Logarithmic and di- } \\
\text { vided by population } \\
\text { and GDP deflator }\end{array}$ \\
\hline Consumption & $\begin{array}{l}\text { BEA, NIPA } \text { Table } \\
1.1 .5, \text { line } 2\end{array}$ & Billions of dollars (SA) & $\begin{array}{l}\text { Logarithmic and di- } \\
\text { vided by population } \\
\text { and GDP deflator }\end{array}$ \\
\hline Investment & $\begin{array}{l}\text { BEA, NIPA Table } \\
\text { 1.1.5, line } 9\end{array}$ & Billions of dollars (SA) & $\begin{array}{l}\text { Logarithmic and di- } \\
\text { vided by population } \\
\text { and GDP deflator }\end{array}$ \\
\hline Gov. Revenue & $\begin{array}{l}\text { BEA, NIPA Table } 3.2 \text {, } \\
\text { line } 2\end{array}$ & Billions of dollars (SA) & $\begin{array}{l}\text { Logarithmic and di- } \\
\text { vided by population } \\
\text { and GDP deflator }\end{array}$ \\
\hline Hours worked & $\begin{array}{l}\text { BLS, Current Employ- } \\
\text { ment Statistics (CES) }\end{array}$ & Thousands (SA) & $\begin{array}{l}\text { Logarithm and divided } \\
\text { by population }\end{array}$ \\
\hline Interest rate & \begin{tabular}{l|l} 
Ramey \\
rate
\end{tabular} & Percentage & - \\
\hline GDP Deflator & $\begin{array}{l}\text { BEA, NIPA } \\
1.1 .4, \text { line } 1\end{array}$ & $\begin{array}{l}\text { Index number, base } \\
\text { year } 2009=100(\mathrm{SA})\end{array}$ & - \\
\hline Population & $\begin{array}{l}\text { BEA, NIPA Table } 7.1 \text {, } \\
\text { line } 18\end{array}$ & Thousands & - \\
\hline
\end{tabular}


The following figures show the evolution of the key macroeconomic variables over time.

Figure 2.6: Key macroeconomic variables
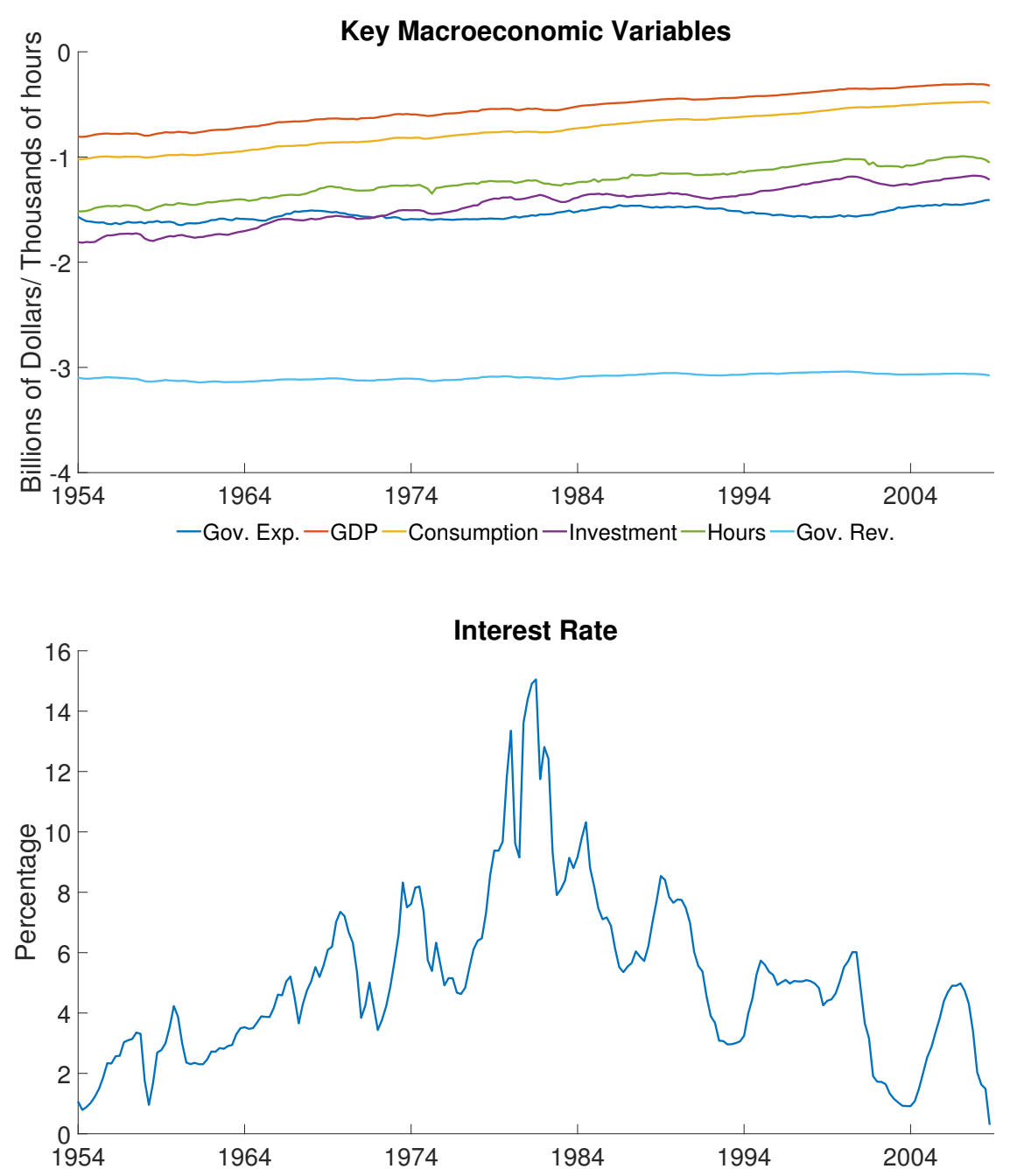

Note: Time series plots of the key macroeconomic variables. All variables are in log real per capita billions of dollars, except hours worked, which is in log per capita thousands of hours. The time series plot of the interest rate is in percentages. This is the T-bill rate reported by Ramey (2011). 


\section{High-dimensional data}

All data that we use to estimate the factors for the dynamic factor model are from Stock and Watson (2012) and are freely available online. The series are divided in 13 different categories:

- National Income and Product Accounts

- Industrial Production

- Employment and Unemployment

- Housing Starts

- Inventories, Orders and Sales

- Prices

- Earnings and Productivity

- Interest Rates

- Money and Credit

- Stock Prices, Wealth, Household Balance Sheets

- Housing Prices

- Exchange Rates

- Other

Some of the series are available on quarterly basis and others on monthly basis. Since we want to use all series on quarterly basis, we convert the monthly data into quarterly data by using the three-month average of the monthly values ${ }^{27}$. We further concentrate on the series that are available from 1959 Q1 until 2008 Q4. We also excluded all series that Stock and Watson (2012) ignore in their paper when the estimate the factors. The reason why these variables are excluded is that it is not necessary to include both an aggregate variable and the disaggregate versions of the same variable. The result is that out of the 200 series that are available, we use only 110 series. If necessary, the series were already seasonally adjusted and converted in real terms ${ }^{28}$. We furthermore transform all series in logs, except

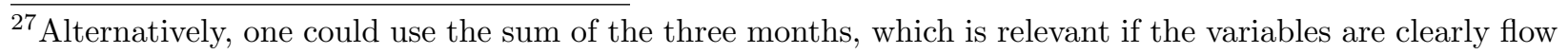
variables, but almost all monthly data are clearly stock variables.

${ }^{28}$ For further details, see the online appendix of Stock and Watson $(2012)$ 
the following 14 series for which Stock and Watson $(2012)$ indicate that they use these series untransformed 29 ,

- Capacity Utilization Manufacturing Industry

- Unemployment rate age 16-19

- Unemployment rate $>20$ men

- Unemployment rate $>20$ women

- Average Working Hours Overtime

- Vendor Performance Index

- Commercial Paper - T-bill spread

- 3-month T-bill rate

- BAA - 10-year Treasury bill spread

- 6-month - 3-month T-bill rate spread

- 1-year Treasury bill - 3-month T-bill rate spread

- 10-year Treasury bill - 3-month T-bill rate spread

- Consumer Expectations

- Change inventories over GDP

- Networth Relative to Personal Disposable Income

Next, we 'globally' de-trend all series by fitting a simple regression model for all series separately with an intercept and linear time trend. Then, we difference all series, except the following 7 series that we include in levels ${ }^{30}$

- Vendor Performance Index

- Commercial Paper - T-bill spread

- BAA - 10-year Treasury bill spread

- 6-month - 3-month T-bill rate spread

${ }^{29}$ In their description, this means the series that are categorized as 1 or 2

${ }^{30}$ According to Stock and Watson (2012) we should also include the following variables in levels: Capacity Utilization Manufacturing Industry, Average Working Hours Manufacturing Industry, Consumer Expectations and Networth Relative to Personal Disposable Income. However, if we do this then the null-hypothesis of a unit root cannot be rejected using an Augmented Dicky Fuller Test, even with the alternative hypothesis of a random walk with drift. Hence, we decided to include these variables in first difference. 
- 1-year Treasury bill - 3-month T-bill rate spread

- 10-year Treasury bill - 3-month T-bill rate spread

- Change inventories over GDP

Finally, in line with Stock and Watson (2012), we also 'locally' de-trend the series by calculating a 30-quarter moving average (local trend). We use the series minus this local trend. Unlike Stock and Watson (2012), we do not take second difference for any of the series. In fact, we checked the stationarity for all of the series using an Augmented Dicky-Fuller Test after all these transformations. For none of the series we could not reject the null hypothesis of a unit root, even when using different alternative hypotheses. This means that second differencing would only lead to over-differencing. 


\section{A.2 Overview of all defense news}

Announcement date Implementation date Appropriation type Anticipation horizon

Truman build-up

$\begin{array}{llll}\text { 1947 Jun } & \text { 1947 Jul } 30 & \text { Regular } & \text { Short } \\ \text { 1948 Jan } & \text { 1948 Jun 24 } & \text { Regular } & \text { Long } \\ \text { 1948 May } & \text { 1948 May 21 } & \text { Supplemental } & \text { Short } \\ \text { 1949 Dec } & \text { 1950 Jul 11 } & \text { Regular } & \text { Long }\end{array}$

Korean War

$\begin{array}{llll}\text { 1950 Jun } & \text { 1950 Sep 27 } & \text { Supplemental } & \text { Short } \\ \text { 1950 Aug } & \text { 1950 Sep 27 } & \text { Supplemental } & \text { Short } \\ \text { 1950 Dec } & \text { 1951 Jan } 6 & \text { Supplemental } & \text { Short } \\ \text { 1951 Mar } & \text { 1951 Jun } 2 & \text { Supplemental } & \text { Short } \\ \text { 1952 Feb } & \text { 1952 Jun } 5 & \text { Supplemental } & \text { Long } \\ \text { 1952 Apr } & \text { 1952 Jul 11 } & \text { Regular } & \text { Short } \\ \text { 1952 Aug } & \text { 1953 Mar } 28 & \text { Supplemental } & \text { Long } \\ \text { 1953 Mar } & \text { 1953 Aug } 1 & \text { Regular } & \text { Long } \\ \text { 1953 May } & \text { 1953 Aug 1 } & \text { Regular } & \text { Short } \\ \text { 1953 July } & \text { 1953 Aug 1 } & \text { Regular } & \text { Short } \\ \text { 1954 Jan } & \text { 1954 Jun } 30 & \text { Regular } & \text { Long }\end{array}$

Eisenhower-Kennedy build-up

$\begin{array}{llll}\text { 1955 Jan } & \text { 1955 Jul 13 } & \text { Regular } & \text { Long } \\ \text { 1956 Jan } & \text { 1956 Jul } 2 & \text { Regular } & \text { Long } \\ \text { 1956 May } & \text { 1956 Jul } 2 & \text { Regular } & \text { Short } \\ \text { 1956 Aug } & \text { 1957 Aug } 2 & \text { Regular } & \text { Long } \\ \text { 1956 Nov } & \text { 1958 Aug } 2 & \text { Regular } & \text { Long } \\ \text { 1957 May } & \text { 1959 Aug } 2 & \text { Regular } & \text { Short } \\ \text { 1957 Dec } & \text { 1958 Feb 11 } & \text { Supplemental } & \text { Short } \\ \text { 1958 Feb } & \text { 1958 Feb 11 } & \text { Supplemental } & \text { Short } \\ \text { 1959 Mar } & \text { 1959 Aug } 18 & \text { Regular } & \text { Long } \\ \text { 1960 Jun } & \text { 1960 Jul } 7 & \text { Regular } & \text { Short } \\ \text { 1961 Mar } & \text { 1961 Aug } 17 & \text { Regular } & \text { Long }\end{array}$




\begin{tabular}{llll}
\hline 1961 May & 1961 Aug 17 & Regular & Short \\
1961 Jul & 1961 Aug 17 & Regular & Short \\
1961 Dec & 1962 Aug 9 & Regular & Long \\
1962 Mar & 1962 Aug 9 & Regular & Long \\
1963 Aug & 1963 Oct 17 & Regular & Short \\
1964 Feb & 1964 Aug 19 & Regular & Long \\
\hline
\end{tabular}

\begin{tabular}{llll}
\multicolumn{3}{c}{ Vietnam War } \\
1965 Mar & 1965 May 7 & Supplemental & Short \\
1965 May & 1965 May 7 & Supplemental & Short \\
1965 Jul & 1965 Sep 29 & Regular & Short \\
1966 Jun & 1966 Oct 15 & Regular & Long \\
1966 Sep & 1966 Oct 15 & Regular & Short \\
1966 Dec & 1967 Sep 29 & Regular & Long \\
1967 Jan 31 & 1968 Oct 17 & Regular & Long \\
1967 Jun & 1967 Sep 29 & Regular & Short \\
1967 Sep & 1967 Sep 29 & Regular & Short \\
1967 Dec & 1968 Jul 9 & Supplemental & Long \\
1968 Mar & 1968 Jul 9 & Supplemental & Long \\
1968 Jun & 1968 Oct 17 & Regular & Long \\
1970 Feb & 1970 Dec 11 & Regular & Long \\
1970 Sep & 1970 Dec 11 & Regular & Short \\
1973 Aug & 1974 Jan 2 & Regular & Long
\end{tabular}

\section{Cold War}

$\begin{array}{llll}\text { 1973 Nov } & \text { 1974 Jan } 2 & \text { Regular } & \text { Short } \\ \text { 1976 Feb } & \text { 1976 Sep } 22 & \text { Regular } & \text { Long } \\ \text { 1977 Sep } & \text { 1978 Oct } 13 & \text { Regular } & \text { Long } \\ \text { 1979 Jan } & \text { 1979 Dec } 21 & \text { Regular } & \text { Long } \\ \text { 1980 Jan } & \text { 1980 Dec } 15 & \text { Regular } & \text { Long } \\ \text { 1981 Feb } & \text { 1981 Dec } 29 & \text { Regular } & \text { Long } \\ \text { 1986 Nov } & \text { 1987 Dec } 22 & \text { Regular } & \text { Long } \\ \text { 1988 Feb } & \text { 1988 Oct } 1 & \text { Regular } & \text { Long } \\ \text { 1988 Nov } & \text { 1989 Nov } 21 & \text { Regular } & \text { Long }\end{array}$

${ }^{31}$ Ramey (2011) states that the news in January included news about FY1967 and FY1968, but these have been included in the announcement in September 1966. The rest of the news was about FY1969 and FY1970, so we put the implementation date at the signing date of the regular budget request for FY1969. 


\begin{tabular}{|c|c|c|c|}
\hline 1989 Dec & 1990 Nov 5 & Regular & Long \\
\hline \multicolumn{4}{|c|}{ Gulf War and Clinton Administration } \\
\hline $\begin{array}{l}1990 \text { Sep } \\
1991 \text { Feb } 32 \\
1999 \text { Jan }\end{array}$ & $\begin{array}{l}1990 \text { Nov } 5 \\
1991 \text { Nov } 26 \\
1999 \text { Oct } 25\end{array}$ & $\begin{array}{l}\text { Regular } \\
\text { Regular } \\
\text { Regular }\end{array}$ & $\begin{array}{l}\text { Short } \\
\text { Long } \\
\text { Long }\end{array}$ \\
\hline \multicolumn{4}{|c|}{ War on Terror } \\
\hline $\begin{array}{l}2001 \text { Sep } \\
2002 \text { Feb } \\
2002 \text { Sep } \\
2003 \text { Mar } \\
2003 \text { Sep } \\
2003 \text { Nov } \\
2004 \text { Jun } \\
2005 \text { Jan } \\
2006 \text { Apr } \\
2007 \text { Oct }\end{array}$ & $\begin{array}{l}2001 \text { Sep } 18 \\
2002 \text { Aug } 18 \\
2002 \text { Oct } 23 \\
2003 \text { Apr } 16 \\
2003 \text { Sep } 30 \\
2003 \text { Nov } 6 \\
2004 \text { Aug } 5 \\
2005 \text { May } 11 \\
\text { 2006 Jun } 15 \\
\text { 2007 Nov } 13\end{array}$ & $\begin{array}{l}\text { Supplemental } \\
\text { Supplemental } \\
\text { Regular } \\
\text { Supplemental } \\
\text { Regular } \\
\text { Supplemental } \\
\text { Regular } \\
\text { Supplemental } \\
\text { Supplemental } \\
\text { Regular }\end{array}$ & $\begin{array}{l}\text { Short } \\
\text { Long } \\
\text { Short } \\
\text { Short } \\
\text { Short } \\
\text { Short } \\
\text { Short } \\
\text { Long } \\
\text { Short } \\
\text { Short }\end{array}$ \\
\hline \multicolumn{4}{|c|}{ Obama Administration } \\
\hline $\begin{array}{l}2008 \text { Dec } \\
2010 \text { Aug } \\
2011 \text { Aug } \\
2011 \text { Nov } \\
2013 \text { Feb }\end{array}$ & $\begin{array}{l}2009 \text { Dec } 19 \\
2011 \text { Apr } 15 \\
2011 \text { Dec } 23 \\
2011 \text { Dec } 23 \\
2013 \text { Mar } 1\end{array}$ & $\begin{array}{l}\text { Regular } \\
\text { Regular } \\
\text { Regular } \\
\text { Regular } \\
\text { Other }{ }^{33}\end{array}$ & $\begin{array}{l}\text { Long } \\
\text { Long } \\
\text { Long } \\
\text { Short } \\
\text { Short }\end{array}$ \\
\hline
\end{tabular}

${ }^{32}$ This announcement date is different from the date that Ramey (2011) uses, because the announcement of the retreat of troops was actually already made on February 28, 1991. We therefore think it is better to put the announcement date earlier. The implementation is then in the regular budget for FY1992.

${ }^{33}$ This news is part of the sequester cuts that became effective on March 1, 2013 
2.A. APPENDIX 


\section{Chapter 3}

\section{Local Fiscal Multipliers of Different Government Spending Categories}

This chapter compares multipliers of different categories of US federal government spending, and in doing so provides a new insight as to why fiscal multipliers may differ across countries and time. It proposes a novel way to estimate exogenous federal government spending shocks at the state level which does not rely on exogenous instruments for specific spending channels and works for all categories of federal spending. Using a projection-based approach, the cumulative multipliers of defense and non-defense spending shocks are estimated. The results indicate that defense spending yields lower multipliers than non-defense spending. Thus, focusing only on defense spending may result in underestimating the multiplier for government spending.

${ }^{1}$ This chapter is based on Van Gemert et al. 2020 . 


\subsection{Introduction}

A central question in macroeconomics is whether the government can effectively stimulate the economy by increasing spending or decreasing taxes. The effectiveness of a short-run spending stimulus can be assessed by estimating the fiscal multiplier, i.e. the additional income generated per unit of additional government spending. However, the existing estimates of the fiscal multiplier vary substantially across studies. These differences are not only due to differences in the empirical approach. Economic factors, such as the state of the business cycle, the exchange rate regime, and the openness of a country, also affect the size of the multiplier (Ramey, 2019). In fact, there are many underlying factors that play a role in the way government spending affects the macro-economy. In chapter 2 , the role of the anticipation horizon has been investigated, and in this chapter, we focus on another factor that may contribute to differences in fiscal multipliers, namely the category (or function) of government spending that dominates a fiscal policy stimulus. Our investigation of the role of government spending categories starts with a simple comparison: defense spending versus non-defense spending. Indeed, defense spending has been often used in the fiscal policy literature due to its acyclical property, allowing researchers to characterize defense spending shocks as events exogenous to the business cycle (Ramey, 2019). However, the way defense spending impacts the local economy may be quite indirect, and depends on the reaction from a few defense contractors. Instead, non-defense spending, which includes social transfers, education, health, or infrastructure, is more aligned with the typical counter-cyclical stimulus tool. The mechanisms by which defense and non-defense spending affect the local economy may differ, and we hypothesize that their economic impact might also depend on the category of spending. From a policy perspective, it is important to know whether there is a difference in the effectiveness across government spending categories in order to effectively use specific counter-cyclical policy measures to dampen economic slowdowns.

Previous studies have estimated fiscal multipliers for defense and for non-defense spending, either at the national level using time series data, or at the sub-national level using panel 
data. ${ }^{2}$ Regarding defense spending, there are both estimates at the aggregate (Ramey and Zubairy, 2018) and the state levels (Nakamura and Steinsson, 2014; Dupor and Guerrero, 2017). Similarly, there are studies investigating the effects of non-defense spending at the aggregate (Alesina et al., 2018) and the state levels (Leduc and Wilson, 2013; Clemens and Miran, 2012, Shoag, 2016). Comparing the fiscal multipliers in these different studies points at higher multipliers for non-defense spending at the state level. However, such a gap may also be driven by other differences between the papers. Indeed, no study has attempted to directly compare the multipliers across government spending categories in a unified framework. This is because the identification method often relies on a specific spending grant or event, while a comparison requires to devise a method which i) could be applicable in a similar way to defense and non-defense spending and ii) allows for causal inference in order to quantify fiscal multipliers.

This chapter contributes to the literature by proposing a novel approach to compare fiscal multipliers of different government spending categories. Our approach relies on identifying exogenous federal government spending shocks at the state-level. We isolate the exogenous part of federal spending allocated to states by removing the common component of spending across states and the endogenous state-level component. The identification strategy for the shocks exploits the cross-sectional variation in federal spending. It specifically uses the fact that part of federal spending to states is allocated independently of the statelevel economic conditions. The estimation approach has two main advantages. Firstly, the estimated shocks for both defense and non-defense spending are better in predicting federal spending at the state level than existing instruments. Secondly, the empirical approach does not rely on external instruments for specific categories of government spending. It is suitable for estimating exogenous shocks for any federal spending category.

The results in this chapter indicate that defense spending yields lower multipliers than non-defense spending, which is in line with previous findings on non-defense state multipliers

${ }^{2}$ An advantage of panel data analysis is that estimation is feasible even if the time dimension is relatively short. Moreover, with time fixed effects, it is easier to control for business cycle dynamics. It is also possible to take a multi-country approach for the cross-sectional analysis (Ilzetzki et al., 2013). 
(Leduc and Wilson, 2013; Clemens and Miran, 2012; Shoag, 2016). The conclusion is that by focusing only on defense spending, one may underestimate the multiplier.

The outline of this chapter is as follows. Section 3.2 places our research question and approach in the related literature. Section 3.3 explains the method and data that we use

to estimate fiscal multipliers for defense and non-defense spending. $3^{3}$ Section 3.4 discusses the baseline results, robustness checks, and extensions. We also test the effect of accounting for spillovers across states, and study a further disaggregation of the non-defense spending category. Finally, section 3.5 concludes the chapter.

\subsection{Local fiscal multipliers in the related literature}

The aim of this chapter is to estimate and compare the fiscal multipliers of state-level defense versus non-defense spending. In this section, we first outline crucial empirical challenges when estimating local multipliers and how they have been tackled in the related literature. We then discuss how we complement these approaches. Our method is further discussed in detail in section 3.3 .

\subsubsection{Estimating local fiscal multipliers: Objectives and challenges}

The estimated fiscal multiplier based on state-level or sub-national data is often labeled as the 'local fiscal multiplier'. Nakamura and Steinsson (2014) argue that such local fiscal multiplier should be interpreted as an 'open economy relative multiplier', because federal states can be considered as open economies that form a currency union. Therefore, the local fiscal multiplier is different from the closed economy aggregate multiplier that can be estimated with time series data (Blanchard and Perotti, 2002, Barro and Redlick, 2011; Ramey, 2011; Ramey and Zubairy, 2018). Furthermore, positive spillovers and general equilibrium effects (i.e. across states), may contribute to a difference between the local and the aggregate multipliers (Auerbach et al., 2019; Dupor and Guerrero, 2017).

\footnotetext{
${ }^{3}$ This methodology is also used in chapter 4 .
} 
Estimating the local fiscal multiplier for different categories of government spending in a fiscal union is difficult, because local and federal government spending shocks are partially endogenous to the state-level business cycle for two reasons. First, government spending by the state government is partially endogenous to the state-level business cycle, because the state government relies on its own revenues to finance spending. In times of economic slack, revenues decrease and therefore the state has to decrease spending, especially since state governments often face balanced budget requirements (Conti-Brown and Skeel, 2012). Second, many federal spending programs intend to economically support states. Hence, the federal government spending stimulus to a state is also endogenous to the state-level business cycle. If we fail to take this into account, then the multiplier estimates are biased upwards.

\subsubsection{Estimating local fiscal multipliers: Possible solutions}

To solve the problems highlighted above, it is common to instrument state or federal spending with variables that are uncorrelated to the state-level business cycle. Following ChodorowReich (2019), we can decompose state-level spending for a specific category into three components: a common component across states, an endogenous state-level component, and an exogenous (random) state-level component. The typical approach in the related literature is to find a variable that proxies the exogenous state-level component to instrument the endogenous state-level component. The common component can be controlled for using time-fixed effects. Previous works can be further separated into those studying defense spending socks, and those focusing on non-defense spending shocks. As we detail in what follows, the instrument chosen is often specific to the chosen spending category, and therefore cannot be used to compare fiscal multipliers across categories (i.e. defense versus non-defense spending).

The papers that study defense spending focus on the effect of direct federal government spending on state-level income, which we will label channel A in the rest of the chapter (see also Figure 3.1 below). Nakamura and Steinsson (2014), Dupor and Guerrero (2017) and Auerbach et al. (2019) construct an instrument to exploit the heterogeneity in the response of local defense contracts to national variation in defense spending. The identifying 
assumption is that the federal government does not increase national defense spending to give a disproportional economic stimulus, because a particular state is doing economically poorly compared to other states. These studies use the approach by Bartik (1991) to instrument military spending per state with the change in national defense spending, scaled by the average level of military spending in that state to its output in previous years. Nakamura and Steinsson (2014) estimate a local fiscal multiplier of 1.5 for a two-year horizon, but Dupor and Guerrero (2017) show that the multiplier is probably lower, depending on the estimation period. Finally, Auerbach et al. (2019) construct a defense contract dataset at the city level for different industries. They confirm the multiplier found by Nakamura and Steinsson (2014) once they sum over positive within-city and rest-of-state spillover effects. Next to these studies, Biolsi (2015) and Hausman (2016) use historical policy examples from the 1930s to illustrate the effect of direct federal spending at the local level without estimating multipliers.

On the other hand, papers that study non-defense spending use specific instruments that relate to spending from the local government, either indirectly funded by the federal state or by states' own resources, which we label channel B and C respectively (see Figure 3.1 below) 4 In the first case, the federal government provides state governments with grants to carry out a particular spending program. The effectiveness of an indirect federal fiscal shock depends on how the shock is transmitted by state governments and whether the grants crowd out spending by state governments. To avoid this, the federal government attaches conditions to grants. In total, $77 \%$ of such granted amount involves either matching or maintenanceof-effort requirements in the United States (FFIS, 2016). Matching requirements require a state government to use its own revenues to match the amount granted by the federal government, while maintenance-of-effort requirements ensure that state governments do not cut spending in the program tied to the grant when it receives federal funds. As a result, empirical studies have found that federal grants do not crowd out state spending, which is the so-called flypaper effect (Gamkar and Oates, 1996; Nesbit and Kreft, 2009). 5 
Many studies that use indirect federal spending focus on exogenous drivers of the grants to state governments, such as specific rules in grant mechanisms (Chodorow-Reich et al. 2012; Wilson, 2012; Fishback and Kachanovskaya, 2015; Suárez Serrato and Wingender, 2016; Chodorow-Reich, 2019). These rules are used to instrument grants from the federal to the state government. Alternatively, Leduc and Wilson (2013) do not use an IV-set up. Instead, they use the difference between the expected amount of grants and the actual amount received to estimate the indirect federal government spending shock. All fiscal multiplier estimates for this spending channel range between 1.4 and 2.0.6

Finally, there are papers that use internally-financed state government (non-defense) spending (channel $\mathrm{C}$ in Figure 3.1) 7 In this case, state governments finance the spending with state taxation, deficits, or other funds, such as rainy-day funds, pension funds, or lottery funds. Clemens and Miran (2012) analyze deficit-financed spending by state governments. They use differences in states' balanced-budget requirements and estimate a multiplier of 0.3. Shoag (2016) analyzes an external shock to state government spending by exploiting windfalls in state pension funds and estimates a multiplier close to 2.0.

The specific instruments used in previous studies do not allow for a comparison across government spending categories. In the next section we describe our method, which, similar to previous studies, removes the endogenous component of state-level spending, but does so in a unified framework which is valid for defense as well as non-defense spending.

\subsection{Empirical approach}

In this section, we discuss the methodology we use to estimate fiscal multipliers for different spending categories. We start by discussing the structure of fiscal flows in the US and the data used. Then, we present the methodology to estimate state-specific federal government spending shocks. We include the shocks in a dynamic panel-data model to estimate impulse responses and construct cumulative multipliers.

${ }^{6}$ Except Fishback and Kachanovskaya (2015), but this study uses data from the Great Depression. Adelino et al. (2017) analyze the effect of municipal spending. 


\subsubsection{Structure of government spending in the United States}

The review of the related literature has highlighted the importance of the structure of government spending in the United States. In a fiscal union or federally organized state, multiple levels of government are engaged in fiscal policy. Typically, there exists a common structure of fiscal flows between the federal government and state governments. These fiscal flows include transfer payments that aim to achieve short-run economic stabilization of a state, or promote long-run convergence between states. Therefore, both the federal government and state-level governments are involved in most spending categories. The federal government is often not actively involved in the implementation of a specific policy, but it finances the policy implemented by lower-level governments through transfers. An exception is defense spending, which usually only takes place at the federal level.

The structure of fiscal flows in the case of the United States is summarized in the nonhierarchical overview in figure 3.1 below. We distinguish three different fiscal channels. Channel A is the direct federal spending channel, where the federal government interacts with the state-level economy without cooperation with the state government. Instead, in channel B the federal government interacts with the state economy only indirectly, via the state government. Finally, in channel $\mathrm{C}$ the state government directly interacts with the state economy, without any involvement of the federal government.

Figure 3.1: Fiscal policy flows in a federally organized state

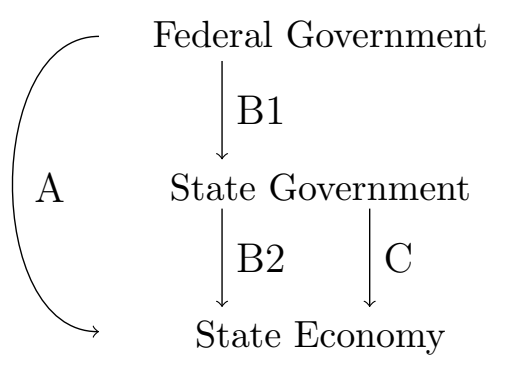

Total government spending affecting the state economy is the sum of channels A, B, and C. Our aim is then to evaluate how different categories of such spending affect the state economy, by estimating the corresponding 'local' fiscal multipliers. To do so, we therefore 
need to break down total spending by category. Those categories can be related for example to government functions (education, health, infrastructure, and defense) or types of spending (consumption, investment, interest payments). Although the latter could make more sense from an economic perspective, only the former disaggregation is allowed given the way the data is constructed. To better complement large parts of the literature, we focus in this chapter on defense versus non-defense spending (c.f. Barro and Redlick, 2011). We classify all non-military spending automatically as non-defense spending.

The categories of spending are linked to the structure of fiscal flows too. Indeed, we know that the federal government is exclusively involved in defense spending. The state economy is therefore only affected by defense spending through channel A. On the other hand, non-defense spending does not belong to a specific channel, although channels B and $\mathrm{C}$ dominate 8 Hence, we have to take into account the specific structure of fiscal flows in the US when analyzing the effect of defense versus non-defense spending at the state level. The disadvantage of using the specific structure of government spending is that we cannot disentangle the effect of different spending channels versus different categories. However, we believe that there is no reason to assume that the channel plays an important role in the local effects of spending. Instead, if we find differences in the estimated multipliers, then these are more likely driven by the different spending categories. In this study, we limit ourselves to federally financed spending at the state-level (channels A and B), because it is easier to identify the exogenous spending component for these channels.

\subsubsection{Data}

We use state-level panel data for 50 US states from 1963 to 2014. In the next paragraphs, we discuss the main variables that we use.

${ }^{8}$ In the US, the federal government spending consists mainly out of defense spending and social transfers, but transfers are generally ignored when studying the effects of spending policy. 


\section{Income}

The main dependent variable is personal income at the state-level, available in the Regional Economic Accounts from the US Bureau of Economic Analysis (BEA). Personal income sums income of all residents, including income received from other states $9^{9}$ We convert these data in real per capita terms, using the population estimates and deflators from Dupor and Guerrero (2017). In line with Shoag (2016), we use personal income instead of output, due to limitations in data availability ${ }^{10}$ In addition, income follows fluctuations of output closely. ${ }^{11}$

\section{Defense spending}

In case of defense spending, there is no involvement from the state government (only channel A). In order to estimate the effect of defense spending, we use data on direct federal spending on defense contracts from Dupor and Guerrero (2017).12 The database was constructed using annual reports on defense contracts ${ }^{13}$ The amounts are aggregated to estimate military procurement actions per state. We use the variable in real per capita terms. It captures the total real amount spent on defense procurement by the federal government in a state and year.

There are two possible concerns when using this variable. First, it is possible that contractors rely on sub-contractors in other states. However, Nakamura and Steinsson (2014) have shown that controlling for subcontracting does not change their results. Second, the actual work related to the defense contract could take place in a different year than the announcement (i.e. the signing) of the contract. This time inconsistency could create biased estimates of the effect that government spending has on income. Dupor and Guerrero (2017) have shown that their results are robust to this problem.

\footnotetext{
${ }^{9}$ The variable comprises wages, proprietors' income, dividends, interests, rents and government benefits. ${ }^{10}$ There is a break in 1997, because the BEA shifted industry classification from SIC to NAICS.

${ }^{11}$ Personal income is a household-side variable, whereas output measures production by firms. Since we rely on a dynamic model, we are interested in modeling the changes of the variables instead of the levels.

${ }^{12} \mathrm{It}$ is the updated version of the work from Nakamura and Steinsson (2014). Strictly speaking, we use proxies for both government spending categories, because the variables that we use do not measure the categories of government spending entirely.

${ }^{13}$ The included contracts are manufacturing (processing and assembling), construction, and service contracts (transportation and communication) from the US Department of Defense (DoD).
} 


\section{Non-defense spending}

To estimate the effect of non-defense spending, we use data on intergovernmental transfers from the federal government to the state government (channel B1) 14 and state government spending (channel B2) ${ }^{15}$, Both variables are available in the Annual Survey of State and Local Government Finances from the US Census Bureau. The series are transformed in real per capita terms. By focusing on intergovernmental transfers, (indirect) federal non-defense spending can be captured in the most complete sense. Instead, in the related literature, studies often focus on specific grants, such as ARRA grants (Chodorow-Reich, 2019) or the Federal-Aid Highway Program (Leduc and Wilson, 2013). The variable intergovernmental transfers consists of all categorical and block grants awarded both on a competitive or formula basis ${ }^{16}$ These grants are an important source of revenue for state governments 17

A possible concern is that although intergovernmental transfers measure revenue for state governments, these are not one-to-one linked with state government spending. ${ }^{18}$ Funds from the federal government could possibly crowd-out other parts of the state government budget, such as own-revenue financed spending (channel C). However, $77 \%$ of the total grant amount from the federal government to state government contain either matching or maintenance-ofeffort requirements (FFIS, 2016). Hence, it is unlikely that grants crowd-out state spending significantly. There is a close link between intergovernmental grants and state spending.

\subsubsection{Econometric model}

In order to compare fiscal multipliers for defense spending and non-defense spending, we need to estimate the dynamic responses of both income and the government spending categories to a shock in one of these spending categories. We propose to use a dynamic approach, which can take directly into account the underlying structure of the government spending

\footnotetext{
${ }^{14}$ We will use the terms intergovernmental grants or transfers interchangeably.

${ }^{15}$ Technically, this means that when we compare defense and non-defense spending, we use two different spending channels. This is unavoidable due to the specific structure of US government spending.

${ }^{16} 94 \%$ of the amount of grants is formula based (FFIS, 2018).

${ }^{17}$ The FFIS (2018) notes that states finance 30\% of their spending with intergovernmental transfers.

${ }^{18}$ In our set-up, we calculate the multiplier of non-defense spending using the amount spent by the state government. Hence, even if there is not a one-to-one link, this does not create bias in our results.
} 
categories to extract the exogenous component of state-level federal government spending. Instead of relying on instruments, we remove the common and the endogenous state-level component in the estimation steps. In appendix 3.A.1, we discuss that using the static IV approach from Nakamura and Steinsson (2014) is not preferable, because the constructed instruments are very weak. Furthermore, the method is not suitable for estimating effects at longer horizons. Instead, our approach does not suffer from the weak instrument problem, because the estimated shocks are designed to explain future movements in spending. The shocks are used in a projection-based setting to estimate effects for longer horizons.

Specifically, the shocks are based on forecast errors for the federal government spending categories at the state level, denoted as $x_{i, t}$, i.e. defense contracts or intergovernmental transfers. By using state-level shocks of federal spending (channels A and B), we avoid the endogeneity problems associated with federal spending at the state-level. Since the spending decisions are made on the federal level, we identify 'external shocks' from the federal government for every state. Formally, the shocks $s_{i, t}$ are defined as the one-step ahead forecast error, i.e. the difference between the realized value and the forecast:

$$
s_{i, t+1}=x_{i, t+1}-\mathbb{E}\left[x_{i, t+1} \mid \mathcal{I}_{i, t}\right],
$$

where $\mathbb{E}\left[x_{i, t+1} \mid \mathcal{I}_{t}\right]$ is the one-step ahead forecast, using the available information at the state level. The shocks are unforecastable with the available information set of economic agents $\mathcal{I}_{i, t}$. This information set can be used to extract the exogenous component of $x_{i, t}$ if it contains information on aggregate government spending to remove the common component, and confounding business cycle variables to remove the endogenous state-level component.

The analysis contains three steps. First, we estimate the shocks as the one-step (i.e. year) ahead forecast error of the federal government spending categories. Second, we use local projections to estimate impulse responses for income and the government spending categories. Third, we construct the cumulative multiplier over an eight-year horizon. 


\section{Step 1: Estimating the shocks}

We start by estimating the shocks for the different government spending categories: defense contracts and intergovernmental transfers for non-defense spending. Ideally, we would have used the forecasts for these variables that are available to the government. This is the approach of Clemens and Miran (2012) and Leduc and Wilson (2013). However, there are no official state-level forecasts available for the variables that we use. Therefore, we estimate state-level forecasts with a panel-data model using a rolling forecast of 10 years to obtain an out-of-sample one-step ahead forecast 19 Since our data contains a panel of 50 states, there are 500 observations for each state-specific forecast.

To obtain the forecast, we use a panel regression for every category of government spending separately, including state-fixed effects. Contrary to the model in the next step, we do not need to use year-fixed effects in this step, because the model is used for out-of-sample forecasting, and the model should therefore not be optimized for in-sample fit 20 However, we include national control variables to control for the national business cycle and aggregate shocks. The panel-data fixed effects model that we use can be written down as follows:

$$
x_{i, t}=\alpha_{i}+\sum_{\ell=1}^{L} \beta_{\ell} x_{i, t-\ell}+\sum_{\ell=1}^{L} \gamma_{\ell}^{\prime} V_{i, t-\ell}+v_{i, t}
$$

where $x_{i, t}$ is either defense contracts for defense spending or intergovernmental transfers for non-defense spending. We include state-fixed effects $\alpha_{i}$ and two lags of the dependent variable (i.e. $L=2$ ). The set of control variables in the vector $V_{i, t}$ includes state personal income, state government spending, state government tax revenue, federal government spending, the oil price and the real interest rate. All variables have been converted in logs and are expressed in real per capita terms. We de-trend the variables by subtracting a state-specific linear trend from the log transformed version. 21

The fit of the model can be assessed with goodness-of-fit indicators. These statistics

\footnotetext{
${ }^{19}$ We want to use an ex-ante measure instead of an ex-post measure to create the shock. We therefore use out-of-sample forecasts instead of the residuals from the estimated model.

${ }^{20}$ Furthermore, we include time-fixed effects in the the second step anyway to remove common cycles.

${ }^{21}$ The results are insensitive to applying a quadratic trend polynomial instead of only a linear trend.
} 
are reported in appendix 3.A.2. Yet, including more variables does not always improve the forecast. It seems to be difficult to outperform the naive forecast that simply uses last-years value as a forecast. However, the results in the next section are robust to the choice of the included variables. 22

We use the forecasts to compute the shocks of the different government spending categories. The shocks are defined as the realized value minus the one-step ahead forecast value:

$$
\hat{s}_{i, t+1}=x_{i, t+1}-\widehat{x}_{i, t+1} .
$$

The estimated shock represents the unexpected (or unanticipated) change in defense or nondefense spending in state $i$ at time $t{ }^{23}$ This shock causes economic agents to update their expectations about current and future government spending and change their behavior. The approach is similar to the estimation of (reduced form) shocks in an SVAR model (Blanchard and Perotti, 2002; Mountford and Uhlig, 2009). Even though we do not estimate the defense and non-defense shocks jointly and do not impose orthogonality between the shocks, the correlation between the shocks is negligible when controlling for year-fixed effects in the next step.

The shocks are a proxy of the exogenous spending component, because we remove the endogenous state-level component using the one-step ahead forecast. In the next step, we remove the common component across states when we include year-fixed effects in the paneldata regression.

\section{Step 2: Estimating the impulse responses}

We use the shocks from the first step to estimate the effect of federal government spending on state-level income. To calculate impulse response functions, we use the local projection method by Jordà (2005). The obtained stationary impulse response function and confidence interval can be used to trace the dynamic local effect of the shocks without modeling explicitly

${ }^{22}$ Only when we include national GDP, we estimate slightly lower multipliers.

${ }^{23}$ Strictly speaking, our approach does not allow to disentangle the direct or indirect channel and category of government spending, i.e. defense or non-defense spending. 
the dynamic interaction between variables. Note that we do not allow for dynamic interaction between states and therefore we do not investigate general equilibrium effects as done by Auerbach et al. (2019). In section 3.4.2, we investigate whether the shocks also have crosssectional spillovers.

First, we estimate the effect of each shock on one of the government spending variables $g_{i, t}$, i.e. we estimate the effect of the defense contracts shock on defense contracts and the non-defense (intergovernmental transfers) shock on state government spending ${ }^{24}$ The panel-data regression model can be written as:

$$
g_{i, t+h}=\zeta_{i, h}+\phi_{t, h}+\sum_{\ell=1}^{L} \kappa_{h, \ell} g_{i, t-\ell}+\sum_{\ell=0}^{L} \xi_{h, \ell}^{\prime} W_{i, t-\ell}+\omega_{h} \hat{s}_{i, t}+\epsilon_{i, t+h} .
$$

For horizon $h$, the government spending variable $g_{i, t}$ is regressed on the shock $\hat{s}_{i, t}$ estimated in equation 3.1. Furthermore, two lags of the dependent variable are included $(L=2)$ to avoid dynamic misspecification of the model and improve estimation efficiency. The vector of controls, $W_{i, t}$, also with two lags, includes state-level personal income, the state-level unemployment $\operatorname{rat}^{25}$ and the state government deficit ratid ${ }^{26}$. Finally, state and year-fixed effects $\left(\zeta_{i, h}\right.$ and $\left.\phi_{t, h}\right)$ are included. The latter removes the common component across states. ${ }^{27}$

The regressions are separately estimated for each shock and each horizon $h=0,1,2, \ldots, 8$. The estimate of $\omega_{h}$ is the estimated impulse response of government spending at horizon $h$ to a spending shock. The coefficient should be interpreted as the percentage change in defense contracts or state spending as a result of one per cent unexpected increase in either defense contracts or intergovernmental transfers. Alternatively, the significance of the estimated coefficient $\hat{\omega}_{h}$ can be interpreted as a measure of how well the shock explains the variation in

\footnotetext{
${ }^{24}$ State government spending also includes spending that is financed with non-federal funds (channel C). As a robustness check, we use only federally financed state spending (channel B2).

${ }^{25}$ The source of the unemployment rate is the Bureau of Labor Statistics (BLS), Local Area Unemployment Statistics (LAUS). These data are available from 1976 until 2014.

${ }^{26}$ Since many states have balanced-budget requirements, state governments budgets are highly pro-cyclical. We calculate the deficit ratio using US Census Bureau data on state expenditures and revenues.

${ }^{27}$ By using year-fixed effects, we assume that states react homogeneously to common shocks. It is difficult to control for all aggregate business cycle dynamics and common shocks without time fixed effects. Not including time fixed effects easily creates upward bias in the response of income.
} 
the government spending variable at different horizons, which is comparable to a first stage (weak instrument) F-test in IV. As expected, when we perform a marginal F-test on $\hat{\omega}_{h}$, we estimate F-statistics of 115.4 and 81.6 at $\mathrm{h}=1$ for defense contracts and intergovernmental transfers respectively, which are well above the common rule-of-thumb critical value of 10 to reject the null hypothesis of a weak instrument ${ }^{28}$ By construction, the explanatory power should be high at short horizons, since the shocks contain the unexplained variation in federal spending one step-ahead. In fact, the F-tests for the shocks gradually decrease, and drop below the value of 10 after 4 years for defense contracts and after 6 years for intergovernmental transfers.

The position of the impulse response function depends on the scaling (or normalization) of the shocks. We scaled the shocks such that the integral of the estimated impulse response function of government spending, i.e. the sum of the coefficients, equals one. The motivation is that we require total defense and non-defense spending (i.e. state government spending) to equal each other over the horizon that we analyze.

To construct confidence intervals, we use the panel moving blocks bootstrap procedure proposed by Gonçalves (2011) ${ }^{29}$ This approach is robust to cross-sectional correlation, which is likely to be present in our case, since we use states from one country.

We proceed similarly when estimating the response of income. We estimate the following panel regression for state-level income $y_{i, t}$, including state and year-fixed effects $\left(\eta_{i, h}\right.$ and $\left.\theta_{t, h}\right)$ and the same control variables in the vector $W_{i, t}$, with $L=2{ }^{30}$,

$$
y_{i, t+h}=\eta_{i, h}+\theta_{t, h}+\sum_{\ell=1}^{L} \lambda_{h, \ell} y_{i, t-\ell}+\sum_{\ell=0}^{L} \psi_{h, \ell}^{\prime} W_{i, t-\ell}+\rho_{h} \hat{s}_{i, t}+\varepsilon_{i, t+h} .
$$

${ }^{28}$ The marginal F-test is separately performed for each horizon on the coefficient for the shock in equation 3.4 using 1,789 and 1,439 degrees of freedom respectively.

${ }^{29}$ Unlike the standard block bootstrap that samples across the cross-sectional dimension, the panel moving blocks bootstrap re-samples the dependent and independent variables across the time dimension. In each bootstrap sample, all cross-sectional units are included. For every iteration, we draw a random vector of starting dates to construct blocks of five consecutive years. We draw as many blocks as needed to construct a bootstrap sample of the same size as in the original sample. Confidence intervals are constructed using the percentile method, using the bias-corrected bootstrap distribution.

${ }^{30}$ Although the exogeneity of the shocks in equation 3.5 cannot be tested, the approach is only valid when the shocks are uncorrelated to the error term $\varepsilon_{i, t}$. Hence, we need to ensure that sufficient control variables are included in equations 3.5 and 3.2 . 
Where this time $\hat{\rho_{h}}$ corresponds to the estimated response of income to either a defense or non-defense spending shock at horizon $h=0,1,2, \ldots, 8$.

\section{Step 3: Constructing cumulative multipliers}

The final step consists in assessing the overall effect of one unit of government spending on the outcome variable personal income. We define the cumulative multiplier as the ratio of the sum of responses of personal income over $h=0,1,2, \ldots, H$ and the sum of responses of government spending over the same horizon scaled by the sample income-spending average:

$$
\text { CumulativeMultiplier }_{H}=\frac{\sum_{h=1}^{H} \rho_{h}}{\sum_{h=1}^{H} \omega_{h}} \times \frac{\bar{y}}{\bar{g}} .
$$

Note that the coefficient $\omega_{h}$ (effect on the government spending variable) is scaled such that it sums up to one after $H$ periods. As a consequence, the cumulative multiplier at horizon $H$ is equal to the normalized sum of the point estimates $\rho_{h}$, i.e. the effect of shock $i$ on income.

We sum the coefficients instead of calculating the cumulative effect by accumulating the dependent variable, which is proposed by Chodorow-Reich (2019). Summing the coefficients to obtain the impulse response function is the standard approach in the SVAR literature (Blanchard and Perotti, 2002; Mountford and Uhlig, 2009).

\subsection{Results}

Next we present and discuss our results. First we use the approach described in section 3.3 , and then we test their robustness to changes in some of our assumptions. We also analyze potential spillover effects across states.

\subsubsection{Baseline results}

In this section we report the results of the analysis following the approach discussed in section 3.3. Figure 3.2 shows the estimated impulse responses, and $90 \%$ confidence intervals in shaded areas, for a shock in non-defense spending (first row) and defense spending (second 
row), referring to equations 3.4 and 3.5. The figure shows both the response of income and of the government spending variable, i.e. state spending or defense contracts.

Figure 3.2: Impulse responses to defense spending and non-defense spending shocks
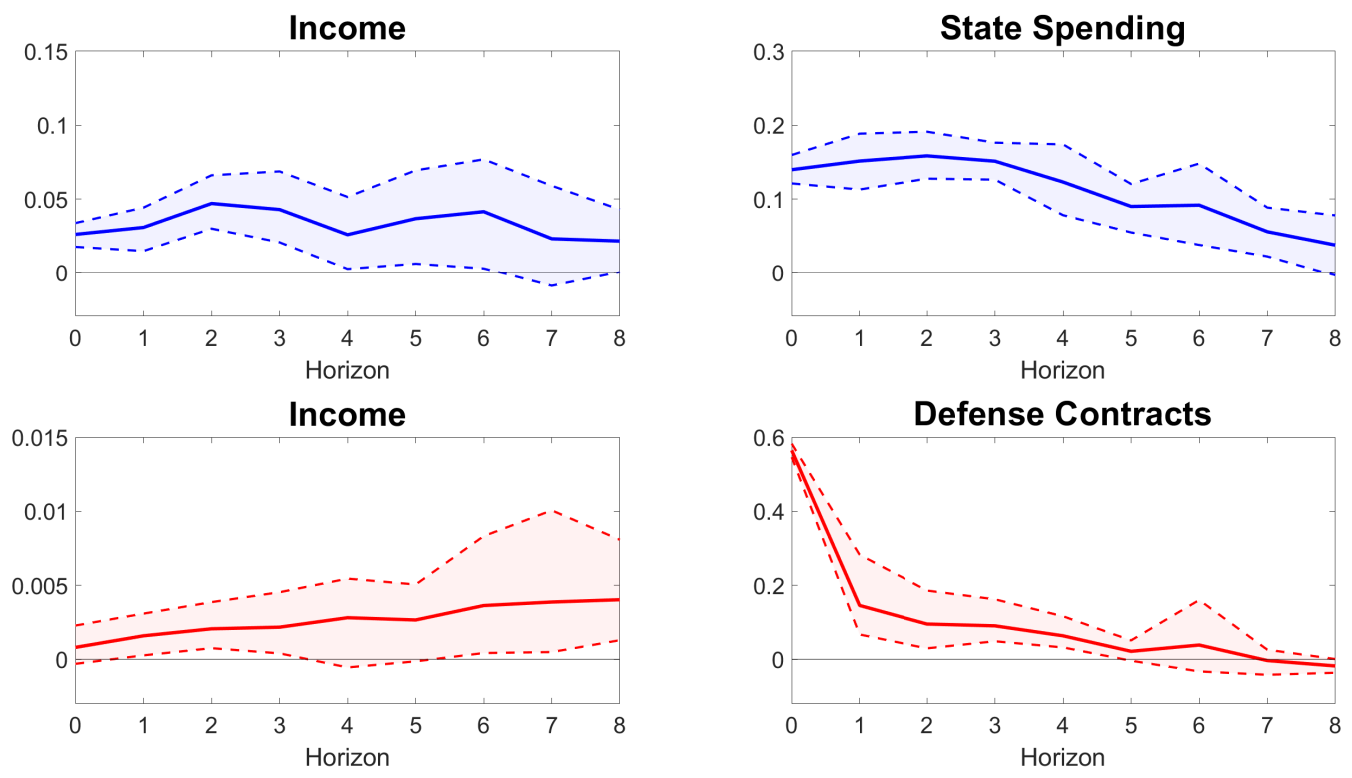

Note: Impulse response functions and bootstrapped $90 \%$ confidence intervals, using a state-specific linear trend and state and time-fixed effects. The top two panels show the effect of a non-defense shock on income (left) (coefficient $\rho_{h}$ ) and on state spending (right) (coefficient $\omega_{h}$ ). The bottom two panels show the effect of a defense shock on income (left) (coefficient $\rho_{h}$ ) and on defense contracts (right) (coefficient $\left.\omega_{h}\right)$.

The plots in the right column show that both shocks have a strong initial positive effect on the spending variable. Over time, this effect slowly decreases. The response for defense contracts shows a stronger initial effect, whereas the response for state spending appears to be more persistent. This is possibly due to the fact that non-defense spending programs are more long-term oriented and therefore a one time shock in non-defense spending has a longer lasting effect on spending. Instead, defense spending is more volatile and a one-time increase in spending does not have a persistent effect on defense spending at the state level.

The figure furthermore shows the response of income to a defense or to a non-defense shock. The response to a non-defense shock remains significantly positive for at least six years. We find that a defense shock has a small positive effect on income, which accumulates over time. However, this effect is not significantly different from zero. 
Figure 3.3: Cumulative multipliers for defense spending and non-defense spending shocks

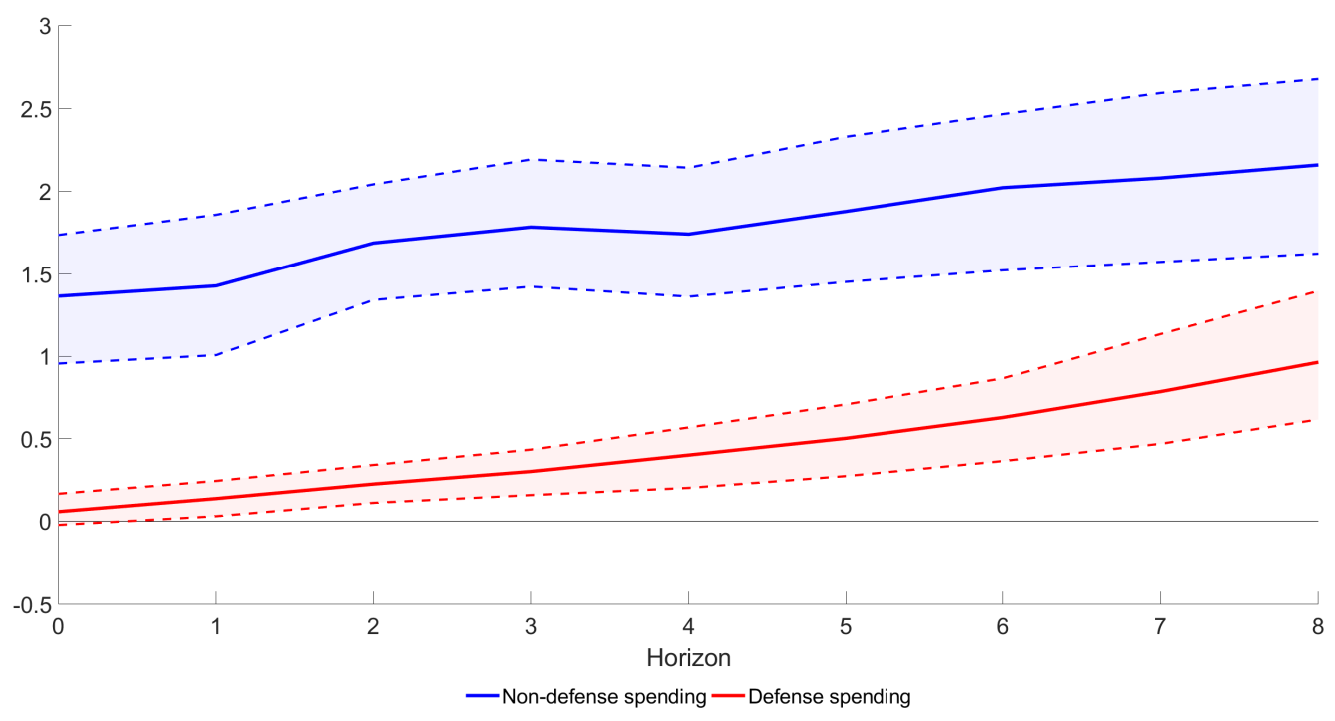

Note: Cumulative multipliers and bootstrapped $90 \%$ confidence intervals of a non-defense spending shock in blue and a defense spending shock in red.

Figure 3.3 shows estimates of the cumulative multiplier and the $90 \%$ bootstrapped confidence intervals as shaded areas, referring to equation 3.6. We find that the multiplier for a non-defense shock starts above 1 and continues increasing until around 2 after 8 years. The multiplier for a defense shock starts around zero on impact and increases towards 1 after 8 years. We find a significant difference between the two multipliers. The cumulative multiplier for a non-defense shock is significantly higher than for a defense shock.

\section{Discussion}

The lower multiplier for defense spending compared to non-defense spending is in line with the existing literature. Several studies confirmed that multipliers are higher for non-defense spending (Clemens and Miran, 2012; Leduc and Wilson, 2013; Shoag, 2016) than for defense spending (Nakamura and Steinsson, 2014; Dupor and Guerrero, 2017) ${ }^{31}$

We will discuss three channels that could explain why defense spending results in lower ${ }^{31}$ This finding has also been confirmed on the aggregate level by Ellahie and Ricco (2017). 
fiscal multipliers. First, firms play an important role in the transmission mechanism of fiscal policy. The characteristics of the firms that receive contracts determine how the economy is affected by defense spending. For example, the connectivity and competition levels of the firm within the industry affect the positive and negative spillovers of such a firm-specific shock. More specifically, when an industry is concentrated around a few large firms, then firm-specific shocks can affect the whole industry ${ }^{32}$ Nakamura and Steinsson (2014) indicate that there are limited positive spillovers from defense contractors to other firms. In contrast, non-defense spending affects a broader set of firms and, hence, may create stronger positive spillover effects within the state-level economy 33

Second, the effectiveness of government spending relies on how news about a policy change is received. Clemens and Miran (2012) claim that military build-ups increase future tax expectations more than increases in non-defense spending. The strong 'Ricardian' response of consumers could explain why the multiplier for defense spending is lower. If consumers are aware that non-defense spending stimulates productivity and labour supply more than defense spending (Barro and Redlick, 2011; Clemens and Miran, 2012), they might believe that an increase in defense spending does not stimulate future income enough to finance government borrowings for military build-ups 34

Third, it is likely that defense spending has a different effect on the supply-side of the economy. When firms in a state receive more defense contracts, this attracts production factors (capital, labour, etc.) from other industries. Since the reallocation of production factors is costly (Ramey and Shapiro, 1998), this limits the positive effect of increase in defense contracts on state-level income. Meanwhile, non-defense spending raises household demand for products and services across a wider variation of industries. Since the demand is less concentrated in a specific industry, the re-allocation effect is likely less pronounced.

${ }^{32}$ The impact of shocks to large firms on aggregate economic fluctuations, or granularity effect, has been identified by Gabaix (2011) and further developed in e.g. Acemoglu et al. (2012).

${ }^{33}$ Since government contractors are concentrated in few states, this creates a downward bias in the effect of defense spending. However, the results are robust to excluding the 10 states with the lowest fraction of defense contracts over state-level income.

${ }^{34}$ There is a growing branch of literature that investigates the effect of household expectations on the real economy, see e.g. Coibion et al. (2018). 


\section{Robustness checks}

We investigate the robustness of the estimated responses in five different ways. First, we check whether the shocks affect the intended spending category. Our interpretation is based on the fact that the shocks only affect the intended spending category and have no effect on the others. We use the same estimation procedure as before, but switch the shocks in equation 3.4. In figure 3.4 we show the effect of a defense shock to non-defense spending on the left and the effect of a non-defense shock to defense spending on the right. The non-defense shock does not affect defense spending significantly. On the other hand, there is a significant increase in non-defense spending up to 2 years after a defense shock. The economic stimulus of defense spending affects state spending positively because it is largely pro-cyclical. However, there is no effect on impact and the effect is not persistent.

Figure 3.4: Impulse responses for the shocks to the opposite variables
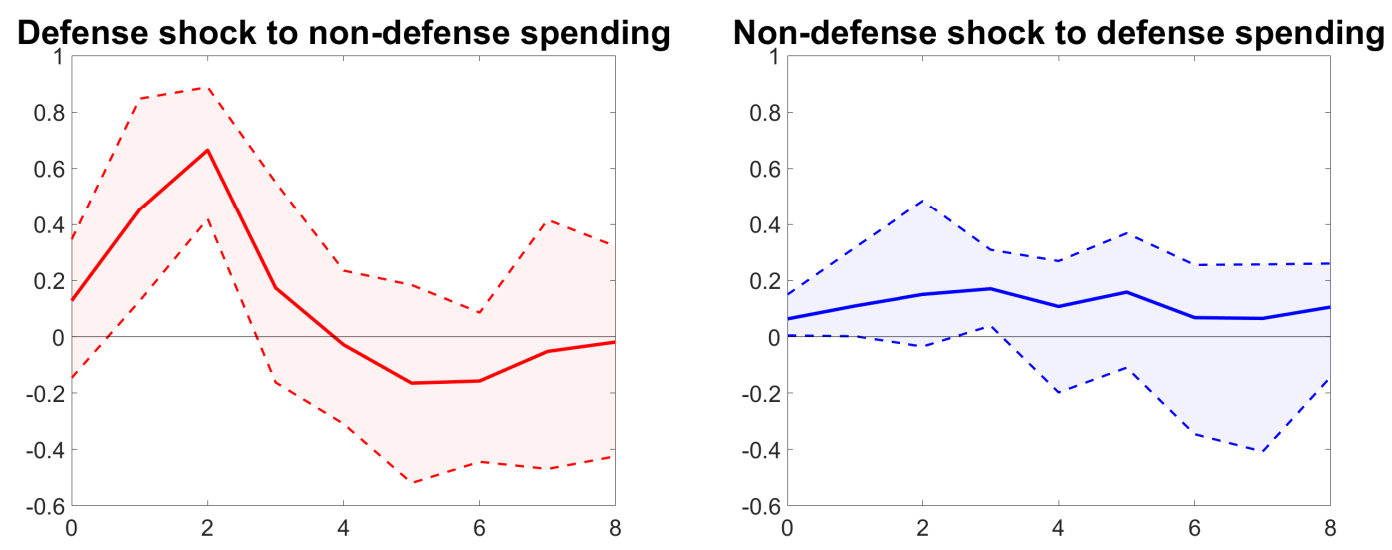

Note: Impulse responses showing the effect of the defense shock on non-defense spending (left) and the non-defense shock on defense spending (right). Estimates and bootstrapped 90\% confidence intervals are computed using a state-specific linear trend and state and time fixed effects.

Second, we check whether the results are robust to including a quadratic trend, because series show concavity over time. We detrend the variables using a quadratic state-level trend polynomial (see appendix 3.A.3). Especially the magnitude of the income response to a nondefense shock decreases, and the multiplier becomes stable around 1. Although the effect of a non-defense shock becomes weaker, the conclusion remains the same. 
Third, we control for political party dominance in states. When a state is dominated by one political party, it can be easier for the state to gain influence at the federal level, especially if that party also controls the federal administration. In that case, the federal government might be willing to spend more in a state that is in need for federal spending. Not controlling for this might create upward bias in the multipliers. We use data on the political dominance of the Democratic Party versus the Republican Party in the state senate, state house, and governorship. We updated the data by Klarner (2013) for the last 4 years using the State Partisan Composition tables from NCSL 35 It seems that including variables on the political party dominance of the Democratic party does not affect the results.

Fourth, we investigate the usage of fiscal or calendar years. The government spending variables are reported in fiscal years (1 July - 30 June), whereas the economic variables income and unemployment are reported in calendar years (1 January - 31 December). Using calendar years instead of fiscal years creates upward bias if it does not control for all business cycle correlation. The estimation results in appendix 3.A.3 confirm this hypothesis, because we find slightly lower multipliers when we match all economic variables to fiscal years.

Finally, we check whether the responses to non-defense spending shock are affected by using an alternative definition of state spending. Instead of the data from the US Census Bureau, we use the data on federally-financed state spending from the NASBO. These data correspond exactly to channel B2 in figure 3.1. The estimation results for the sample 19912014 are very similar when using the NASBO and Census data (see appendix 3.A.3), although the multiplier is slightly lower when the NASBO data are used.

To conclude, the results seem to be robust to alternative specifications. Although the exact multiplier estimates can slightly differ across specifications, our main finding that defense spending results in a lower multiplier remains.

\footnotetext{
35 Source: Www.ncsl.org/research/about-state-legislatures/partisan-composition.aspx.
} 


\subsubsection{Spillovers across states}

So far, we have analyzed the effects of shocks to defense and non-defense spending to the states itself. However, it is possible that a shock to one state also affects other states. We therefore estimate the cross-state spillover effect in state $i$ from other states by weighting the shocks from all other states using the bilateral Commodity Flow Survey 2012 data on total shipments between states $i$ and $j{ }^{36}$ The weights $w_{i, j}$ from state $j$ to state $i$ are constructed such that they sum up to 1 for every state state $i$. The 'partner shock' $\hat{p}_{i, t}$ can be written down as follows:

$$
\hat{p}_{i, t}=\sum_{j=1}^{N} w_{i, j} \hat{s}_{j, t} \quad \text { where } \quad \sum_{j=1}^{N} w_{i, j}=1 \quad \text { and } \quad w_{i, i}=0 \quad \forall i, j .
$$

We cannot just analyze the spillover effect of a shock in state $j$ on income in state $i$, because it is likely that the shocks between states $i$ and $j$ are correlated. To make sure that we can interpret the effect of the partner shock as the cross-state spillover effect, we remove the effect of the own shock by regressing state-by-state the estimate $\hat{p}_{i, t}$ on the own shock $\hat{s}_{i, t}$ and using the residual from this regression, which we denote as $\tilde{p}_{i, t}$. Afterwards, we include both $\tilde{p}_{i, t}$ and $\hat{s}_{i, t}$ in the same regressions as before to construct the impulse responses.

The results are shown in figure 3.5 below. The two figures on the left show the response of income to the partner shock. We find that non-defense spending clearly results in significant positive spillover effects between 2 and 6 years. However, for defense spending, we find only marginally positive effects for the first three years. Afterwards, the estimate is negative, although insignificant. These results show that beyond the spillover effects within a state that are found in Auerbach et al. (2019), there are also also positive cross-state spillover effects. This confirms that for non-defense spending the positive demand effects outweigh negative supply effects. However, the positive effect is less strong for defense contracts. An increase in production by contractors in other states probably increases competition for

\footnotetext{
${ }^{36}$ The methodology to estimate the spillovers is similar to section 4.4 in chapter 4 . As an alternative, Dupor and Guerrero (2017) identified for every state the main trading partner state from the Commodity Flow Survey 2007 data to estimate the spillover effect.
} 
Figure 3.5: Impulse responses for cross-state spillovers
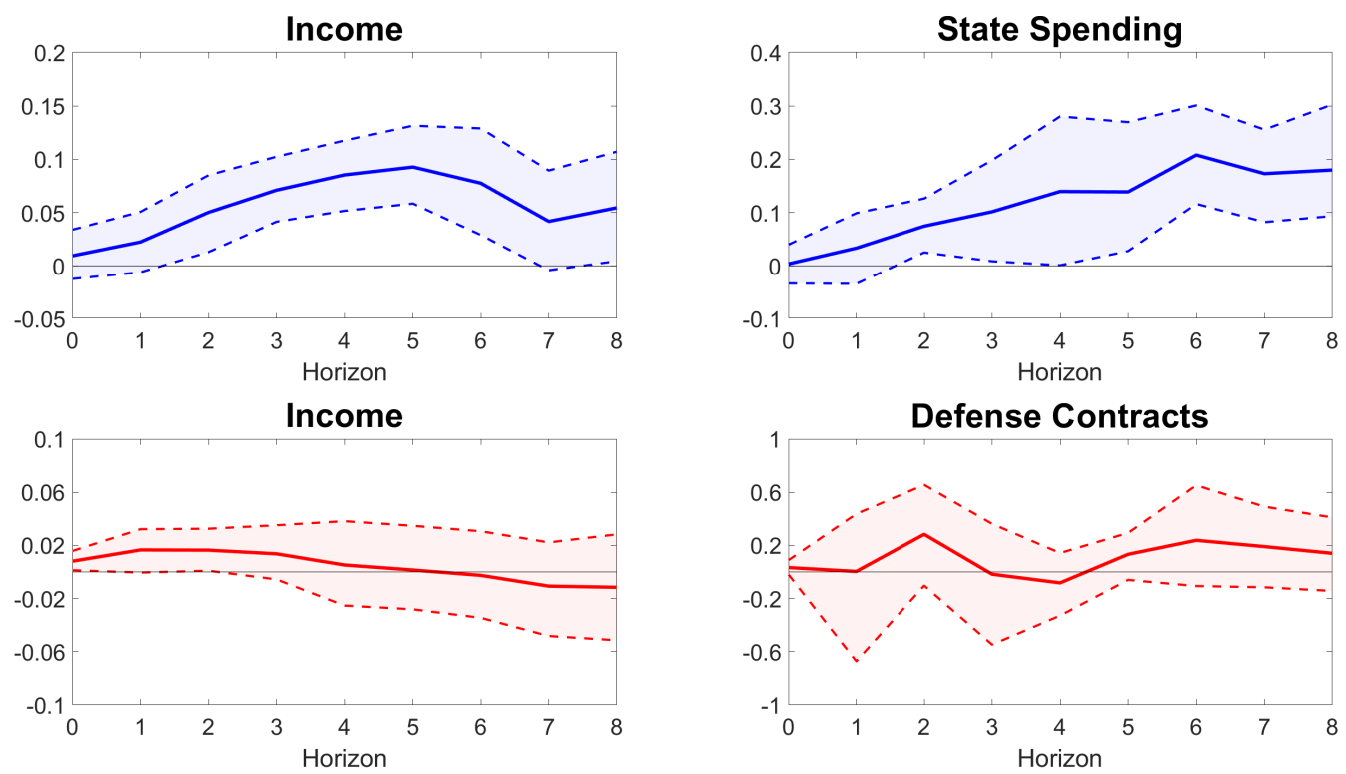

Note: Impulse responses and bootstrapped $90 \%$ confidence intervals for a partner shock, using a state-specific linear trend and state and year-fixed effects. The top two panels show the effect of a non-defense shock on income (left) and on state spending (right). The bottom two panels show the effect of a defense shock on income (left) and on defense contracts (right).

production factors in state $i$, which limits the positive demand effect.

The two right-hand side figures show the effect of a partner shock on state spending and defense contractors. On the one hand, we find that state spending increases after two years. Since state government spending is largely pro-cyclical, it increases when there is an increase in income due to the partner shock. On the other hand, we do not see a significant effect on defense contracts in state $i$ when other states experience an increase in defense contracts, which is in line with our intuition.

\subsection{Conclusion}

This chapter estimates local fiscal multipliers for different categories (or types) of government spending in the US. We focus in particular on the difference between defense and non-defense spending. For estimation, we propose a novel approach that does not rely on exogenous 
instruments, or proxy, for a specific spending shock.

Using a dynamic approach, we isolate the part of federal defense or non-defense spending allocated to state governments that is exogenous to the state-specific economic conditions. We estimate this exogenous component of federal spending at the state-level by removing the common component of spending across states, and the endogenous state-level spending component. The estimated shocks are included in a dynamic model, which avoids the weak instrument problem in instrumental variables (IV) analysis. We use US data on state-level defense contracts and federal intergovernmental transfers to state governments to estimate (state-level) shocks to federal defense and non-defense spending and their implied (local) multipliers.

We find that non-defense spending multipliers are higher than those for defense spending. This finding is robust across different model specifications, controls, constructions of the measure we use to estimate the shocks, and other factors. Moreover, beyond the within-state spillover effects found by Auerbach et al. (2019), we find significant cross-state spillover, as well particularly strong for non-defense spending.

Our findings may imply that multipliers estimated based on defense expenditures understate the effectiveness of spending policies. However, this chapter only scratches the surface of such issue. A deeper understanding of how different types of spending affect the economy is crucial for effective policy design. 


\section{A Appendix}

\section{A.1 Static approach}

In the static approach, we follow the two-stage least squares (2SLS) set-up from Nakamura and Steinsson $(2014)^{37}$ to estimate the effect of defense and non-defense spending on statelevel income. This approach relies on the Bartik (1991) approach to construct instruments to capture the exogenous component of a government spending category. The procedure therefore uses only information from the federal level and state-specific characteristics from previous years. The identifying assumption behind the construction of the instruments is that fluctuations of the national level of government spending are exogenous to state-specific business cycles. These instruments are used to instrument the endogenous component of state-level federal government spending categories.

We investigate whether there is a difference in the two-year static multiplier of defense versus non-defense spending. The instruments $z_{i, t}$ are created separately by interacting the national one-period growth of a category of aggregate spending $x_{i, t}^{n}$ with a state-specific scaling factor:

$$
z_{i, t}=\frac{s_{i, t}^{x}}{s_{i, t}^{y}} \frac{x_{t}^{n}-x_{t-1}^{n}}{x_{t-1}} .
$$

The scaling factor is the lagged share of the state in the total national amount for that type of spending $s_{i, t}^{x}$, divided by the share in national personal income $s_{i, t}^{y}$. Both shares are computed using the average of the previous year and the year before.

We estimate the first and second stage and compute the standard errors that are asymptotically robust to heteroskedasticity and autocorrelation. In the first-stage regression, government spending $g_{i, t}$, i.e. either defense spending or state-government spending (for nondefense spending), is instrumented using the instrument $z_{i, t}$, and state and year-fixed effects $\left(\mu_{i}\right.$ and $\left.\nu_{t}\right)$ :

$$
\frac{g_{i, t}-g_{i, t-2}}{y_{i, t-2}}=\mu_{i}+\nu_{t}+\theta z_{i, t}+\epsilon_{i, t}
$$

${ }^{37}$ This approach is also used by Dupor and Guerrero (2017) and Auerbach et al. (2019) for defense spending 
We use the instrumented value in the second stage to estimate the effect on the two-year growth rate of income. The second-stage regression can be written down as follows:

$$
\frac{y_{i, t}-y_{i, t-2}}{y_{t-2}}=\alpha_{i}+\gamma_{t}+\beta \frac{g_{i, t}-g_{i, t-2}}{y_{i, t-2}}+\varepsilon_{i, t}
$$

where $y_{i, t}$ is personal income and the third term on the right-hand side is the instrumented value from the first stage of either defense contracts or state government spending for nondefense spending. This regression also includes state and year-fixed effects $\left(\alpha_{i}\right.$ and $\left.\gamma_{t}\right)$. We can compute directly the short-horizon two-year multiplier through the coefficient $\beta{ }^{38}$

Table 3.1: Static results for defense and non-defense spending

\begin{tabular}{lcc}
\hline \hline & $(1)$ & $(2)$ \\
& Pers. Income & Pers. Income \\
\hline Defense Spending & $1.2078^{* *}$ & - \\
& $(0.4757)$ & 1.3658 \\
Non-defense Spending & - & $(1.3312)$ \\
& & State, Year \\
& State, Year & 8.53 \\
Fixed effects & 7.24 & 2700 \\
$\mathrm{~N}$ & 2700 & \\
\hline \hline Robust and clustered SEs in parentheses. ${ }^{*} p<0.10,{ }^{* *} p<0.05,{ }^{* * *} p<0.01$
\end{tabular}

Table 3.1 shows the estimated multipliers from the second stage regression. We estimate a 2-year multiplier around 1.2 for defense spending with an F-statistic of 7.24 ${ }^{39}$ This result is close to the estimate from Nakamura and Steinsson (2014), even though we use a longer period for estimation. For non-defense spending we estimate a 2-year multiplier of 1.4 with an F-statistic of 8.53. However, the large standard errors prevent us from claiming that there is a significant difference between the estimated multipliers.

The first-stage F-statistics indicate that both instruments suffer from the weak instrument problem, because both F-statistics are below 10, which is the common rule-of-thumb ${ }^{38}$ The results do not change qualitatively if we use the one-year growth rate instead of the two-year growth rate when constructing the variables.

${ }^{39}$ This is an exclusion test for removing only the instrument in the first stage regression, while keeping the other control variables. 
critical value to reject the null hypothesis of a weak instrument 40 The low relevance of the instruments indicates that they do not capture the main fluctuations in spending. The underlying reason is probably that federal spending at the state level is largely driven by aggregate dynamics. However, since the Bartik (1991) approach uses mainly aggregate information to construct the instrument, the relevance of the instrument decreases once we take into account state and year-fixed effects to control for aggregate dynamics.

Furthermore, the results are sensitive to the choice of the horizon for the dependent variable. To illustrate this, consider table 3.2 below, which shows the second stage coefficients and the first stage F-statistics for longer horizons, where we shift the dependent variable one period ahead for each horizon. We would expect to see a peak in the F-statistic at a short horizon and then a gradual decrease in the statistic. However, for both instruments this is not the case. The estimated second-stage coefficients are very erratic.

Table 3.2: Estimated multipliers and F-statistics for longer horizons using IV

\begin{tabular}{rrrrr}
\hline \hline & \multicolumn{2}{c}{ Defense spending } & \multicolumn{2}{c}{ Non-defense spending } \\
Horizon & Multiplier & F-test & Multiplier & F-test \\
\hline 0 & 1.2078 & 7.2370 & 1.3658 & 8.5306 \\
1 & 1.0135 & 45.2670 & 3.6673 & 0.6353 \\
2 & 3.8520 & 5.5285 & -1.8022 & 5.0999 \\
3 & -7.1938 & 0.7457 & -3.1313 & 17.6982 \\
4 & -3.1818 & 0.7876 & -17.4862 & 0.1976 \\
5 & -1.2366 & 4.6774 & 8.4948 & 0.2467 \\
6 & 3.5979 & 0.8110 & 8.1495 & 0.5616 \\
7 & 46.3177 & 0.0107 & 15.9766 & 0.3041 \\
8 & 1.2142 & 6.1649 & 21.2363 & 0.1590 \\
\hline \hline
\end{tabular}

To conclude, the results indicate that the multiplier for non-defense spending is higher than for defense spending, although the large standard errors prevent us from concluding that there is a significant difference between the multipliers. However, we do not think that the static approach produces reliable measures of the fiscal multipliers, because the instruments are weak and the estimation result is very sensitive to the chosen horizon. Since we are interested in both the short and long horizon multiplier, we do not prefer this approach.

${ }^{40}$ We do not use the critical values from $[$ Stock and Yogo $(2005)$, because they assume i.i.d. standard errors. 


\section{A.2 Forecasting model for the dynamic approach}

We construct a forecast for the federal spending variables defense contracts and (the categories of) intergovernmental transfers for non-defense spending. This forecast is based on a 10-year rolling-window panel regression with fixed effects using two lags of the following variables: personal income, state-government spending, state-government tax revenue, federal-government spending, the oil price and the real interest rate. Based on this regression, we compute a one-step ahead out-of-sample forecast $\hat{X}_{i, t}$. This forecast is different from the residual of the model. Hence, the model can be very good at making in-sample predictions, but perform bad when making forecasts. The forecast quality of the model can be evaluated using the root mean squared forecast error (RMSE):

$$
R M S E=\sqrt{\frac{1}{N} \sum_{n=1}^{N}\left(x_{i, t}-\hat{x}_{i, t}\right)^{2} .}
$$

Here $N$ is the total number of observations in the sample across all states. The forecast is made after detrending the variables at the state level. We check the quality of the forecast both when using a linear and quadratic trend polynomial. In table 3.3 below, we report the RMSE of both the linear and the quadratic forecast. We compare this to the naive forecast, where we use last year's value as a forecast.

Table 3.3: Root mean squared forecast error

\begin{tabular}{llll}
\hline \hline Spending category & RMSE Naive & RMSE Linear & RMSE Quadratic \\
\hline Defense contracts & 0.4161 & 0.4168 & 0.4443 \\
IGT & 0.0929 & 0.1442 & 0.1546 \\
IGT Education & 0.1635 & 0.1463 & 0.1548 \\
IGT Health & 0.2365 & 0.2244 & 0.2283 \\
IGT Highways & 0.4595 & 0.5579 & 0.5604 \\
IGT Medicaid & 0.1213 & 0.1690 & 0.1686 \\
\hline \hline
\end{tabular}

The results in the table show that including a quadratic trend does not improve the forecast quality. The model performs better in forecasting IGT than defense contracts and in particular education and Medicaid grants. However, for some spending categories, the 
naive forecast performs even better. Especially for total IGT, Highways and Medicaid, the RMSE naive forecast is lower. Additionally, we check the role of forecast window. In the standard specification, we use a 10-year rolling window. Below in table 3.4, we show the results when using a 15-year window. A longer window improves the forecast.

Table 3.4: Root mean squared forecast error using a 15-year window

\begin{tabular}{llll}
\hline \hline Spending category & RMSE Naive & RMSE Linear & RMSE Quadratic \\
\hline Defense contracts & 0.4161 & 0.3769 & 0.3699 \\
IGT & 0.0929 & 0.0887 & 0.0824 \\
IGT Education & 0.1635 & 0.1199 & 0.1187 \\
IGT Health & 0.2365 & 0.2171 & 0.2016 \\
IGT Highways & 0.4595 & 0.5269 & 0.5210 \\
IGT Medicaid & 0.1213 & 0.1185 & 0.1138 \\
\hline \hline
\end{tabular}

Indeed, we find that the forecast improves a lot when using a longer window. All forecasts improve and in all cases except Highways the linear forecast now beats the naive forecast. Moreover, in all cases the quadratic forecast has a lower RMSE than the linear forecast. 


\section{A.3 Robustness checks}

Figure 3.6: Impulse responses and multipliers with quadratic trend

\section{Impulse responses}
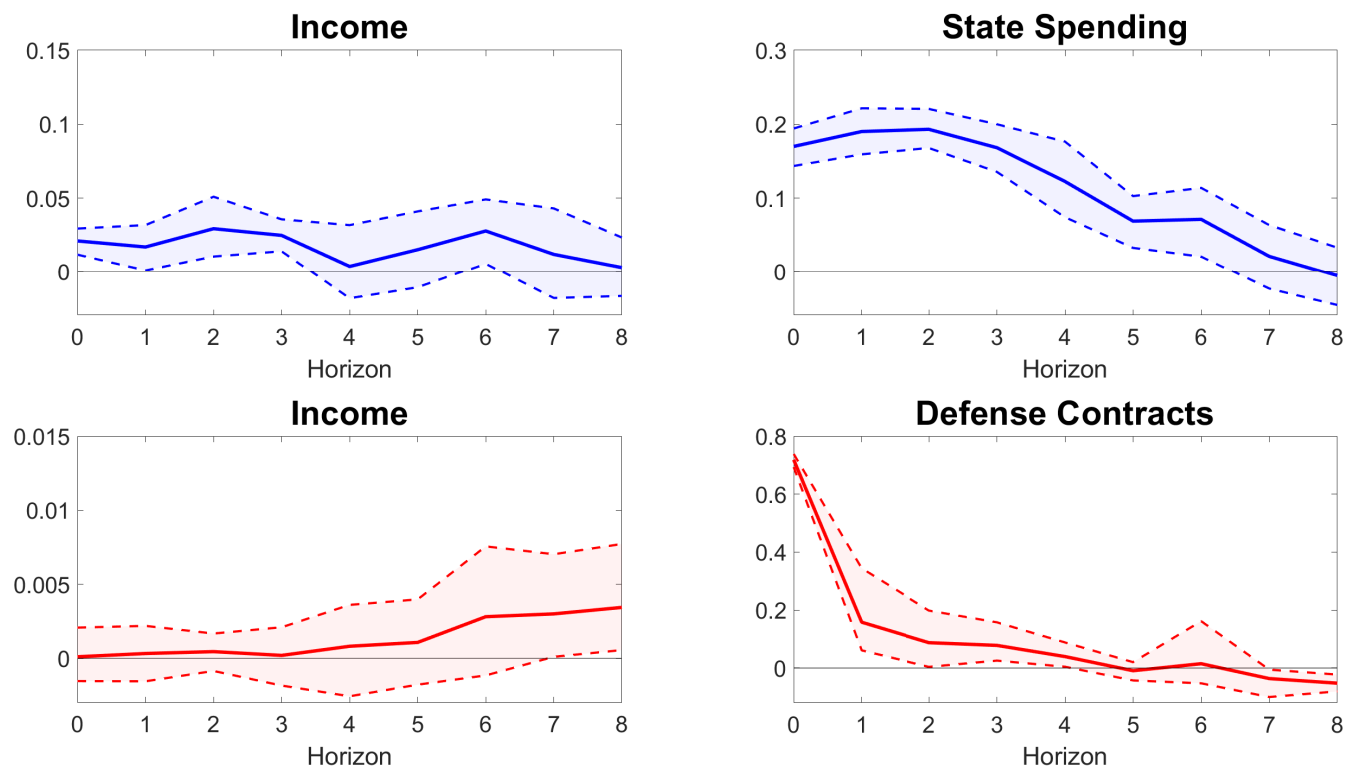

Cumulative multipliers

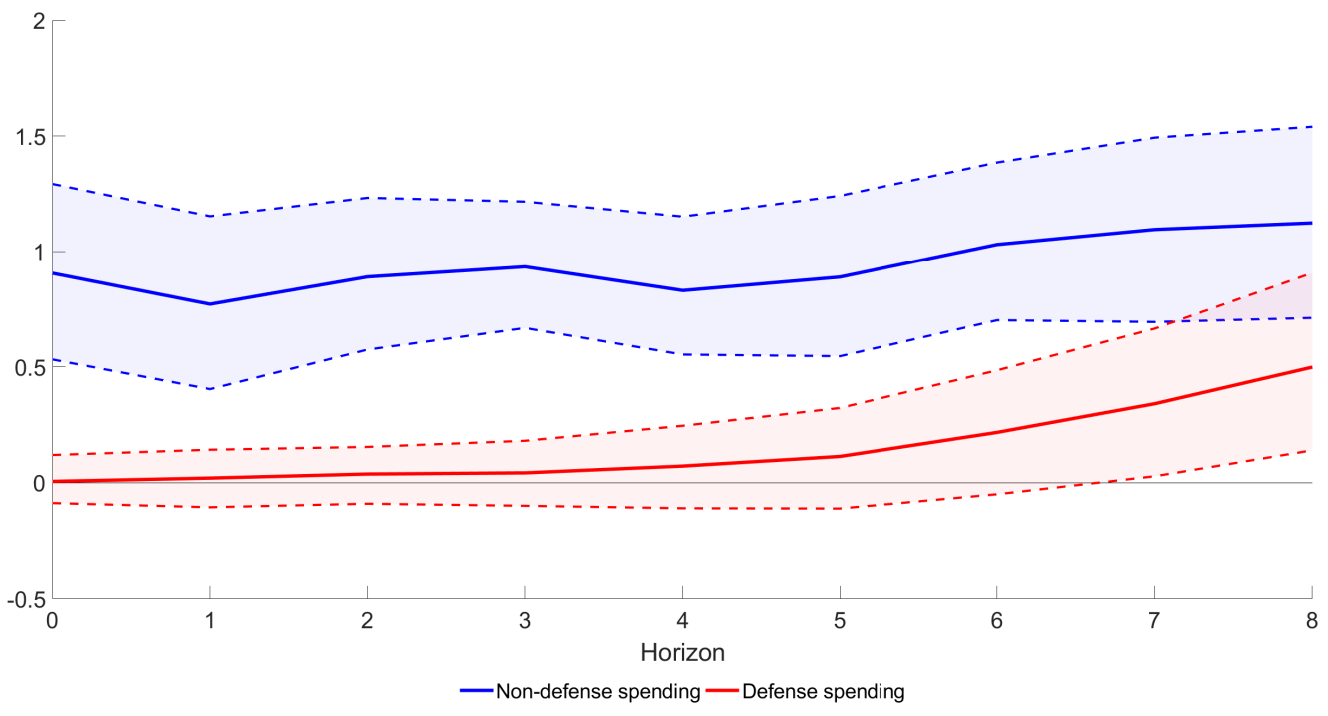

Note: Estimates and bootstrapped $90 \%$ confidence intervals for the impulse response functions and cumulative multipliers, using a state-specific quadratic trend and state and time-fixed effects. 
Figure 3.7: Impulse responses and multipliers with fiscal year data

\section{Impulse responses}
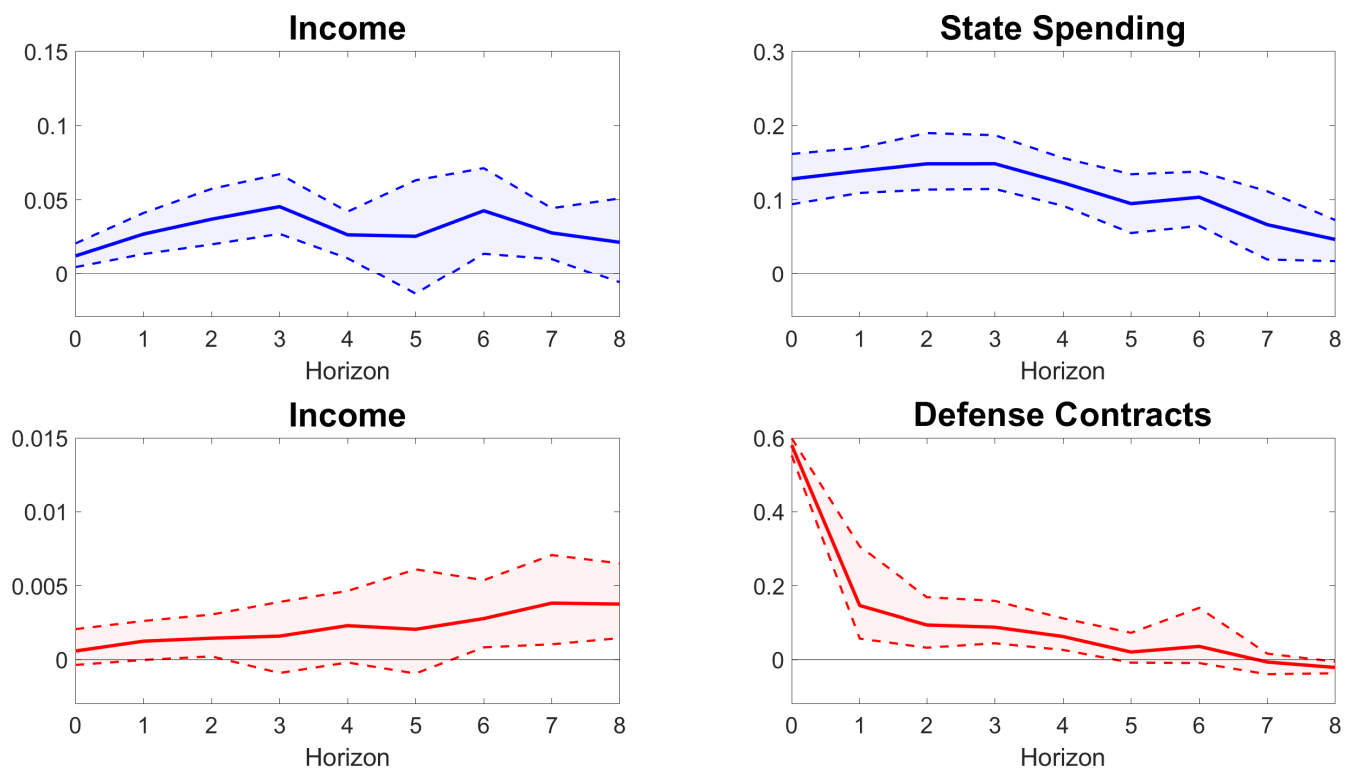

\section{Cumulative multipliers}

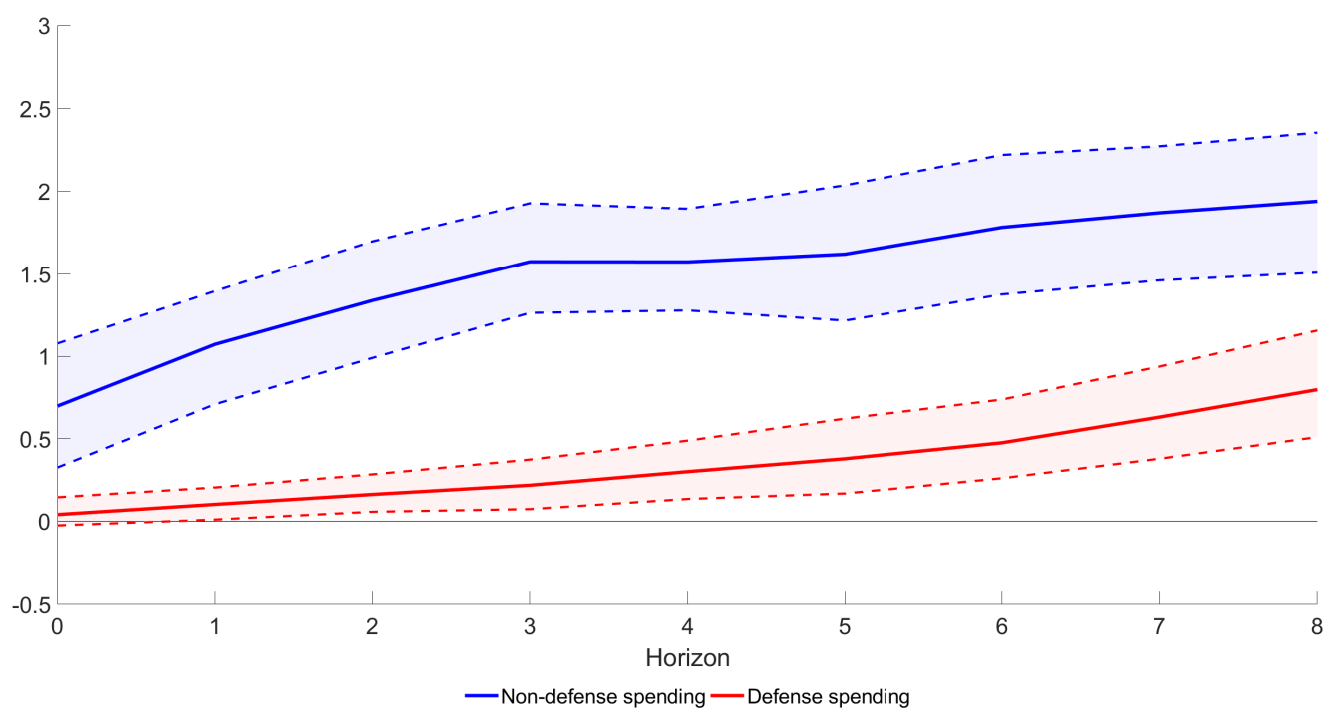

Note: Estimates and bootstrapped $90 \%$ confidence intervals for the dynamic analysis, using a state-specific linear trend and state and time-fixed effects. The results are obtained using fiscal year data. 
Figure 3.8: Impulse responses and multipliers with NASBO vs Census data

\section{Impulse responses}
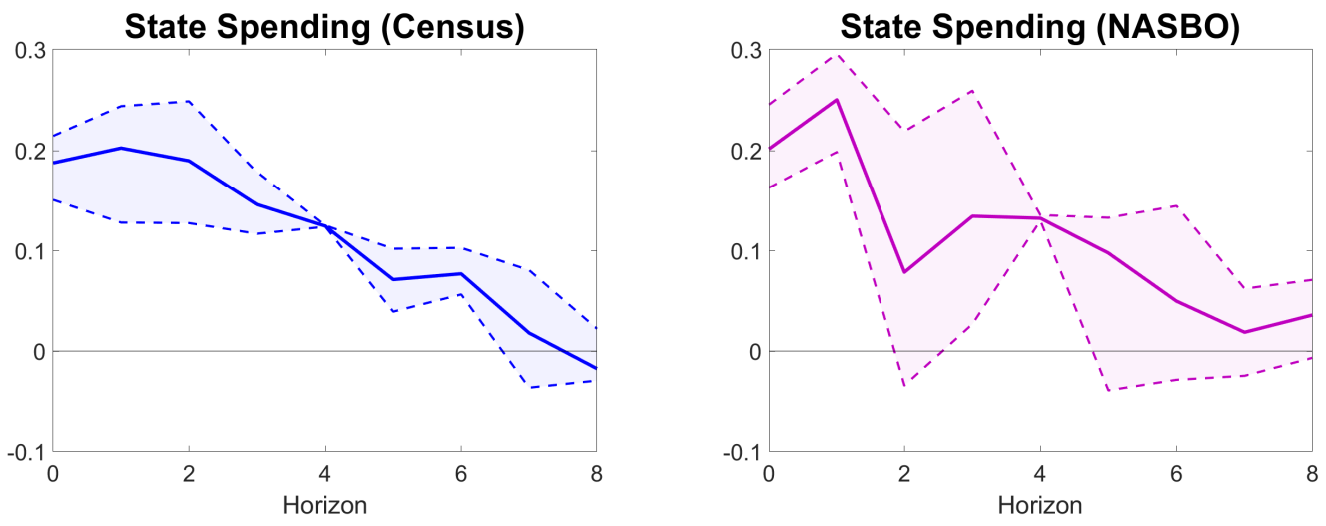

Cumulative multipliers

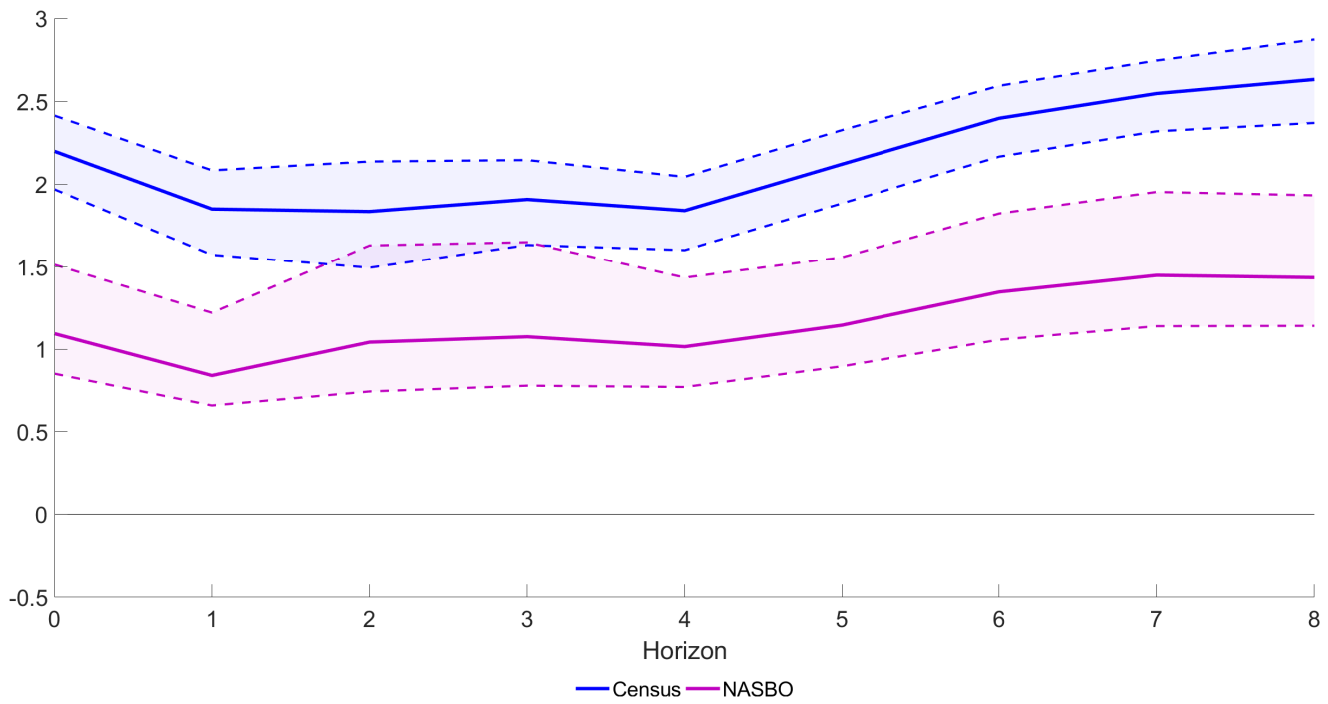

Note: Estimates and bootstrapped $90 \%$ confidence intervals for the dynamic analysis for a non-defense spending shock, using a state-specific linear trend and state and time-fixed effects. The results show the comparison of the NASBO data (purple) versus Census data (blue) for the period 1991-2014. 
3.A. APPENDIX 


\section{Chapter 4}

\section{Sectoral and Regional Spillover Effects of Government Spending}

This chapter investigates the short-run sectoral and regional spillover effects induced by region-specific shocks in EU Structural and Investment Funds. Even though the results indicate that in general the effects of EU funds are rather limited, there are several relevant policy conclusions. In line with the literature, this chapter finds a mild positive direct effect from a shock between programming periods in less-developed regions, which seem to be driven by the industry and public sector. The same shock has a slight negative effect in moredeveloped regions, due to sectoral substitution effects between mainly the construction and services sector. The regional spillover effects are very limited at the regional level, although some sectors experience spillovers, which are in general opposite to the direct effects. This finding suggests that the spillovers are likely to be supply-driven. 


\subsection{Introduction}

In recent years, the question of how fiscal policy affects the economic performance of subnational regions has increasingly received attention. As also discussed in chapter 3, many studies have confirmed that a fiscal stimulus from a central government can have expansionary effects at the local or regional level (Nakamura and Steinsson, 2014; Dupor and Guerrero, 2017; Dupor and McCrory, 2017; Chodorow-Reich, 2019). Although estimates of the so-called 'local fiscal multiplier' differ substantially across studies, there is consensus that fiscal shocks from central governments benefit regional economies in the short run. As shown in chapter 3, both federal defense and non-defense spending in US states create a positive multiplier effect, even though the multiplier for non-defense spending is significantly higher. The main advantage of studying the effects of fiscal policy at the sub-national level, is that this makes it possible to evaluate specific effects across regions. Some consequences cannot be observed when evaluating the aggregate effect of a policy. But, in making policy decisions, it is important that policymakers are aware of all potential consequences, and avoid misleading policy evaluations.

This chapter investigates sectoral and regional effects of shocks in Structural and Investment Funds in the European Union (EU). These funds are an important fiscal policy tool to promote economic convergence between sub-national regions of member states. They constitute the second largest spending category of the EU budget, after the common agricultural policy. Although several panel data studies confirm the positive effects on annual regional economic growth (Mohl and Hagen, 2010; Esposti and Bussoletti, 2018) or on average growth across years (Pellegrini et al., 2012; Becker et al., 2010, 2012, 2018), the short run policy consequences are unknown. In order to evaluate such consequences, this chapter takes the perspective that regions in the EU are affected by policy decisions from a central government. The two main supporting arguments are that (i) there exists free mobility of production factors between regions and (ii) most regions have a common monetary policy. Specifically, this chapter focuses on two short-run policy consequences. The results contribute to the literature on local effects of fiscal policy, initiated by Nakamura and Steinsson (2014). 
First, it is likely that the effects of a stimulus are not uniformly distributed across sectors. If initially production in one sector reacts positively, then over time other sectors can be affected positively or negatively, depending on the scarcity of production factors. For example, when EU funds are used to improve infrastructure in a region, labour and capital will be pulled towards the construction sector, which makes it harder for other sectors to attract production factors. The negative effect in the other sectors can be described as sectoral substitution. It is important for policymakers to not only be aware of aggregate effects, but also of specific effects across sectors. There is empirical evidence from the United States about heterogeneity in sectoral responses to an untargeted federal government spending shock. Nakamura and Steinsson (2014) find that production in the construction, manufacturing, retail, and service sectors respond positively to a shock in federal spending. Other sectors, such as the agricultural sector, do not benefit significantly from a federal spending shock. Furthermore, using European data, Bénétrix and Lane (2010) show that national fiscal shocks matter for the sectoral composition of output. To my knowledge, no study has estimated sectoral responses to changes in EU funds.

Second, since regions are interconnected, a change to the funds in one region potentially affects other regions. It is important for policymakers to be aware of possible spillovers to other regions, when they aim to provide a stimulus to a specific region. Mohl and Hagen (2010) and Becker et al. (2010) estimate positive regional spillover effects of EU funds between neighboring regions. There are two shortcomings in these studies. First of all, the studies focus on long-term convergence effects and therefore ignore short-run regional spillover effects. As recent studies from the US indicate, spillovers can be substantial even in the short-run (Auerbach et al., 2019, Dupor and McCrory, 2017). Secondly, both studies ignore economic linkages between regions that are geographically apart. However, it is known that other types of proximity, such as relational, social, and technological proximity also play a role in regional productivity growth (Basile et al., 2012). This chapter provides an alternative method to model regional spillovers using intra-EU trade connections.

The objective of this chapter is first to investigate the direct effects for EU funds in 
the short run across six different economic sectors, and second to estimate whether there regional spillover effects arise after an increase in EU funds. I use regional data for $\mathrm{EU}$ funds between 1989 and 2015 in 264 sub-national (NUTS-2) regions. Since EU funds intend to support less-developed regions, the change in the regional amount of funds is partially endogenous to the regional economic development. This could lead to biased estimates of the effects that funds have on regional economic activity. Therefore, this chapter uses the same approach as in chapter 3 to estimate exogenous region-specific shocks in EU funds both within and between programming periods. To study the short-run effects of these shocks, I estimate impulse response functions based on a panel-data regression model for sectoral production at the regional level. Furthermore, I estimate spillover effects using a weighted average of the shocks from all other regions. The weights are based on intra-EU trade between regions. The method to estimate cross-regional spillovers is similar to 3.4.2.

This chapter contributes to the related literature in three ways. First, unlike existing studies that evaluate whether long-term convergence is achieved by EU funds, this chapter studies short-run economic effects. It is important for policymakers to be aware whether unintended short-run policy consequences arise. Second, the empirical approach covers more variation in EU funds both in the cross-sectional and time series dimension. Including more variation possibly helps for estimation precision, but more importantly, it is important for policymakers to know whether effects of EU funds are possibly different across clusters of regions, such as more-developed regions versus less-developed regions. Third, the dynamic projection-based approach from this chapter is preferable over a static instrumental variables or difference-in-difference approach, because it can be used to estimate dynamic responses of economic variables over several years. The impulse response functions can be used to study possible substitution effects between sectors over time, which are relevant for policymakers, especially when policy changes have lagged effects.

The results indicate that in general the effects of EU funds are rather limited. There are no significant effects from a shock within a programming period, and there are also no overall effects from a shock between programming periods. However, in line with the literature, the 
overall effect of shock between programming periods is slightly positive in less-developed regions. This result is driven by the industrial and public sector. In less-developed regions, there is even a small negative overall effect. It seems that the positive effect in for example the construction sector is outweighed by the negative effect in the services sector. Hence, in more developed regions there is some sectoral substitution. Intuitively, this means that when EU funds are used to finance infrastructural projects, this stimulates demand in the construction sector, but this increases competition for production factors in other sectors. This effect occurs especially in more-developed regions, due to more scarcity in production factors. Regarding the regional spillovers, there are also no effects at the regional level, neither for less-developed nor for more-developed regions. However, the sectoral results show that all sectors except the public sector experience regional spillovers that are opposite to the direct effect in the region where the shock occurs. This finding suggests that EU funds stimulate production in one region, which attracts production factors from other regions, creating negative supply-driven spillover effect.

The structure of this chapter is as follows. Section 1 summarizes the related literature on EU Structural and Investment Funds and provides a theoretical description of the possible effects. Section 2 analyzes the direct effects of shocks in EU funds on sectoral production. Section 3 analyzes the regional spillover effects. Finally, section 4 concludes.

\subsection{Regional effects of government spending}

In this section, I discuss possible effects of shocks in EU funds on sectoral production across regions. EU funds are used to finance eligible projects that stimulate regional economic development. There are four funds, as shown in appendix 4.A.1. In the remainder of this

chapter, I focus on the sum of all funds, because they have the same long-term goal, and therefore also similar hypothesized effects. 


\subsubsection{Existing literature}

A clear advantage of studying the effects of EU funds at the regional level, is that the spending decision takes place at the European level, which makes it plausible that policy changes are to a lesser extent endogenous to the regional economy. Therefore, it is more likely that one can identify exogenous fiscal shocks at the regional level, which are required for causal interpretation. Estimating the effects of region-specific fiscal shocks has also a disadvantage, because the effects can only be interpreted as relative effects, since the general equilibrium effects can usually not be identified! All common effects of the shock in EU funds that are the same for all regions are absorbed by the time-fixed effects. This effect also occurs in studies that focus on the effects of federal fiscal shocks across US states or cities (Nakamura and Steinsson, 2014, Dupor and Guerrero, 2017; Auerbach et al., 2019). The estimated fiscal multipliers in these studies usually exceed the aggregate multipliers that are estimated with national data (Ramey, 2019). The fiscal multipliers in studies that use regional data can only be interpreted as open-economy relative multipliers, because states can be regarded as member states of a monetary union with a common monetary policy.

Existing studies that investigate the effects of EU funds focus on effects in less-developed regions that receive most of the funds. Since the awarded amount of EU funds is partially endogenous to the ongoing regional economic development, it is difficult to study directly the causal effect of a change in EU funds on regional production. To deal with this problem, existing studies identify exogenous drivers in eligibility for EU funds for less-developed regions between EU programming periods. More specifically, several studies investigate whether gaining an 'Objective 1 status ${ }^{23^{3}}$ has an effect on regional economic growth. Becker et al. (2010, 2018) and Pellegrini et al. (2012) use a regression-discontinuity design and conclude

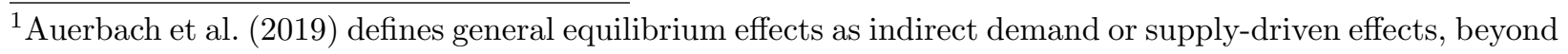
direct and spillover effects through backward linkages.

${ }^{2}$ In the past, less-developed regions were called 'Objective 1' regions, because convergence between regions was the key objective. Only regions with a GDP less than $75 \%$ of the EU average received these funds. Objective 2 funds supported economic and social conversion in areas that experienced structural economic difficulties. Objective 3 funds supported education and job market policies outside Objective 1 regions.

${ }^{3}$ Currently, the EU classifies regions as more developed regions (GDP per capita $\geq 90 \%$ of EU average), transition regions (GDP per capita between 75 and $90 \%$ of EU average), and less-developed regions (GDP per capita $\leq 75 \%$ of EU average). 
that there is a positive effect on regional GDP growth. Other studies use different methods to study the effects of 'Objective 1 funds'. Esposti and Bussoletti (2018) use the generalized method of moments (GMM) to test for conditional convergence and estimate the effect of Objective 1 funds. Similarily, Puigcerver-Peñalver (2007) estimate a panel data model for conditional convergence together with the impact of Objective 1 funds. Both studies find positive effects of Objective 1 funds and conditional convergence between regions. These studies however ignore a large part of the variation in EU funds.

First of all, changes in EU funds for more-developed regions are ignored In order to properly investigate the short run effects of EU funds, the effect on more-developed regions should be included. Mohl and Hagen (2010) is one of the few studies that not exclusively focuses on Objective 1 regions. They estimate the effects of Objective 1, 2, and 3 funds on regional GDP growth using GMM. They find that only Objective 1 funds have a positive effect on GDP growth. For other funds, related to Objective 2 and 3, they do not find positive effects on regional GDP growth. Thus, it is important to not only focus on less-developed regions, because it ignores the 'treatment' to more-developed regions, creating bias in the estimates. The actual treatment effect to all regions is likely to be lower, which is in line with the estimation results from Mohl and Hagen (2010). Although this only holds if this effect outweighs the declining marginal treatment effect, identified by Becker et al. (2012) 5

Secondly, existing studies that focus on Objective 1 regions only study changes in eligibility for EU funds between programming periods. However, there is also considerable variation of EU funds throughout the programming period, both at the regional and the aggregate level. The data on payments of EU funds clearly show that the payments are not evenly spread throughout the programming period. It is therefore important to take into account the timing within a period. Moreover, the changes between periods and within a period have a very different interpretation. The changes between programming periods are mostly due to changes in eligibility conditions for regions. When a region becomes eligible for

\footnotetext{
${ }^{4}$ In fact, more-developed regions are eligible for all EU funds, except the European Social Fund (ESF).

${ }^{5}$ If the marginal treatment effect is declining, then the effectiveness of funds is lower in regions that receive more funds. This could outweigh the upward bias from focusing only on the more effective funds.
} 
certain funds, then it is likely that the region receives more funds throughout the entire programming period. Thus, the shocks between programming periods cause a semi-permanent 'level shift' in the amount of EU funds. Instead, shocks within a programming period only affect the total amount of funds in a specific year, without having a persistent effect. These transitory shocks are caused by payments to specific eligible projects. Hence, it is important to study the effects of both the shocks within and between programming periods separately.

\subsubsection{Short-run policy consequences}

This chapter focuses on short-run policy consequences of shocks in EU funds. Although there is empirical evidence that an increase in EU funds has a positive overall effect on the regional economy, it is important to consider also other policy consequences. It is very likely that the effects of shocks over time are not uniformly distributed across sectors, and that over time effects can spill over to other sectors or regions. For a policymaker, it is relevant to know about the magnitude of such 'side effects' when designing the fiscal policy stimulus, even if the effects only occur in a subset of regions, under specific conditions, or only in the short run, while fading out in the long run. It is especially important for policymakers to know the extent to which fiscal policy has a heterogeneous effect across specific sectors in regions, and the extent of regional interactions, because these effects have different interpretation.

On the one hand, the positive overall effect in a region is an intended policy consequence of EU funds. The funds aim to stimulate long-run economic convergence, instead of short-run stabilization, which explains why studies only evaluate the effectiveness of the funds through long-term economic growth. In general, a policy can be created to achieve both stabilization and economic growth, although in practice policies are often designed to achieve only one of these goals, as can be seen for EU funds. Alternatively, fiscal policy can be used as stabilization mechanism in a fiscal union when regions are affected by idiosyncratic shocks. Farhi and Werning (2017) discuss the role of transfers in a fiscal union to achieve stabilization.

On the other hand, sectoral substitution effects and regional spillover effects can be regarded as unintended policy consequences. These effects can be described as 'side effects'. 
It is unlikely that policies officially aim to stimulate one sector while crowding out another. Also, a cross-regional spillover effect is usually regarded as a 'side effect' and not as the intended goal. A positive spillover implies that part of the positive stimulus leaks to other regions, and negative spillovers are definitely not in line with the intentions of policymakers. Since it is reasonable to assume that the effect of a shock is not uniformly distributed across sectors, this chapter investigates the direction and magnitude of sectoral substitution effects and regional spillover effects.

The following theoretical example illustrates the three aforementioned effects caused by a government spending shock. Specifically, it shows the effects of a shock in central government spending to one sector in a specific region $\sqrt{6}$ Consider two regions (A and B) and two sectors (1 and 2). Assume there is free trade and free movement of production factors between the regions and sectors. Furthermore, there is nearly full employment and prices are flexible. There is one central government that can introduce a fiscal policy shock. Consider an increase in government demand for the good produced by sector 1 in region $\mathrm{A}$. An increase in government spending can for example stimulate demand in the construction sector when funds are used to build a new bridge in region A. Furthermore, assume that there is no change in taxes, i.e. fiscal policy is deficit financed. The stimulus to sector 1 in region A can have the following three effects.

First, if there is higher production in sector 1 in region A, this can also have a positive demand effect on sector 2 in region A. However, the higher production in sector 1 also attracts production factors from sector 2. If the latter effect dominates, then the fiscal stimulus for sector 1 in region A creates a negative sectoral substitution effect for sector 2 in region A. This substitution effect is clearly an example of an unintended policy consequence. Both studies in the US (Nakamura and Steinsson, 2014) and in the EU (Bénétrix and Lane, 2010) confirm that fiscal policy has different effects across sectors.

Second, the sum of production in sectors 1 and 2 indicates whether the overall effect is

${ }^{6}$ It should be noted that this theoretical example is a simplified representation of reality. In the remainder of this chapter, I analyze the effect of a shock in EU funds, but I do not have information about the sector that is targeted. 
positive or negative. When the production levels of sectors in a region react in opposite direction, the overall effect on total production in region A can go in two directions. If total production in region A increases, then there is a positive overall effect, or crowding-in effect: 7 However, if total production decreases, then there is a negative overall effect, although this result seems less plausible intuitively. It is more likely that that there is a positive overall effect when temporarily additional government demand increases total demand for good 1 , which outweighs the possible sectoral substitution effect. The overall effect can only be negative when the reallocation of production factors between sectors 1 and 2 affects the production possibilities for both sectors, as observed through the sectoral substitution. In general, existing studies find a positive overall effect of EU funds (Mohl and Hagen, 2010; Becker et al., 2010, 2012, 2018).

Third, if there is a positive overall effect in region A, then it is likely that imports from region $\mathrm{B}$ increase. Then, production in region $\mathrm{B}$ is stimulated due to higher demand from region A. This demand-side effect is called a positive regional spillover. However, if production factors move from region $\mathrm{B}$ to region $\mathrm{A}$, because production in region $\mathrm{A}$ is stimulated, then region B can also experience a negative supply-side induced spillover. Thus, the net effect seems ambiguous. Existing studies that investigate regional spillovers in the US find positive regional spillovers using either defense shocks (Auerbach et al., 2019) or ARRA-spending (Dupor and McCrory, 2017). For EU funds, Becker et al. (2010) and Mohl and Hagen (2010) find small positive regional spillovers.

To summarize, the following effects of a shock in EU funds can be identified: (i) the direct effect at the sectoral level, (ii) the overall direct effect at the regional level, and (iii) the regional spillover effect at the sectoral level. In section 4.3 the direct effects (i) and (ii) are estimated, and in section 4.4 the spillover effects (iii) are estimated.

${ }^{7}$ It is common in the literature to define crowding-in of fiscal policy when the fiscal multiplier is above unity. In this chapter, no multipliers are calculated, because this is impossible at the sectoral level. This chapter therefore refers only to positive overall effects. 


\subsection{Direct effects}

In this section, I estimate the direct effects of shocks to EU funds. The method that is used to construct the shocks and responses is similar to chapter 3 . This method allows to study effects of a shock in any category of central government spending to economies of subnational regions. In this section, I explain in detail how the method can be used to study the dynamic effect of shocks to EU funds on sectoral production in regions. First, I explain how to obtain impulse response functions to the shocks using a panel data fixed-effects model. Second, I clarify how these shocks are constructed. Finally, I present the estimation results for sectoral responses to shocks within and between programming periods.

\subsubsection{Estimation method}

The goal of this section is to estimate the effects of regional shocks in EU funds on sectoral production. To that aim, I use data on structural and investment funds for 264 NUTS-2 region $\AA^{8}$ provided by the European Commission for the period 1989 until $20159^{9}$ It should be emphasized that data on funds are only available by region and not by sector. The estimated shock is therefore a region-specific shock, and not a sector-specific shock.

Moreover, the data include only payments, which differ possibly in timing from the actual expenditures financed with these funds. When payments are used to create 'unanticipated' fiscal shocks, the timing of the shocks can be incorrect, especially when (part of the) expenditures precede payments. Unfortunately, no data exist for actual expenditures, apart from simulations. Since the results in this chapter are based on payments instead of expenditures, the estimated immediate response in the first year(s) should be interpreted with caution.

To estimate the effect of EU funds on production across horizons for different sectors in region $i=1,2, \ldots, N$, the following linear panel regression model is estimated for each

${ }^{8}$ French oversees departments (FR91, FR92, FR93, FR94), Spanish autonomous cities (ES63, ES64), Cyprus (CY) and Croatia (HR) are dropped. UKI3 and UK4 are combined as Inner Londen (UKI1) and UKI5, UKI6 and UKI7 as Outer Londen (UKI2).

${ }^{9}$ For more details, see appendix 4. A.2. 
sector and horizon separately, both for shocks between and within programming periods ${ }^{10}$

$$
y_{i, t+h}=\alpha_{i, h}+\beta_{t, h}+\sum_{\ell=1}^{L} \gamma_{h, \ell} y_{i, t-\ell}+\sum_{\ell=0}^{L} \delta_{h, \ell}^{\prime} X_{i, t-\ell}+\theta_{h} \hat{s}_{i, t}^{k}+\varepsilon_{i, t+h} \quad \text { with } \quad k \in\{b, w\},
$$

where $\alpha_{i, h}$ and $\beta_{t, h}$ denote the region-fixed effects and time-fixed effects and $\hat{s}_{i, t}^{k}$ is the shock. I denote the shock between programming periods as $\hat{s}_{i, t}^{b}$, and within a period as $\hat{s}_{i, t}^{w}$.

Production, or gross value added, at horizon $h$ for region $i$ is denoted as $y_{i, t+h}$. These series are available for every NUTS-2 region and are disaggregated into six economic sectors, namely the agricultural, industrial, construction, wholesale, services, and public sector ${ }^{11}$ The variables are transformed into per capita levels and deflated. More details about the data can be found in appendix 4.A.2.

Two lags of the dependent variable are included to avoid dynamic misspecification and improve estimator efficiency. Furthermore, contemporaneous and lagged control variables are included in the vector $X_{i, t}$. These control variables include the aggregated production in other sectors and the following variables at the level of EU member states: GDP per capita, unemployment, and inflation. The control variables are included to control for contemporaneous correlation with macroeconomic shocks at the level of EU member states. All variables are de-trended at the regional level with a log-linear trend.

Equation 4.1 is estimated for six sectors and for the sum of all sectors across 4-years both for a shock within a programming period and between programming periods. Since the variables are de-trended using a log-linear trend, the coefficients should be interpreted as the percentage deviation from the trend caused by a 1 per cent change in EU funds. The coefficient $\theta_{h}$ is the component of the impulse response function at horizon $h$. It traces the dynamic effect of the shock on production at horizon $h$. Using this so-called local projection method, the elements of the impulse response function can be estimated independently in separate regressions without modeling the dependencies between variables across horizons.

\footnotetext{
${ }^{10}$ The same equation is also estimated for employment, where $y_{i, t}$ denotes employment in region $i$ at time $t$. ${ }^{11}$ More details about the sectoral decomposition can be found on the website of Cambridge Econometrics: wWw. camecon.com/european-regional-data
} 
The confidence intervals of the impulse response function are bootstrapped, to make inference possible even in the presence of non-normality, heteroskedasticity and autocorrelation. However, due to the regional panel structure of the data, a standard block bootstrap procedure for panel data is not optimal. There is high cross-sectional correlation, because regions are exposed to the same (unobserved) economic conditions. Hence, it is preferable to use the panel moving blocks bootstrap, developed by Gonçalves (2011). This procedure re-samples both dependent and independent variables along the time dimension, instead of the cross-sectional dimension 122 The bootstrapped distribution can be used to conduct inference on the estimated coefficient for $\theta_{h}$. At every iteration, the entire impulse response function is estimated, i.e. at every horizon $h$. The figures in subsection 4.3.3, report the estimated coefficients together with the $90 \%$ confidence intervals ${ }^{13}$

\subsubsection{Estimating region-specific shocks}

In this subsection, I explain how the shocks that are used in equation 4.1 are estimated. The region-specific shocks to EU funds both within and between programming periods are defined as the difference between the actual value of the funds and the expected value of the funds for region $i$. Hence, these shocks can be interpreted as the unanticipated change in EU funds. Unfortunately, there does not exist an official publicly available region-specific forecast for EU funds. I therefore have to obtain the forecasts based on estimates.

The estimate for the shock between programming periods, denoted as $\hat{s}_{i, t}^{b}$, is defined as the difference in the average values of the current and previous programming period for region $i$. This shock measures the 'level shift' between two periods, i.e. a semi-permanent change in funds caused by policy changes between two periods.

After calculating this shock, the amount of funds for region $i$ is de-meaned and de-trended using a log-linear trend for every programming period separately. The inverse hyperbolic sine transformation is used instead of a natural logarithm, because of many zeros. The

\footnotetext{
${ }^{12}$ In practice, a random vector of starting dates is drawn to construct blocks of years with replacement. The number of blocks is chosen such that the bootstrap sample has the size as the original sample.

${ }^{13}$ The intervals are constructed with the percentile method, using the bias-corrected bootstrap distribution centered around the bias-corrected point estimate.
} 
detrended series are used to obtain the shock within a programming period, denoted as $\hat{s}_{i, t}^{w}$. To obtain this shock, I calculate the difference between the actual amount of de-trended funds in region $i$ at time $t$, minus a forecast based on an econometric model that uses as many relevant variables as possible to construct an optimal forecast. Ideally, the estimated shocks should be uncorrelated to other past and future economic shocks, after control variables are included (Stock and Watson, 2018). Therefore, the forecast model uses information about several macroeconomic variables at the level of EU member states.

The forecast of the funds $f_{i, t}$ in region $i$ in a year $t$, is a 5 -year rolling forecast that uses the coefficients obtained in the following fixed-effects linear panel regression model:

$$
f_{i, t}=\rho_{i}+\sum_{\ell=1}^{L} \phi_{\ell} f_{i, t-\ell}+\sum_{\ell=1}^{L} \psi_{\ell}^{\prime} Y_{i, t}+\sum_{\ell=1}^{L} \zeta_{\ell}^{\prime} Z_{i, t-\ell}+\epsilon_{i, t}
$$

where the region-fixed effects are denoted as $\rho_{i}$. Furthermore, there are three groups of right-hand side variables: lags of the dependent variable are included, a vector of sectoral control variables $Y_{i, t}$ that includes production for every sector in region $i$, and a vector $Z_{i, t}$ with control variables. The control variables include the (aggregated) production for every sector in a country and the variables GDP per capita, unemployment, and inflation at the EU member state level 14 The lag length $L$ is always 2.

Based on the model in equation 4.2 , I compute the out-of sample one-step-ahead forecast $\hat{f}_{i, t+1}$. In other words, I run the regression for a 5-year sample, and save the coefficients to produce the forecast for the year thereafter, which has not been included in the sample. With this out-of sample (ex-ante) forecast, I calculate (ex-post) the within-programming periods EU funds shock as follows:

$$
\hat{s}_{i, t+1}^{w}=f_{i, t+1}-\hat{f}_{i, t+1} .
$$

Figure 4.1 shows how structural and investment funds respond to a shock between or within programming periods. The response to a shock within a programming period is close ${ }^{14}$ The EU-average is used for countries with only one NUTS-2 region (EE, LV, LU, LT and MT). 
to 1 on impact, which implies that the series for funds $f_{i, t}$ is very persistent, i.e. close to a random walk, which implies that the shock has a unit impact in the estimated regression. The effect of this shock dies out soon, while on the other hand, the response of the funds to a shock between programming periods remains constant.

Figure 4.1: Impulse responses shocks within and between programming periods
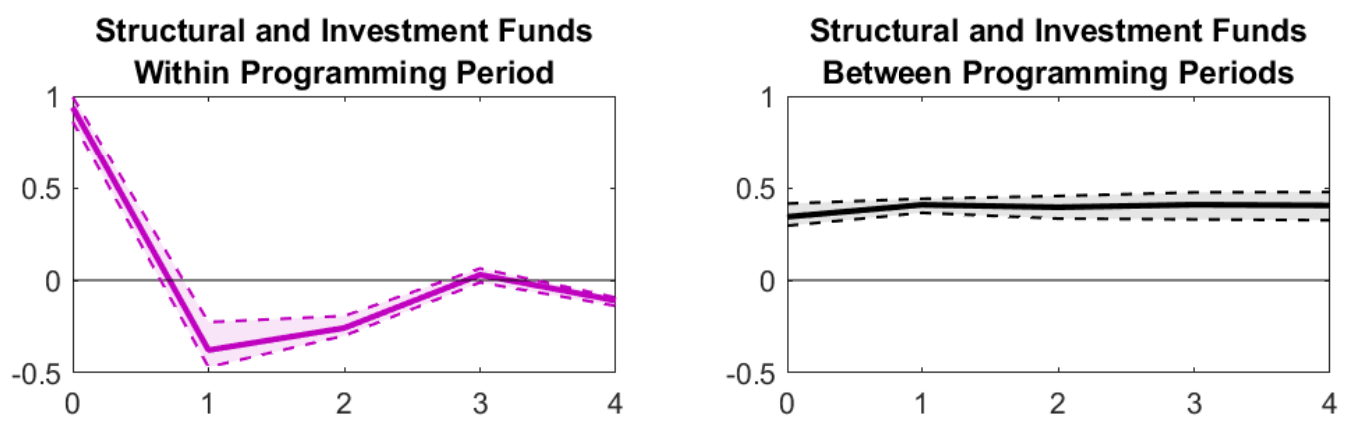

Note: Impulse responses for structural and investment funds to a shock within a programming period (left) and between programming periods (right). To calculate the impulse response, the dependent variable is detrended for every programming separately in the left figure. In the right figure, the dependent variable is detrended over the full sample. The impulse responses are calculated by estimating equation 4.1 where $y_{i, t}$ is replaced by $f_{i, t}$.

Both shocks represent an unexpected change in EU funds for region $i$ at time $t$. Although the shocks are region specific, the shocks across regions are used together in a panel regression to measure the unanticipated overall effect of EU funds. It is impossible to estimate anticipation effects effects based on these shocks, because anticipation effects arise prior to the change in the funds.

The validity of the approach depends on the underlying forecast. For the shock between two programming periods, the forecast is the average value of the previous programming period. In contrast, the shock within a programming periods is based on a forecast model that includes more information and therefore provides a better forecast. The quality of this model can be checked with goodness-of-fit indicators 15

${ }^{15}$ As a benchmark, I compared the econometric forecast to a naive forecast, i.e. $f_{i, t}$. This corresponds to the same approach that I use between programming periods. Using the naive forecast does not have a major effect on the results, which are available on request. However, the root mean squared forecast error (RMSE) decreases by $24 \%$ when the naive forecast is replaced with the econometric forecast. 


\subsubsection{Estimation results for direct effects}

In this subsection, I present the estimation results for the responses of sectoral production across sub-national regions in the EU. The aim is to show how shocks in EU funds directly affect sectoral production in sub-national regions in the EU. Since the existing literature finds that EU funds are more effective in less-developed regions (Mohl and Hagen, 2010), I present the results for all regions, and separately for less-developed (including transition) regions and more-developed regions, 16

First, I investigate the direct overall effects of shocks in EU funds. Figure 4.2 below shows that there is no evidence of a positive overall effect, neither within nor between programming periods ${ }^{17}$ Actually, I find that within a programming period, the effect is even significantly negative for the first two years. These findings seem counter-intuitive and in contrast with studies that find positive overall effects (Mohl and Hagen, 2010; Becker et al., 2010, 2012, 2018). However, most existing studies focus on less-developed regions and only estimate the effects of shocks in EU funds between programming periods. In the next paragraphs, I therefore analyze the shock between programming periods at a deeper level. The results for the shock within a programming period can be found in appendix 4.A.3.

Figure 4.2: Direct effects for a shock within and between programming periods
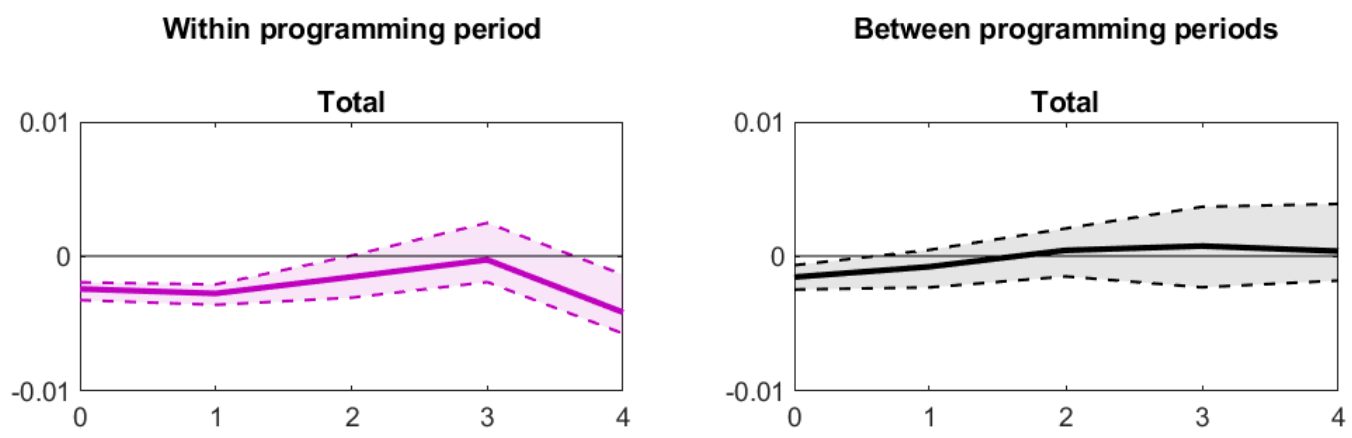

Note: Impulse responses for sectoral production to a shock in structural and investment funds between and within programming periods (left) and between programming periods (right). The bias-corrected point estimates and the bootstrapped $90 \%$ confidence intervals are shown. The underlying regressions include region and year-fixed effects and national control variables.

\footnotetext{
${ }^{16}$ More information about the classifcation of the regions can be found in appendix 4.A.2.

${ }^{17}$ As shown in appendix 4.A.5, there is also no clear effect on employment, although the response between programming periods is positive after two years.
} 
Figure 4.3 shows that when regions are clustered according to their development level, I find a positive effect after two years for less-developed regions (including transition regions). Unfortunately, the wide confidence intervals prevent me from claiming that the effect is significant. Nevertheless, when I remove the transition regions (not shown), the confidence intervals shrink, and the effect turns significant at the $90 \%$ level. Therefore, I conclude that there is some indication that less-developed regions benefit from EU funds. On the other hand, more-developed regions do not benefit from the shock in EU funds. The effect even seems negative after three years, which explains why I could not find a positive overall effect.

Figure 4.3: Direct effects for less and more developed regions

Less developed

Total

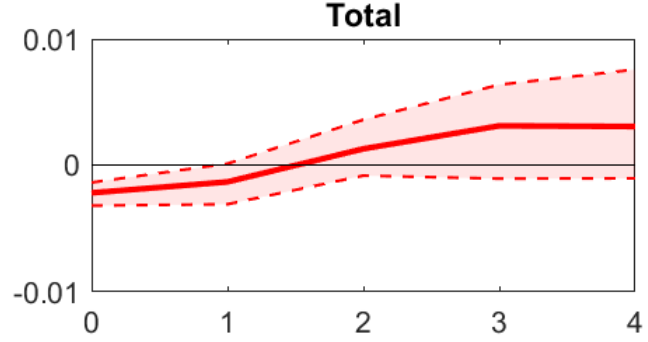

More developed

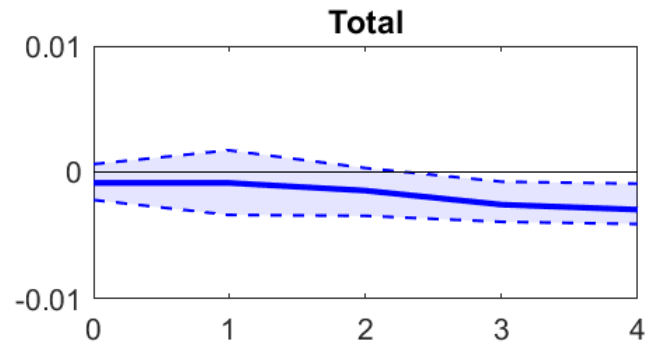

Note: Impulse responses for sectoral production to a shock in structural and investment funds between programming periods for less-developed regions (left) and more-developed regions (right). The bias-corrected point estimates and the bootstrapped $90 \%$ confidence intervals are shown. The underlying regressions include region and year-fixed effects and national control variables.

The intuition could be that in more-developed regions there are substitution effects, because there is more scarcity in production factors. Instead, in less-developed regions, these constraints do not play a significant role, and therefore positive effects from additional government demand dominate, and outweigh the negative effects. This finding raises two questions. First, which sector(s) cause(s) the positive effect in less-developed regions? Second, between which sectors does sectoral substitution take place in more-developed regions?

To answer the first question, figure 4.4 shows responses to a shock between programming periods for the industrial and public sector. There is a small positive overall direct effect in the industrial sector across all regions 18 This effect is dominated by less-developed regions.

${ }^{18}$ As shown in appendix 4.A.5 the response of employment in the industrial sector is also significantly positive. 
The public sector only responds positively in less-developed regions.

It remains difficult to interpret the positive effect in these sectors. Technically, the estimates show the effect of the shock on future values of gross value added per sector. For the industrial sector, this probably means that the additional government demand raises value added, but it is unclear through which channel. It could imply that the quantity demanded rises, or that the type of products produced changes. For the public sector it is even less clear what exactly the increase in value added entails. It could imply a combination of an increase in wages and/ or a higher level of employment at governmental agencies.

Figure 4.4: Direct effects for the industrial and public sector
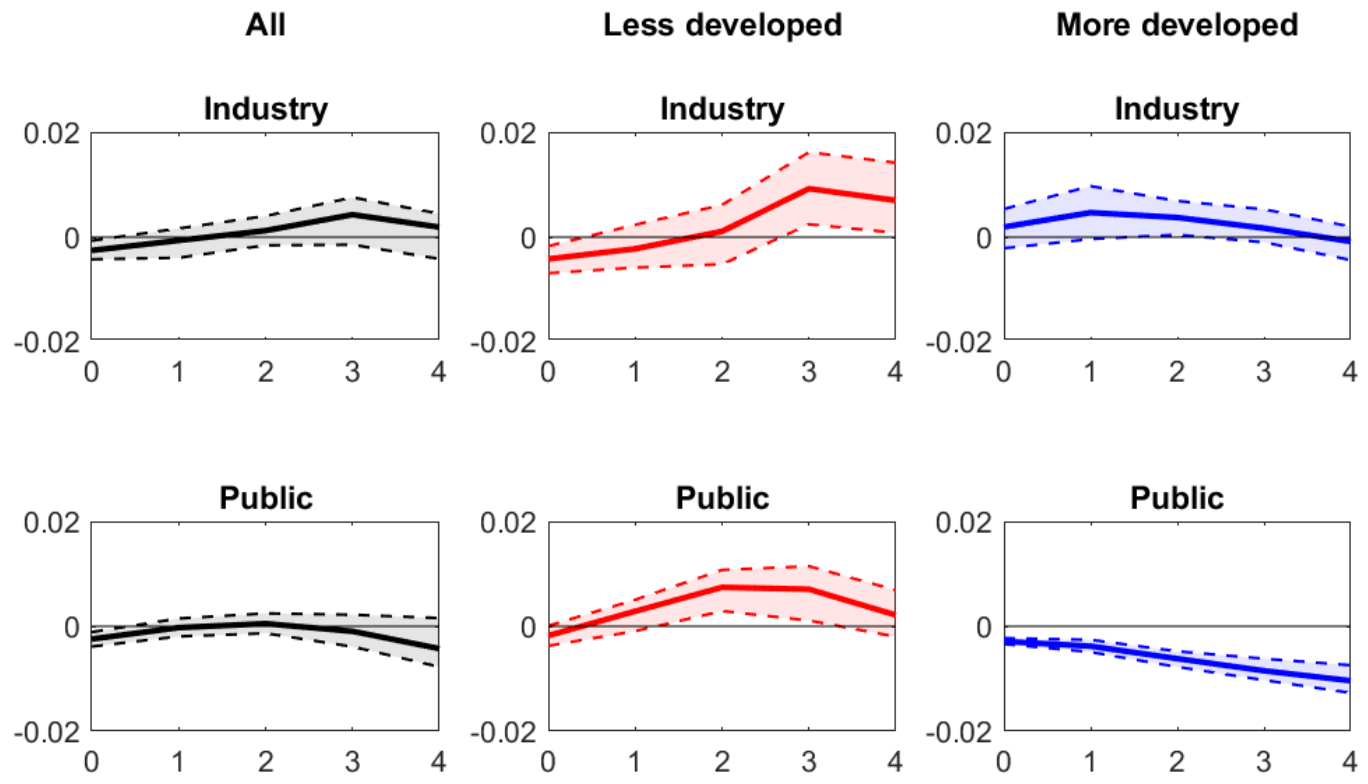

Note: Impulse responses for sectoral production to a shock in structural and investment funds between programming periods for all regions (left column), less-developed regions (middle column) and more-developed regions (right). The bias-corrected point estimates and the bootstrapped $90 \%$ confidence intervals are shown. The underlying regressions include region and year-fixed effects and national control variables.

To answer the second question about sectoral substitution in more-developed regions, figure 4.5 compares responses of the construction and service sectors. Across all regions, there is a small positive effect in the construction sector for the first three years. This effect is dominated by more-developed regions. There is no significant effect in less-developed regions. In the service sector, there is a negative overall effect, which is again dominated 
by more-developed regions. Apparently, there is evidence for sectoral substitution in moredeveloped regions between the construction sector that is positively affected, while the service sector is negatively affected ${ }^{19}$ In fact, not only the service sector in more-developed regions, but also the agricultural and public sector are negatively affected (see appendix 4.A.3). On the other hand, the wholesale sector is positively affected.

The intuition for the sectoral substitution effect is that EU funds apparently stimulate the construction sector, because additional government demand stimulates infrastructural and other construction works. The additional demand increases the need for labor, capital and other production factors, and this negatively affects other sectors in the regional economy. Apparently, some sectors, including the service sector, are affected more than others. This could indicate that the mobility of the production factors in these sectors is higher. I find no significant sectoral substitution in less-developed regions, because there is probably less scarcity for production factors in these regions.

In short, the results indicate that there is no overall positive effect at the regional level between or within programming periods in the short run. However, in line with the literature, I find a positive effect between programming periods for less-developed regions, although this effect is not significant in all specifications. Furthermore, I find sectoral substitution effects in more-developed regions, where a shock between programming periods stimulates production in the construction sector, while crowding out production in the service, agricultural and public sector. This effect can be explained through an increase in competition for production factors when demand in one sector is stimulated. Intuitively, the findings suggest that the level of scarcity of production factors could be an important driver of the results, because both crowding-out effects and sectoral substitution effects are only found in more developed regions, where scarcity of production factors plays a dominant role.

${ }^{19}$ This finding is confirmed by the results for employment per sector, as shown in appendix 4.A.5. 
Figure 4.5: Direct effects for the construction and service sector
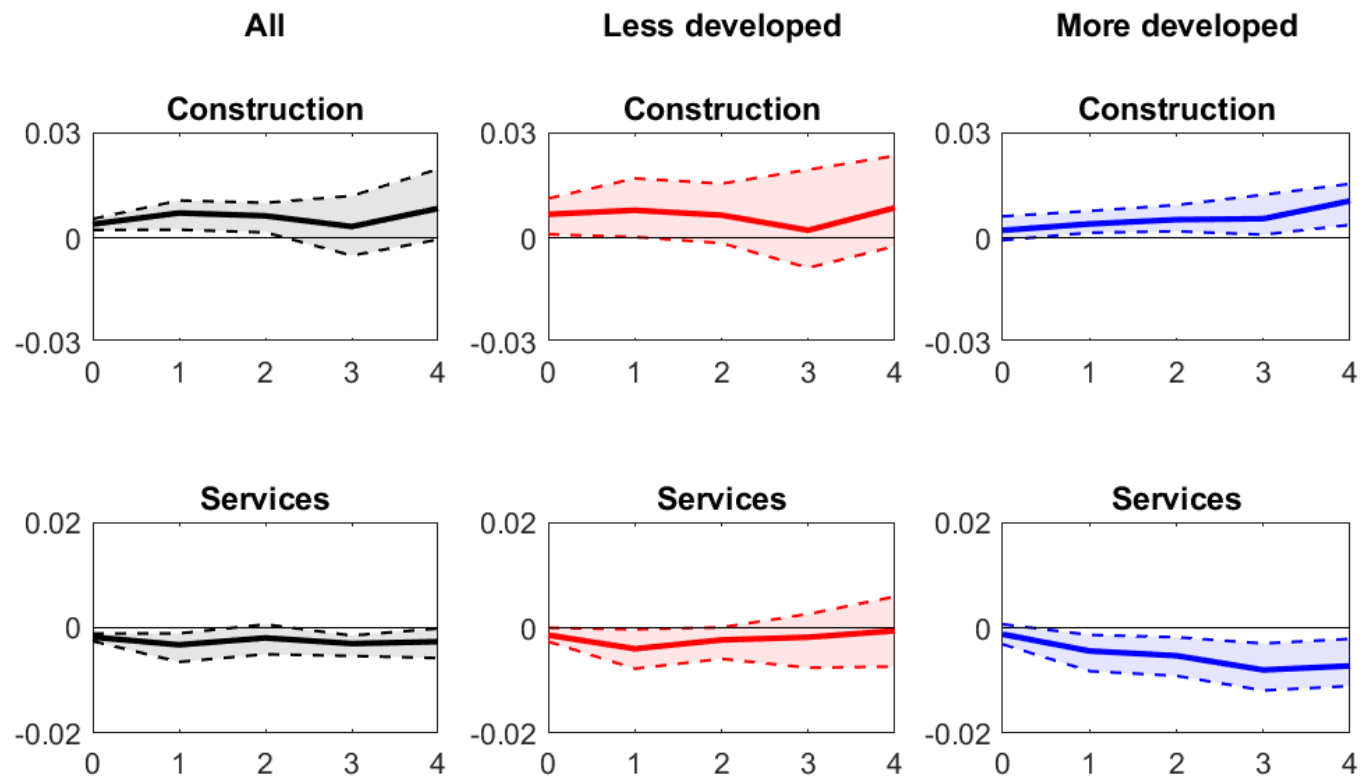

Note: Impulse responses for sectoral production to a shock in structural and investment funds between programming periods for all regions (left column), less-developed regions (middle column) and more-developed regions (right ). The bias-corrected point estimates and the bootstrapped $90 \%$ confidence intervals are shown. The underlying regressions include region and year-fixed effects and national control variables.

\subsection{Regional spillover effects}

In this section, I estimate regional spillover effects for EU funds. The region-specific shocks that have been estimated in the previous section are used to construct 'partner shocks', that measure the exogenous change in EU funds in other regions within and between programming periods. These shocks are used to investigate the cross-regional spillover effects.

\subsubsection{Constructing partner shocks}

To study the connections between regions, I use a spatial approach with trade-based weights in line with Dupor and Guerrero (2017), who estimate spillovers for federal fiscal shocks in US states. ${ }^{20}$ Existing studies that estimate spillover effects of EU funds do not use a trade-

${ }^{20}$ The results by Dupor and Guerrero (2017) indicate that the spillover effects explain the difference between local multipliers estimated at the state level and aggregate multipliers estimated at the national level. 
based method, but focus on geographic proximity. Becker et al. (2010) controls for spillovers by excluding regions if neighbors receive treatment, which is called spatial exclusion. Mohl and Hagen (2010) estimate spillover effects using the distance between the centroids of the regions as weights in a spatial lag model. Both studies find small positive spillover effects.

It is preferable to not only focus on geographic proximity when estimating spillover effects, since there can also be spillovers between regions that are geographically apart. Therefore, I use a trade-based method, even though most trade takes place with neighboring regions and regions within the same EU member state ${ }^{21}$ Although trade is a proxy for interactions between regions, it does not imply that the spillovers are solely caused by trade 22

The connections between regions are modeled using calibrated trade data on intra-EU trade. For every region $i$, the total of intra-EU imports and exports is computed for every 'partner region' $p=1,2, \ldots, P$. The data on intra-EU trade from Thissen et al. (2017) cover trade between NUTS-2 regions in the EU ${ }^{23}$ In the construction of the 'partner shocks', I only use data from 2010, and therefore assume that trade volumes between regions are time invariant. Based on the available intra-EU trade data between 2000 and 2010, it seems that trade shares are relatively constant over time. Therefore, it is unlikely that using only data from 2010 has a major effect on the results.

The 'partner shock' for region $i$ is a combination of the shocks in partner regions, weighted by the trade share with region $i$. I follow this procedure both within and between programming periods. The weights are based on a $N \times N$ weighting matrix, which is constructed using the input-output matrix between regions. The weights are constant across sectors for region $i$. Furthermore, diagonal elements in the weight matrix are set equal to zero and off-diagonal elements are summed, resulting in a symmetric $N \times N$ matrix of total exports and imports. Finally, the weights per region are scaled to sum up to one. To obtain the partner shock, I use a two step procedure. First, I use the elements of the weight matrix $w_{i, j}$

${ }^{21}$ In 2010, 80\% of European production was sold within national borders (Thissen et al., 2013).

${ }^{22}$ The method does not identify the source of the spillover effect. The aim is only to find a proxy for the interactions between regions when modeling the spillovers, which can be both supply and demand driven.

${ }^{23}$ The following regions are combined to one: DE41 and DE42 are DE40, DEE1, DEE2 and DEE3 are DEE0, and FI13 and FI13 and FI1A are FI1D. Finally, Greece is recoded from GR to EL. 
for region $i$ with partner region $j$, to obtain an initial estimate of the partner shock $\hat{p}_{i, t}^{k}$ :

$$
\hat{p}_{i, t}^{k}=\sum_{j=1}^{N} w_{i, j} \hat{s}_{j, t}^{k} \quad \text { where } \quad \sum_{j=1}^{N} w_{i, j}=1 \quad \text { and } \quad w_{i, i}=0 \quad \forall i, j \quad \text { with } \quad k \in\{b, w\} .
$$

Intuitively, equation 4.4 calculates the weighted average of shocks for all other regions, weighted by the relative importance of intra-EU trade between these other regions and region $i$.

Second, I ensure that the partner shock is uncorrelated to the own shock in region $i$. Therefore, I regress $\hat{p}_{i, t}$ on the shock $\hat{s}_{i, t}$. The residual from this regression is used as the final estimate for the partner shock. Due to the assumption of a time-invariant weight matrix, the analysis requires a balanced panel. Consequently, only data from 1996 onward are included for 242 regions. ${ }^{24}$ Related studies that analyze spillover effects, such as Mohl and Hagen (2010) and Becker et al. (2010), also use a balanced panel.

To estimate the spillover effect, equation 4.1 from section 4.3 is re-estimated, including both the shock and the partner shock. The coefficients of the partner shock across horizons $h$ estimate directly the impulse response function. The bootstrapped confidence intervals are used to determine whether the spillover effect is significantly different from zero. This procedure is followed both for the shock within and between two programming periods.

\subsubsection{Estimation results for regional spillovers}

The results for the regional spillovers are based on the estimate for the effect of the partner shocks. ${ }^{25}$ The figure below shows the regional spillover effect across all regions. Clearly, I find no indication of any overall spillover effect at the regional level, neither within nor between programming periods ${ }^{26}$ To analyze the spillovers further, I estimate the spillovers at the

\footnotetext{
${ }^{24}$ The following countries are excluded: Slovenia (SI), Bulgaria (BG) and Romania (RO). Two Portugese regions are excluded: PT20 and PT30. Finally, the following regions are combined to one: DK03, DK04 and DK05 are DK03 and FI1B and FI1C are FI1C.

${ }^{25} \mathrm{I}$ also investigated the possibility of scaling shocks by an indicator for 'openness to trade', i.e. the share of total exports and imports in regional production. The conclusions are robust to this alternative measure. ${ }^{26}$ The results in appendix 4.A.5 for employment also do not show any significant response.
} 
sectoral level, and across different levels of development. Therefore, I estimate the model separately for the less-developed regions and more-developed regions, but for the spillover I combine the shock of all other regions in the 'partner shock' ${ }^{27}$ I focus again on the results between programming periods. All results for the shock within a programming period can be found in appendix 4.A.4.

Figure 4.6: Regional spillovers within and between programming periods

Within programming period

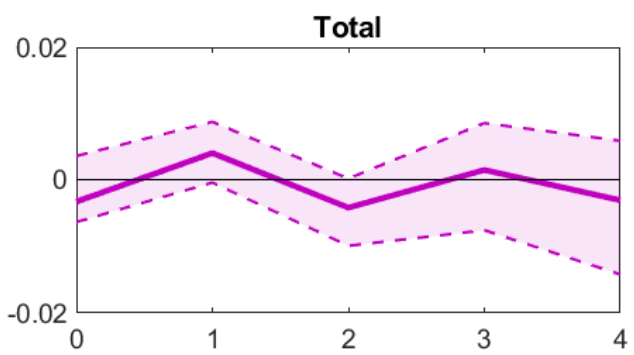

Between programming periods

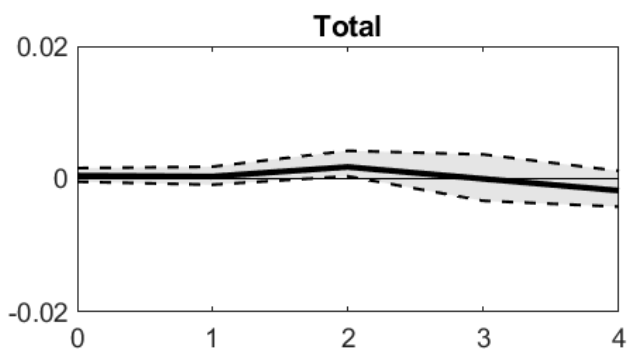

Note: Impulse responses for sectoral production in a region to a shock in structural and investment funds in partner regions within a programming period (left) and between programming periods (right). The bias-corrected point estimates and the bootstrapped 90\% confidence intervals are shown. The underlying regressions include region and year-fixed effects and national control variables.

Figure 4.7 shows responses in less-developed and more-developed regions to a shock between programming periods. Again, there is no clear indication of a regional spillover effect due to wide confidence intervals. The shocks in other regions do not significantly affect production in either less-developed or more-developed regions. This result does however not imply that there are no spillover effects at all, because spillovers could also cancel out at the aggregate level. Therefore, in the next paragraphs, I analyze the spillover effects at the sectoral level.

${ }^{27}$ The intuition is that it does not make sense to only study the spillovers between less-developed regions and more-developed regions separately. 
Figure 4.7: Regional spillovers for less and more-developed regions
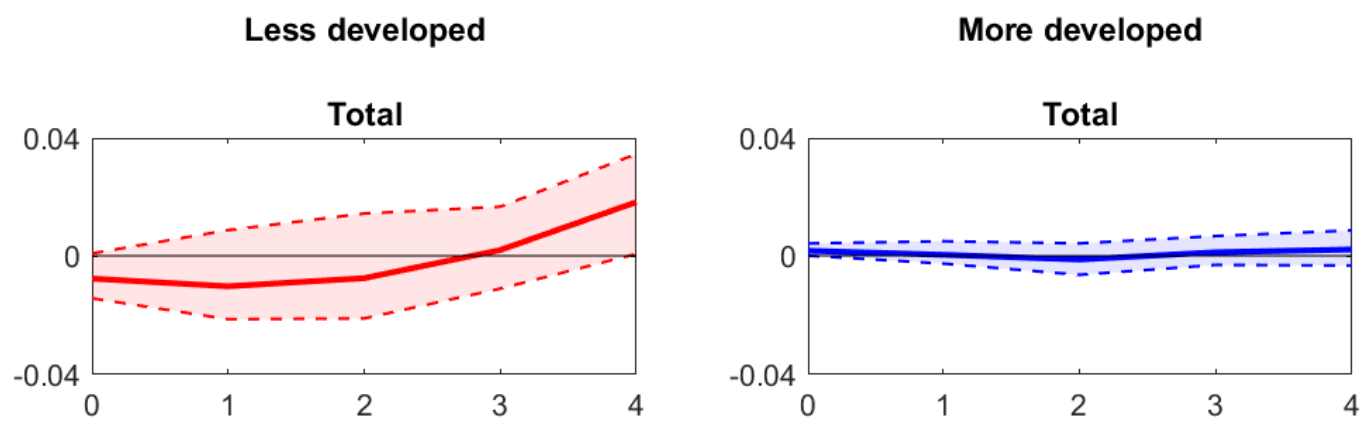

Note: Impulse responses for sectoral production in a region to a shock in structural and investment funds between programming periods in partner regions for less-developed regions (left) and more-developed regions (right). The bias-corrected point estimates and the bootstrapped 90\% confidence intervals are shown. The underlying regressions include region and year-fixed effects and national control variables.

Figure 4.8 shows the spillover effects in the industrial and public sector. Across all regions, there is a small positive effect in the industrial sector, and small negative effect in the public sector ${ }^{28}$ However, when I distinguish between levels of development, the results are more interesting. In less-developed regions, there is a negative spillover for the industrial sector, while the spillover is positive for more-developed regions. Recall that the industrial sector was driving the positive direct effect in less-developed regions. Hence, the spillover effect goes into the opposite direction of the direct effect of the shock. The intuition is that EU funds stimulate the production in the industrial sector, and that this attracts production factors from other regions. These regions experience a negative spillover effect. In the public sector, this pattern is not visible. Both the direct effect and the spillover effects in less-developed regions for the public sector are positive, and both effects are negative in less-developed regions. Apparently, the positive direct effect in the public sector does not attract production factors from other regions to the same extent as for the industrial sector. It remains difficult to explain intuitively why the positive direct effect in the public sector also creates a positive spillover effect to other regions.

\footnotetext{
${ }^{28}$ These results are confirmed by the results in appendix 4. A.5 for employment.
} 
Figure 4.8: Regional spillovers for the industrial and public sector

All
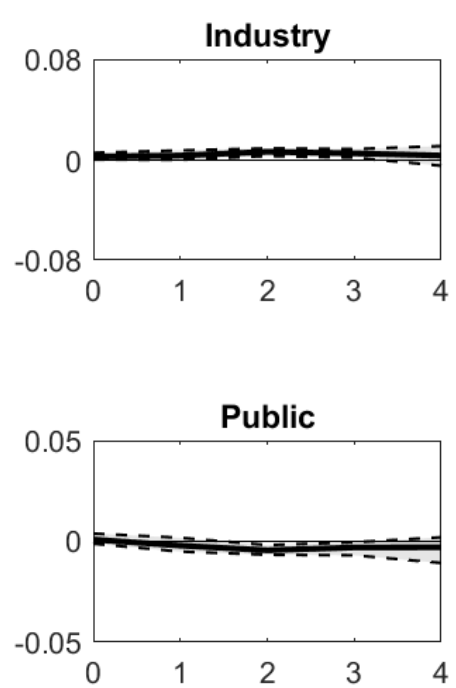

Less developed
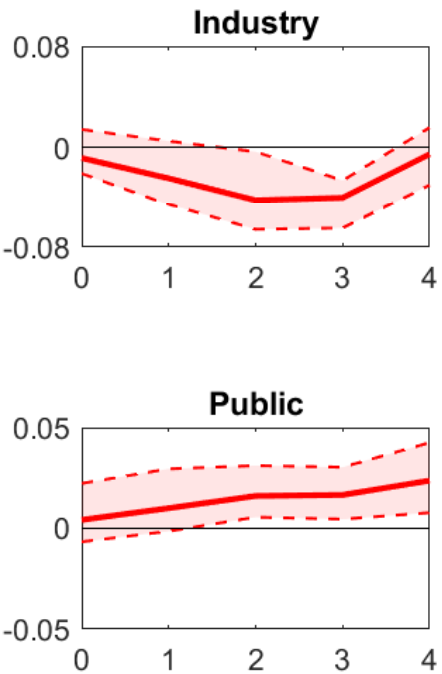

More developed
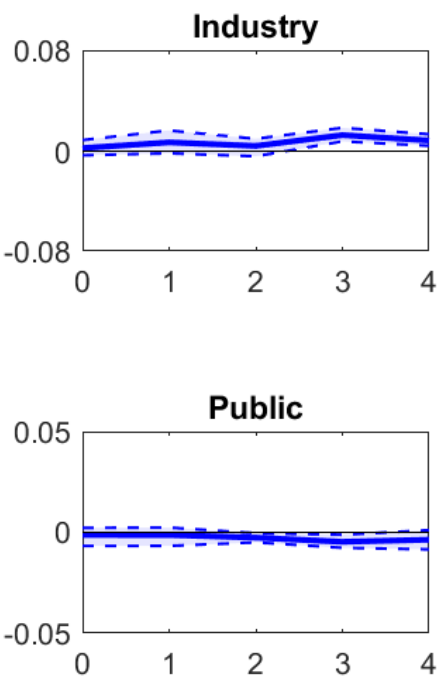

Note: Impulse responses for sectoral production in a region to a shock in structural and investment funds between programming periods in partner regions for all regions (left column), less-developed regions (middle column) and more-developed regions (right ). The bias-corrected point estimates and the bootstrapped 90\% confidence intervals are shown. The underlying regressions include region and year-fixed effects and national control variables.

Figure 4.9 investigates the spillover effects further by showing the spillover effect in the construction and service sector. For these sectors, I identified sectoral substitution effects in the previous section. These effects were most prominent in more-developed regions, where the construction sector responded positively, while the service sector responded negatively. The spillover effect however points in the opposite direction. I find a negative response for the construction sector in less-developed regions, and a positive spillover for the service sector both in less- and more-developed regions. This pattern holds for more sectors. For example, as shown in appendix 4.A.4. I find a strong negative spillover effect in the wholesale sector in more-developed regions. This response is again opposite to the direct effect, because the direct effect in the wholesale sector in more-developed regions was significantly positive.

Therefore, I conclude that apart from the public sector, the spillover effects are generally in opposite direction of the direct effect in the region where the shock occurs. This finding 
is both present in less-developed and more-developed regions. Intuitively, this result implies that there is some indication that regional spillovers are supply-driven effects. The increase in production in other regions enhances the competition for production factors, which leads to negative spillovers. This supply-driven effect outweighs the positive demand-side effect from additional demand from other regions. Note that the results for the spillover effects that have just been presented are a selection of all results. However, all results for the spillovers across six sectors can be found in appendix 4.A.4.

To conclude, the regional spillover analysis shows that there is no spillover effect at the regional level. However, I find significant spillovers in some sectors in either more or lessdeveloped regions. In general, the sign of the spillovers is opposite to the direct effect in all sectors, except for the public sector. This finding implies that supply-side effects could explain the regional spillover effects. When one sector in a region is stimulated by EU funds, this creates additional competition for production factors to the same sector in other regions.

Figure 4.9: Regional spillovers for the construction and service sector
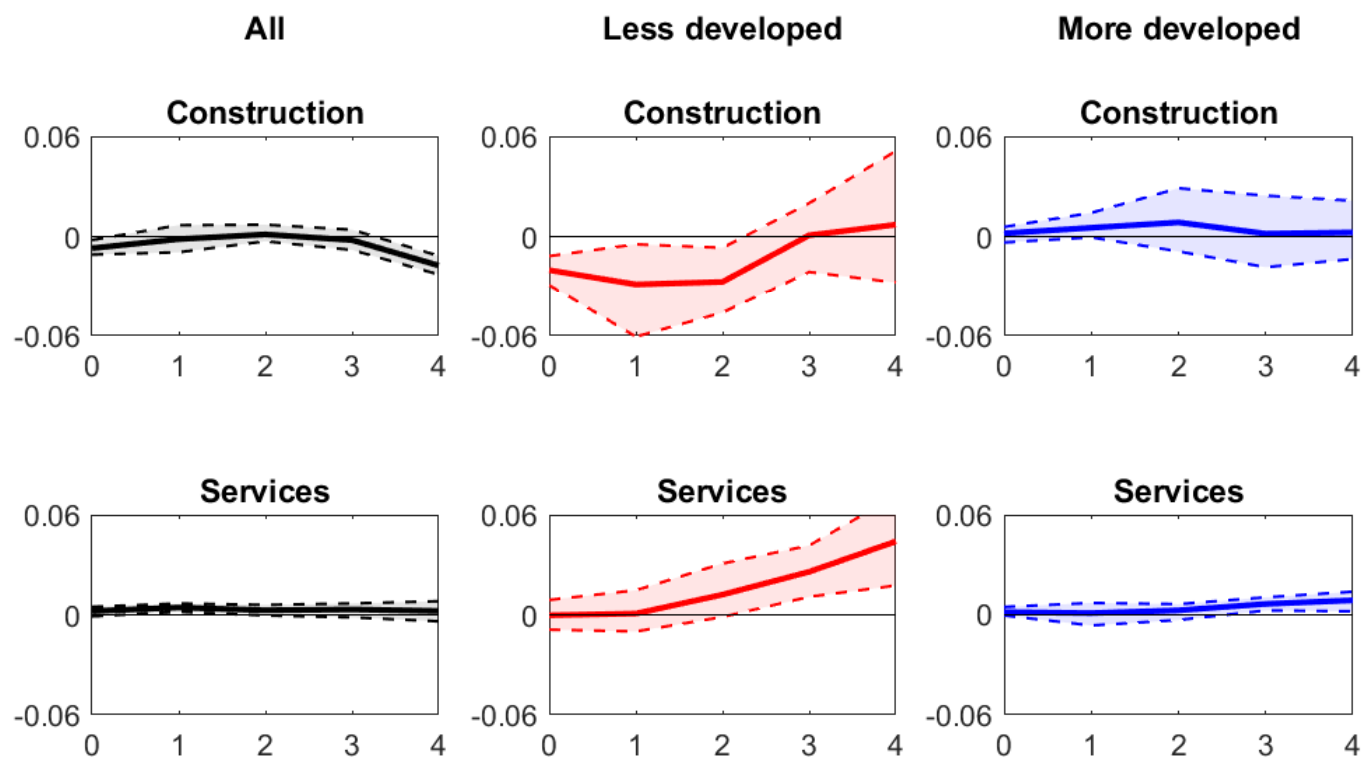

Note: Impulse responses for sectoral production in a region to a shock in structural and investment funds between programming periods in partner regions for all regions (left column), less-developed regions (middle column) and more-developed regions (right ). The bias-corrected point estimates and the bootstrapped $90 \%$ confidence intervals are shown. The underlying regressions include region and year-fixed effects and national control variables. 


\subsection{Conclusion}

This chapter shows that even though in general the effects of EU funds are rather limited, there are several relevant conclusions for policymakers. It is important for them to be aware of possible unintended effects of fiscal policy at the regional or sectoral level. Even though EU Structural and Investment Fund intend to promote long-run economic convergence between regions of member states, there exist apparently sectoral substitution and negative regional spillover effects due to shocks in EU funds between programming periods.

The impulse response functions for sectoral production indicate that there are some direct sectoral substitution effects in more developed regions, induced by a shock in EU funds between programming periods. EU funds stimulate production in the constructing sector, while depressing the service sector and several other sectors. This effect can be explained, because EU funds stimulate production in the construction sector, while other sectors, such as the service sector, experience an increase in competition for their production factors. The results indicate that abundance of production factors is an important driver of the results, because both crowding-out effects and sectoral substitution effects are only found in more-developed regions, where scarcity of production factors plays a dominant role.

Furthermore, this chapter proposes a new way to estimate cross-regional spillover effects. By using intra-EU trade data between regions as weights, the response to 'partner shocks' shows directly the estimate for the spillover effect. In general, the spillover effects are very weak. There seems to be no significant regional spillover effect at the regional level, neither

for less-developed nor for more-developed regions. However, the effects at the sectoral level for the regional spillovers are more interesting. Apart from the public sector, all sectoral responses are in the opposite direction to the direct responses to a shock in the region itself. Therefore, it is likely that the supply channel drives the spillover effects. When EU funds stimulate production in one region, other regions experience an increase competition for production factors.

There are interesting avenues for future research. This chapter finds evidence for a different effect of EU funds between less-developed and more-developed regions. It would 
be interesting to see whether the results are robust to using other estimation methods. Furthermore, the proposed trade-based method for spillovers could be evaluated, by using different measures of proximity. It would be interesting to combine both geographic and other measures of proximity into one approach. Finally, the spillover analysis shows that the spillovers are supply driven. More research is needed to understand which underlying factors drive the spillovers. 


\section{A Appendix}

\section{A.1 Different EU funds}

In the analysis in this chapter, four main EU funds are included. These are the Cohesion Fund (CF), the European Agricultural Fund for Rural Development (EAFRD), the European Regional Development Fund (ERDF) and the European Social Fund (ESF).

Table 4.1: Description of EU funds

\begin{tabular}{lll}
\hline \hline Name & Aim & Eligibility \\
\hline CF & $\begin{array}{l}\text { Trans-EU transportation networks and } \\
\text { environmental projects }\end{array}$ & Less-developed regions ${ }^{29}$ \\
ERDF & $\begin{array}{l}\text { Innovation, digitalization, competitiveness, } \\
\text { and sustainability (low-carbon economy) }\end{array}$ & All regions \\
EAFRD & $\begin{array}{l}\text { Agriculture, natural resources, and } \\
\text { territorial development } 30\end{array}$ & All regions \\
ESF & $\begin{array}{l}\text { Employment, social inclusion, education, and } \\
\text { institutions }\end{array}$ & All regions \\
\hline \hline
\end{tabular}

In 2010, the total amount of funds was 48 billion euro. Figure 4.10 shows the share of the individual funds in the total amount of funds.

Figure 4.10: Relative sizes of EU structural and investment funds in 2010.

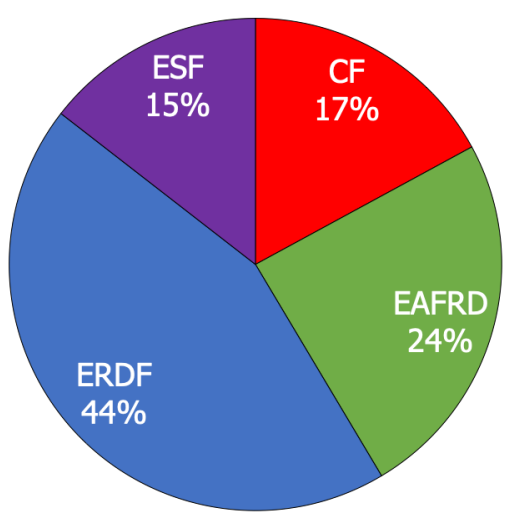


Figure 4.11 plots the sum of the EU funds funds to all regions over time. All funds are increasing over time and throughout the programming periods (indicated with dashed vertical lines). The main results in this chapter are shown for the sum of all funds, because some regions do not receive all funds.

Figure 4.11: EU structural and investment funds over time

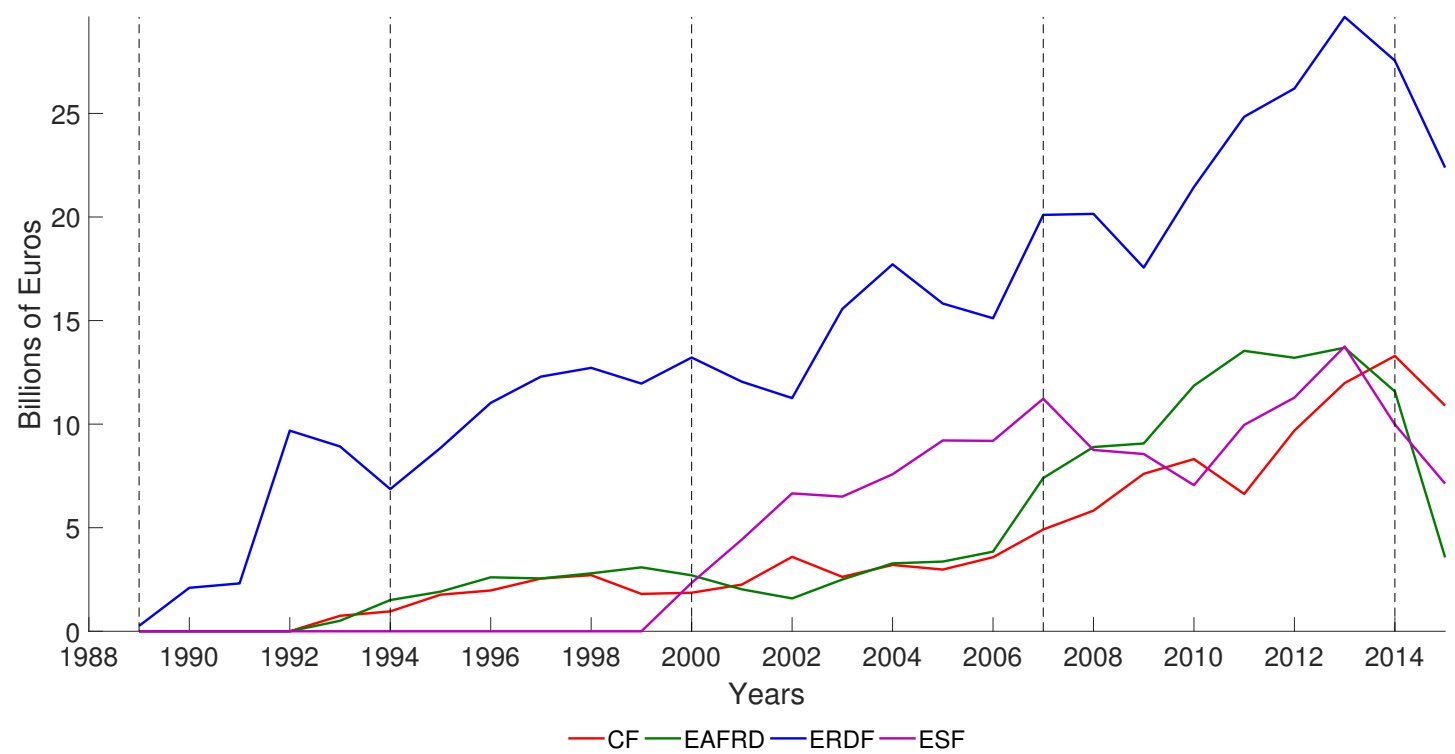

Note: The sum of EU structural and investment funds to all regions over time. The dashed vertical lines mark the beginning of a new programming period for the EU. 


\section{A.2 Data description}

The following table provides information on the source and unit of measurement for the variables used in this chapter.

Table 4.2: Data description

\begin{tabular}{lll}
\hline \hline Variable & Source & Unit of measurement \\
\hline Regional EU funds & European Commission & Euros in real per capita \\
Regional production & Cambridge Econometrics & Euros in real per capita \\
Regional employment & Cambridge Econometrics & Number of workers in real per capita \\
Regional population & Cambridge Econometrics & Number of inhabitants \\
National GDP & AMECO Database & Real per capita index \\
National unemployment & AMECO Database & Per cent of active population \\
National inflation & AMECO Database & GDP deflator index \\
Intra EU trade & Thissen et al. (2017) & Millions of Euros \\
\hline \hline
\end{tabular}

Figure 4.12 shows the NUTS-2 regions in Europe according to the development classification that the European Commission uses for the period 2014-2020 in the allocation of structural funds (ERDF and ESF). The EU classifies regions as more developed regions (GDP per capita $\geq 90 \%$ of EU average), transition regions (GDP per capita between 75 and $90 \%$ of EU average), and less-developed regions (GDP per capita $\leq 75 \%$ of EU average)

Figure 4.12: Development levels of NUTS-2 regions in the EU

(a)

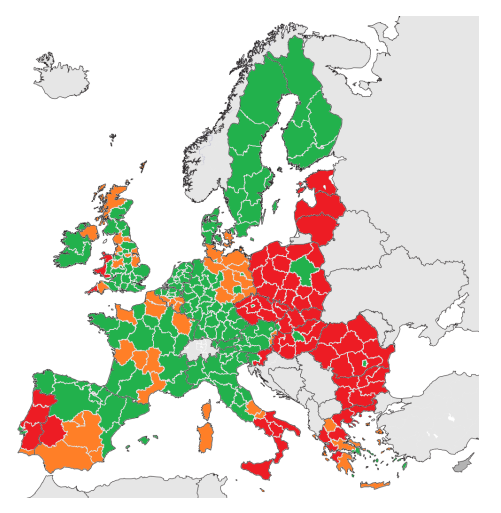

(b)

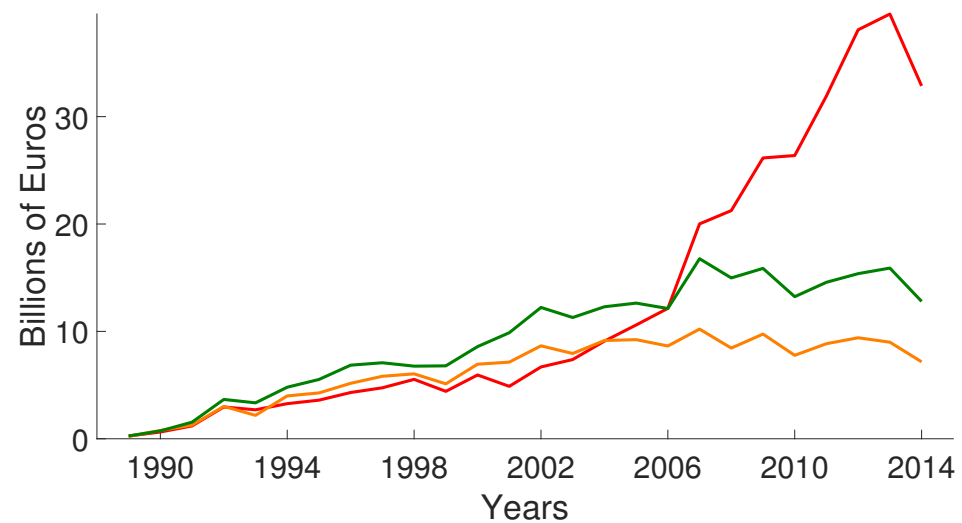

Note: Green regions are 'more developed', orange regions are in 'transition' and red regions are 'less developed'. The graph in (b) shows the total nominal amount of EU funds over time for the different classifications. 


\section{A.3 Results sectoral responses}

Figure 4.13: Direct effects within and between programming periods

Within Programming Period
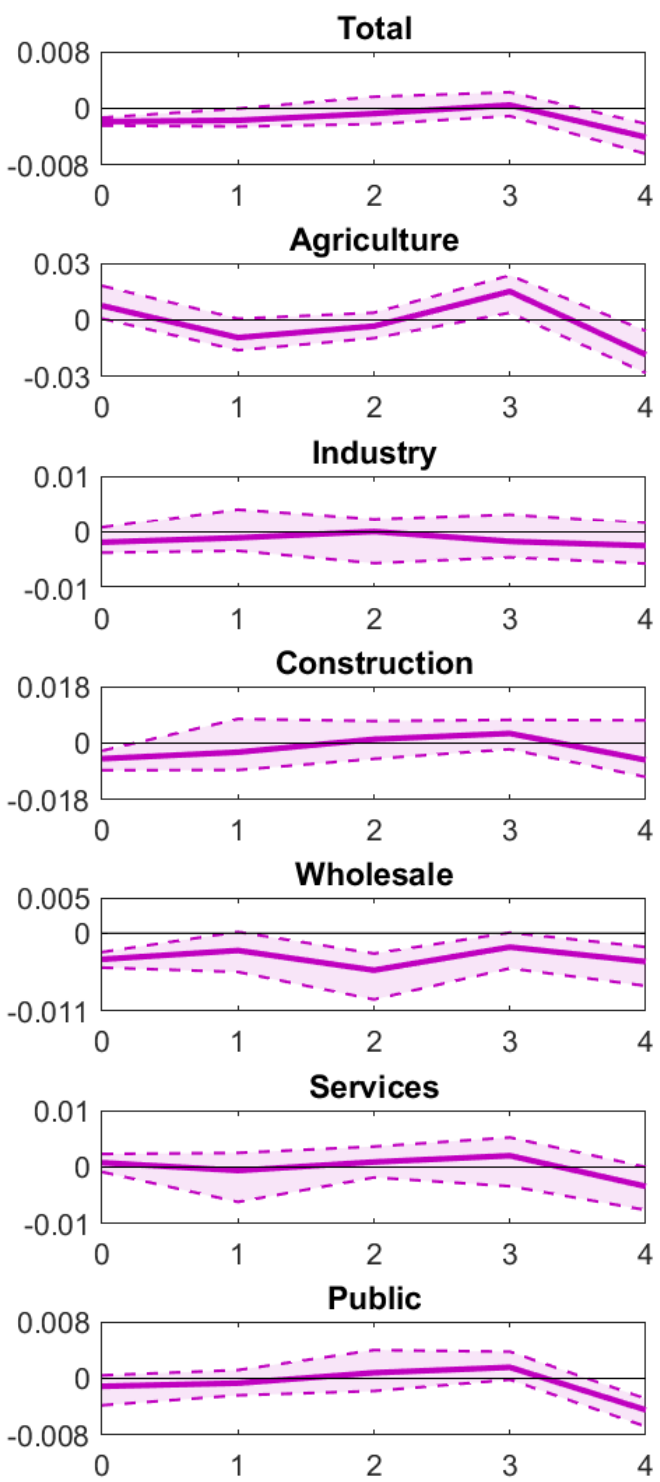

Between Programming Periods
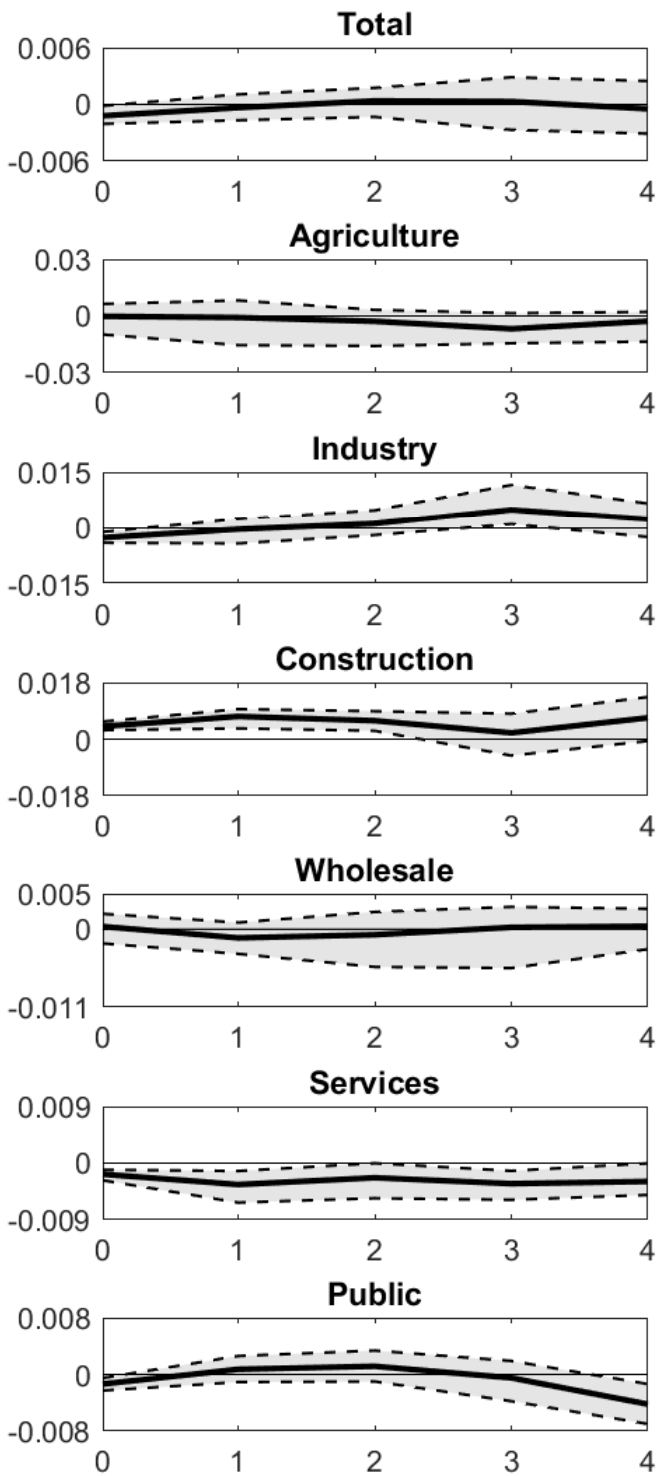

Note: The bias-corrected point estimates and the bootstrapped $90 \%$ confidence intervals for the impulse responses are shown. The underlying regressions include region and year-fixed effects and national control variables. 
Figure 4.14: Direct effects within a programming period for development levels
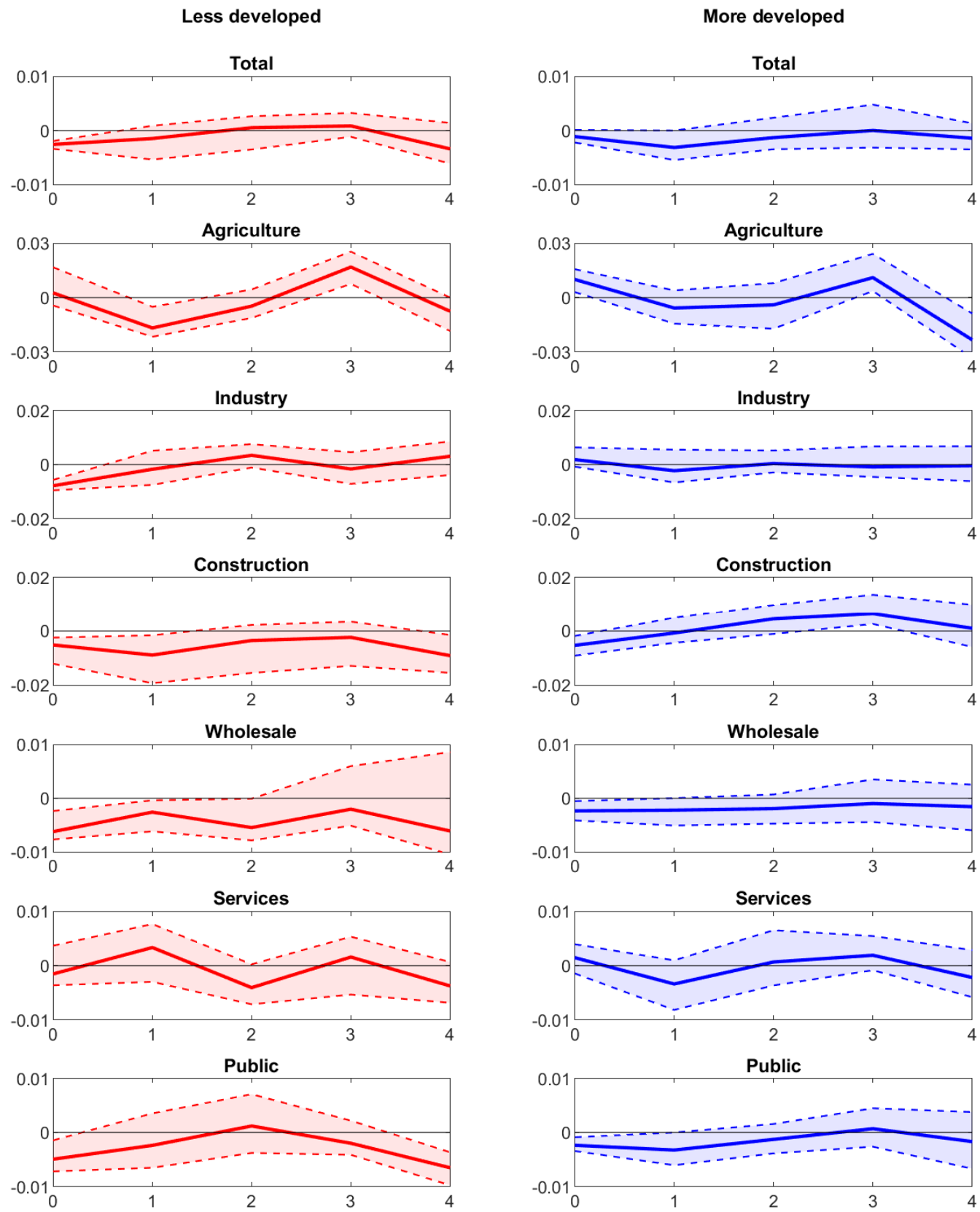

Note: The bias-corrected point estimates and the bootstrapped $90 \%$ confidence intervals for the impulse responses are shown. The bias-corrected point estimates and the bootstrapped $90 \%$ confidence intervals are shown. The underlying regressions include region and year-fixed effects and national control variables. 
Figure 4.15: Direct effects between programming periods for development levels
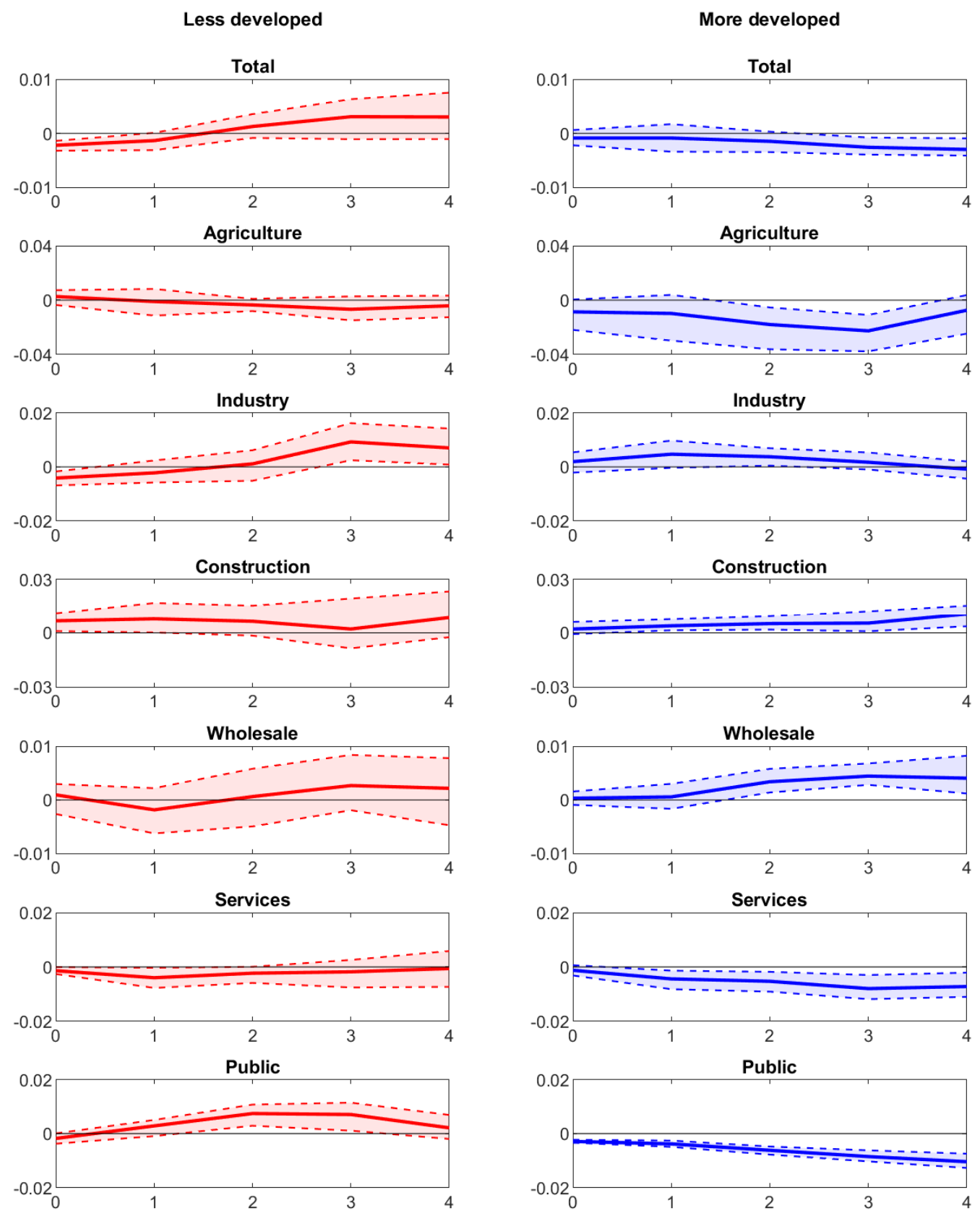

Note: The bias-corrected point estimates and the bootstrapped $90 \%$ confidence intervals for the impulse responses are shown. The bias-corrected point estimates and the bootstrapped $90 \%$ confidence intervals are shown. The underlying regressions include region and year-fixed effects and national control variables. 


\section{A.4 Results regional spillovers}

Figure 4.16: Spillover effects within and between programming periods

Within Programming Period

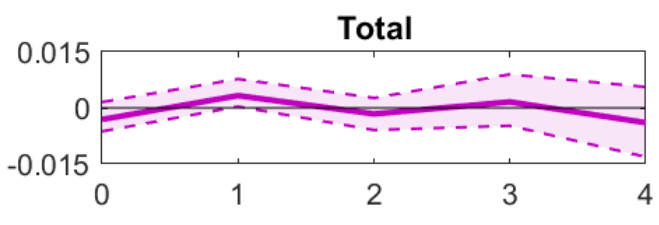

\section{$0.1 \quad$ Agriculture}

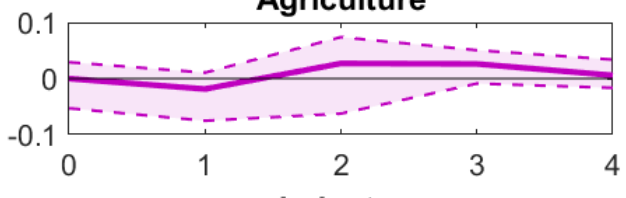

Industry
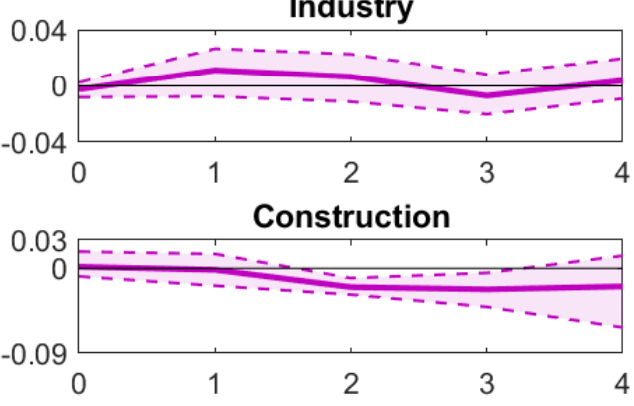

Wholesale
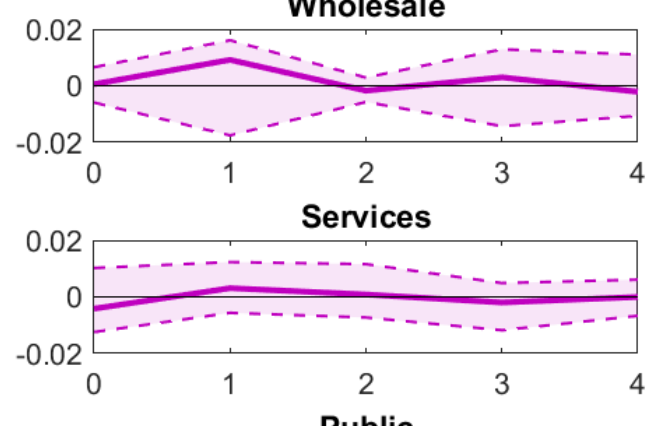

Public

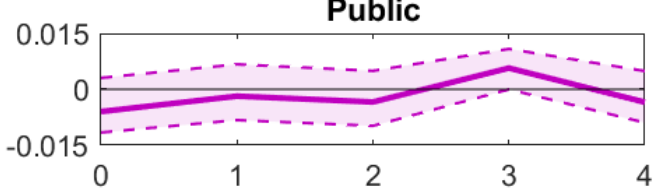

Between Programming Periods
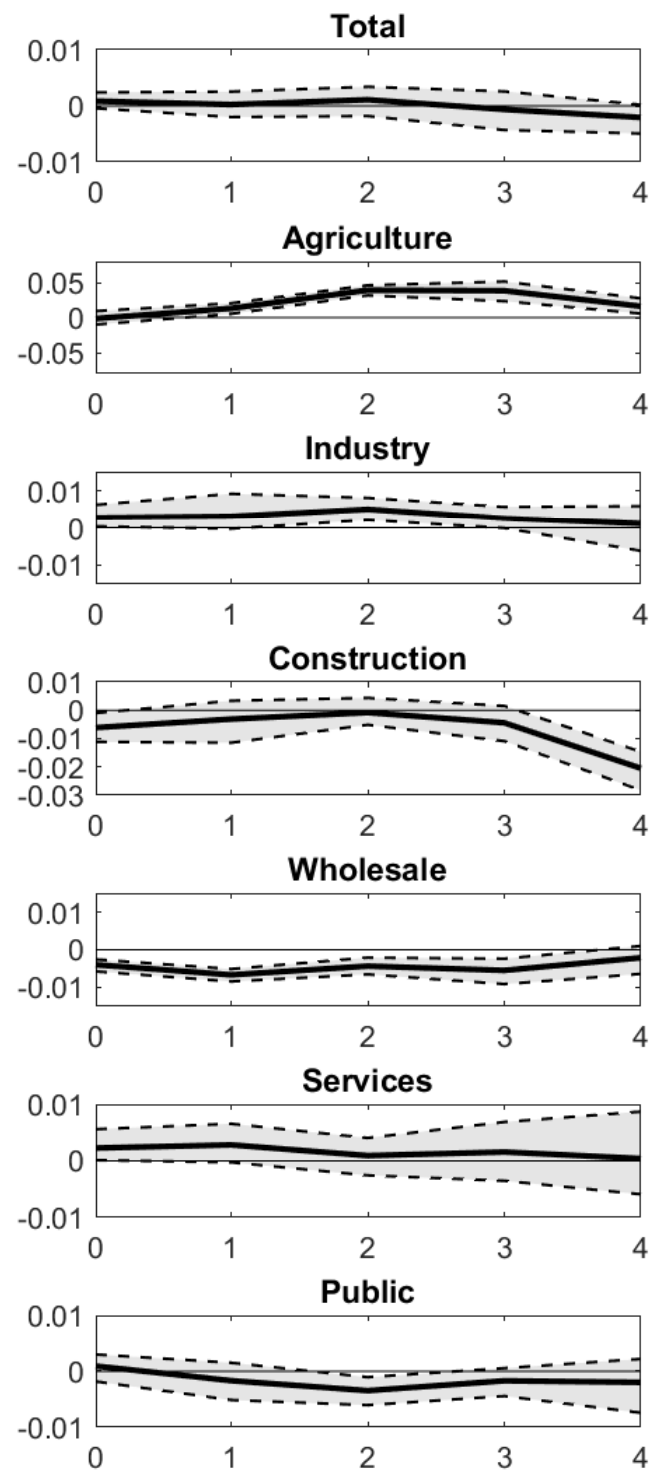

Note: The bias-corrected point estimates and the bootstrapped $90 \%$ confidence intervals for the impulse responses are shown. The underlying regressions include region and year-fixed effects and national control variables. 
Figure 4.17: Spillover effects within a programming period for development levels
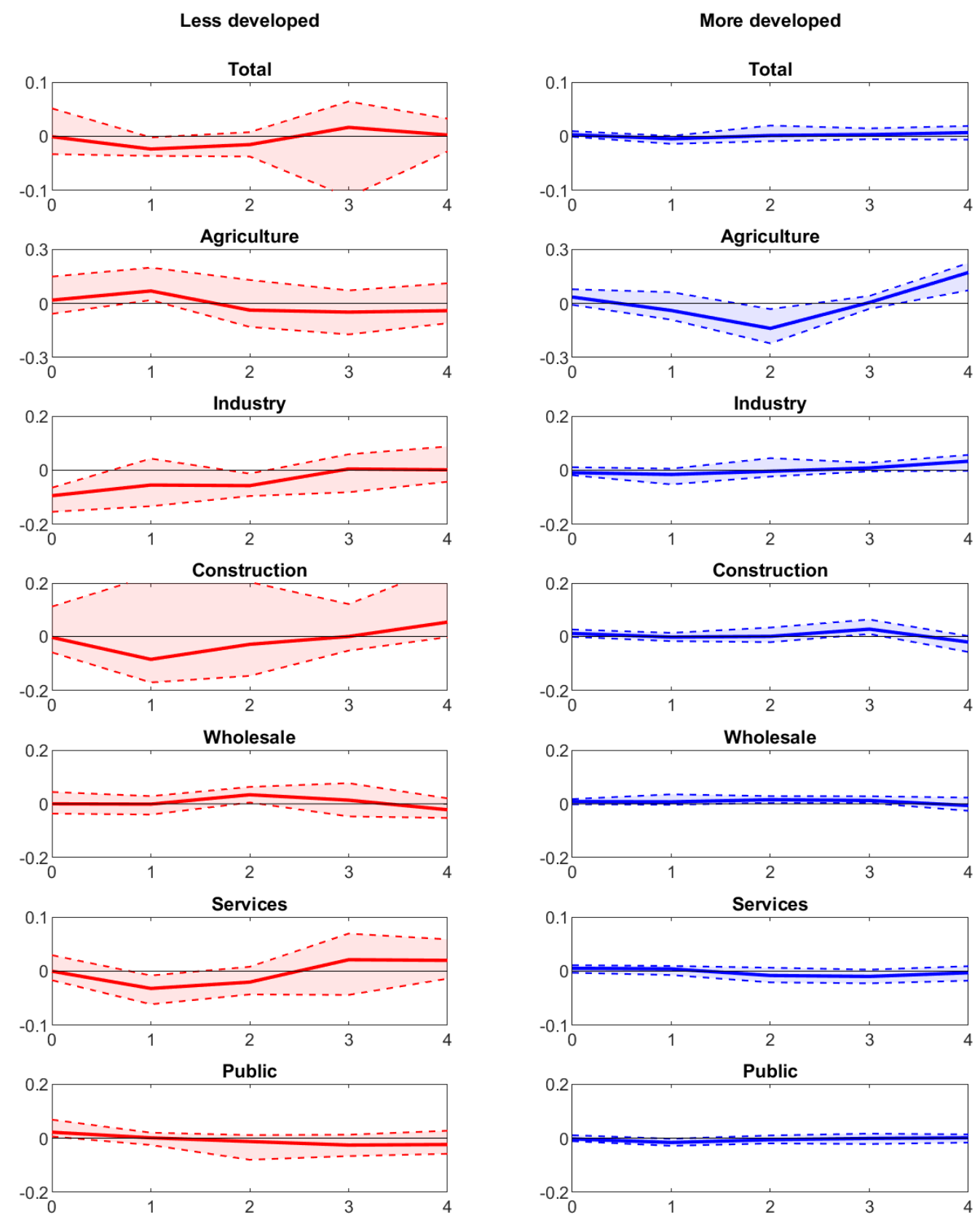

Note: The bias-corrected point estimates and the bootstrapped $90 \%$ confidence intervals for the impulse responses are shown. The underlying regressions include region and year-fixed effects and national control variables. 
Figure 4.18: Spillover effects between programming periods for development levels
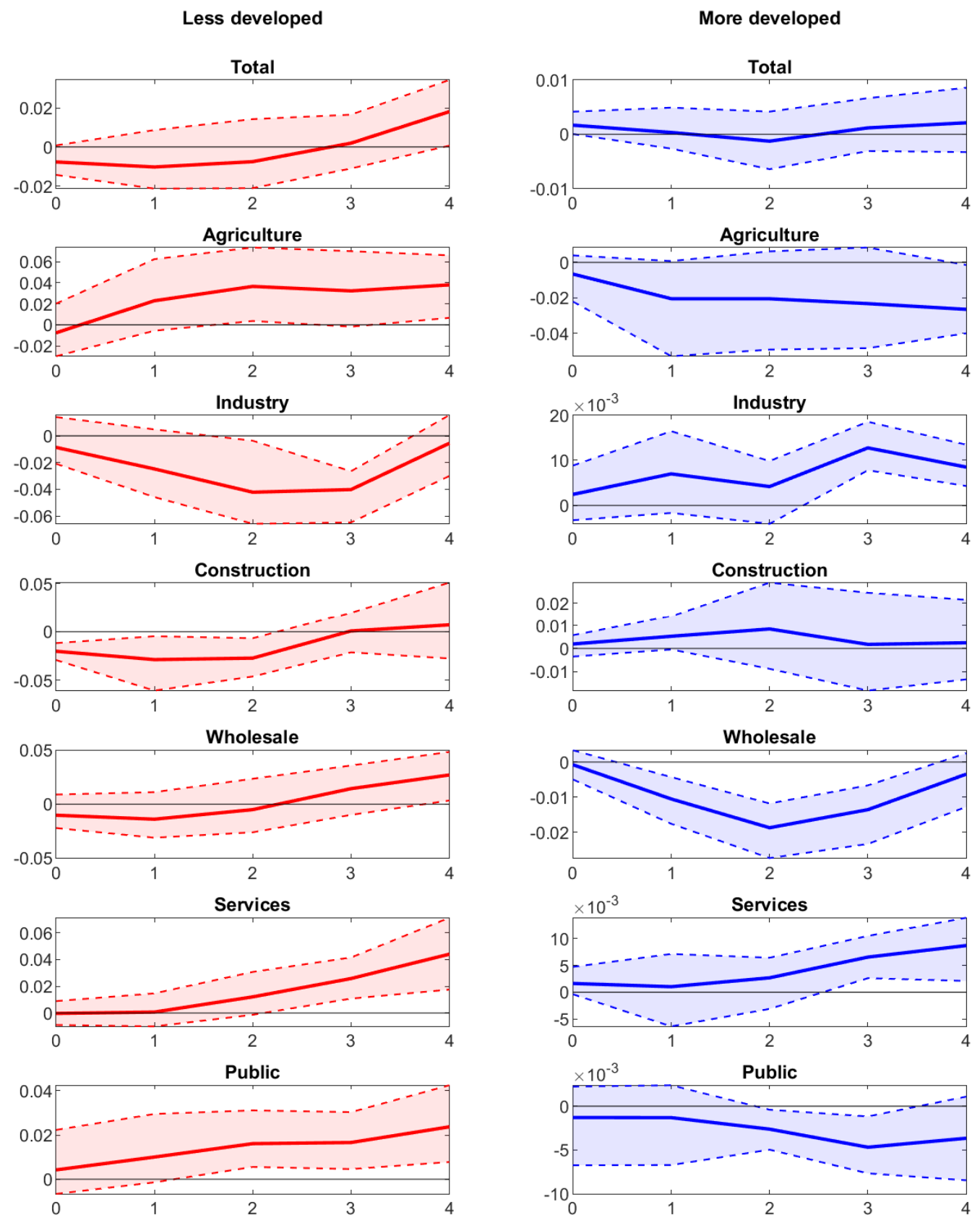

Note: The bias-corrected point estimates and the bootstrapped $90 \%$ confidence intervals for the impulse responses are shown. The underlying regressions include region and year-fixed effects and national control variables. 


\section{A.5 Results employment}

Figure 4.19: Direct effects within and between programming periods for employment
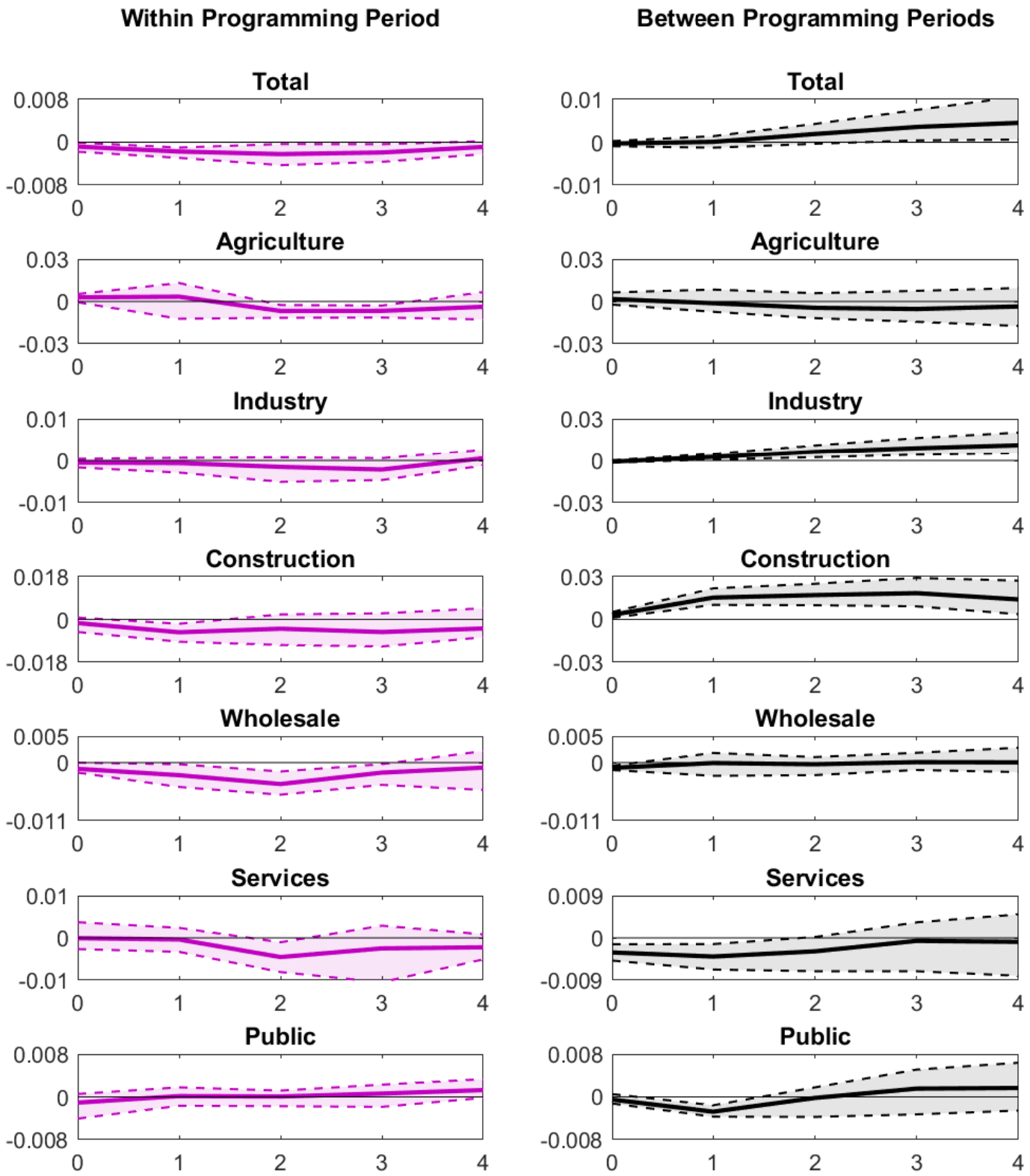

Note: The bias-corrected point estimates and the bootstrapped $90 \%$ confidence intervals for the impulse responses are shown. The underlying regressions include region and year-fixed effects and national control variables. 
Figure 4.20: Spillover effects within and between programming periods for employment

\section{Within Programming Period}
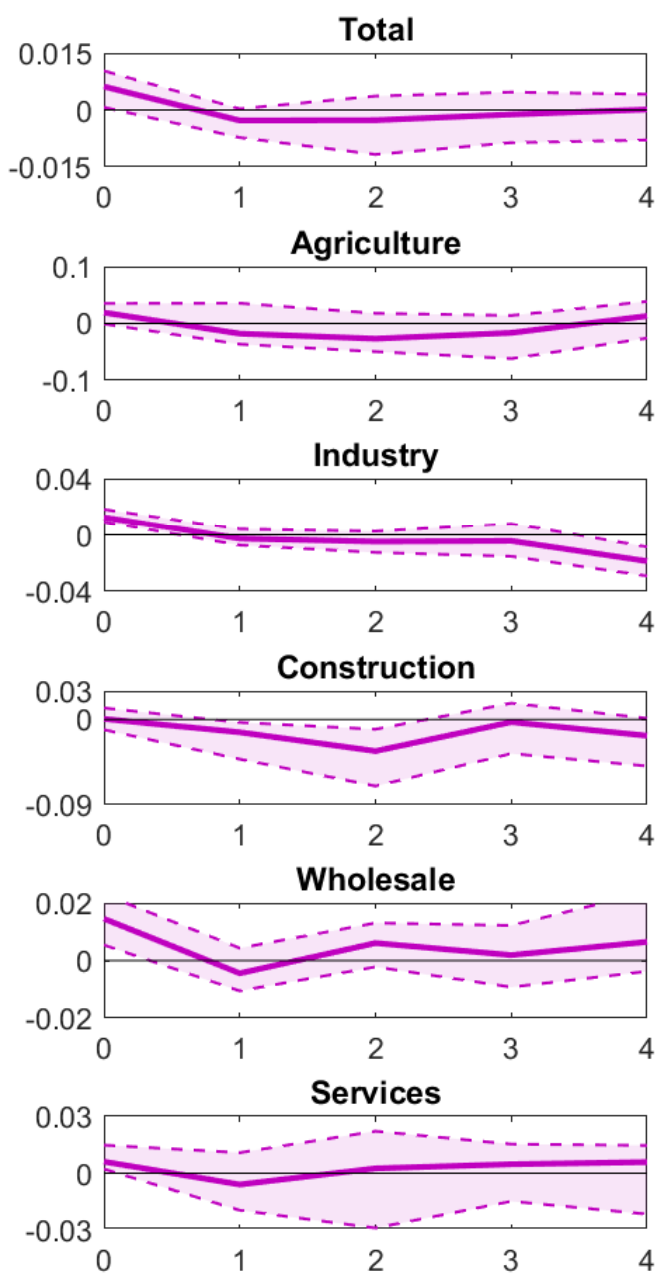

Public

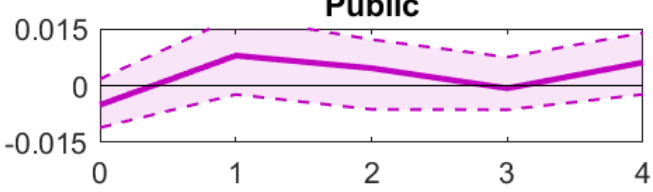

Between Programming Periods
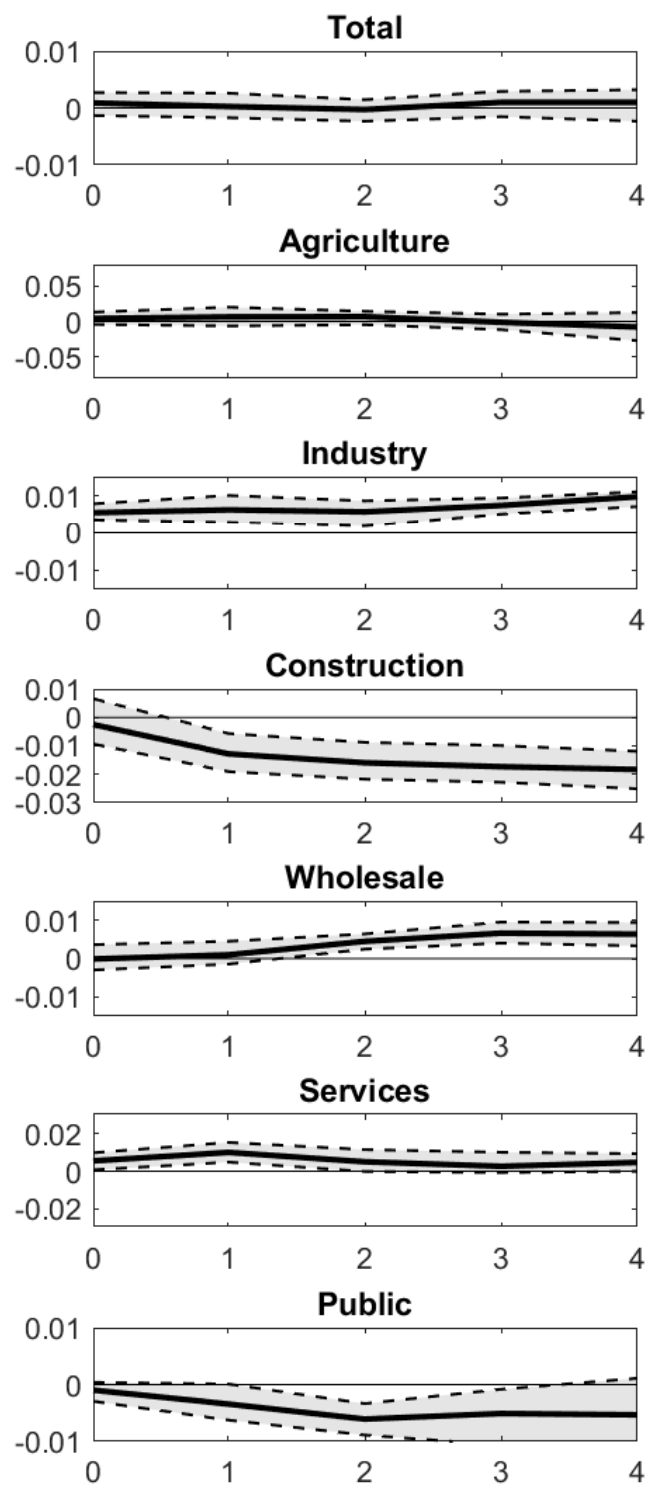

Note: The bias-corrected point estimates and the bootstrapped $90 \%$ confidence intervals for the impulse responses are shown. The underlying regressions include region and year-fixed effects and national control variables. 
4.A. APPENDIX 


\section{Chapter 5}

\section{Conclusion}

This chapter provides an overall conclusion of the thesis. More detailed conclusions can be found in each of the main chapters. In this conclusion, I first discuss the main contributions of the chapters of the thesis and the implications for policymakers and researchers. Then, I reflect on the strengths and weaknesses of the approach taken in the chapters of the thesis. Finally, I discuss some directions for future research. 


\subsection{Contributions and implications}

This thesis analyzes the short run macroeconomic effects of government spending. Each of the chapters discusses one specific underlying factor that plays a role in the macroeconomic consequences of government spending. It is important both to identify the underlying factors, and to understand how these exactly influence the way government spending affects the macro-economy.

Chapter 2 provides insight into the role of the anticipation horizon in the transmission of government spending news shocks. Although the importance of anticipation effects of fiscal policy is widely recognized in the literature, the aspect of the anticipation horizon has not received much attention. The empirical findings from this chapter however point out that the anticipation horizon plays an important role in the transmission of government spending news shocks. We find very distinct responses of private consumption and investment to government spending news shocks with longer versus shorter anticipation horizons. Only news shocks with long anticipation horizons have a significant positive effect on both private consumption and investment, while news shocks with short anticipation horizons crowd out private consumption and investment. These findings suggest that longer anticipation horizons enhance the role of expectations in agents' reactions to policy changes. Policymakers should therefore take the anticipation horizon into account when using fiscal policy as a forward guidance tool. If the aim is to provide an economic stimulus, then agents should have sufficient time to anticipate on the policy changes for the stimulus to be effective. Furthermore, research into the macroeconomic effects of government spending news should take into account the effect of the anticipation horizon more explicitly. Apparently, when fiscal news shocks with short anticipation horizons dominate in the empirical analysis, then the fiscal multiplier will be underestimated.

Chapter 3 studies the effects of different categories of government spending. The main focus of the chapter is on defense versus non-defense spending. It is usually difficult to compare the effects of categories of government spending, because a separate external instrument has to be found for every spending category. The advantage of the methodology in 
this chapter is that exogenous shocks can be estimated for every category of federal spending. It seems that these shocks explain the variation in government spending better than existing external instruments. The findings from this chapter indicate that it is crucial for policymakers to take the specific category of spending into account that is used for a spending stimulus. It appears that defense spending creates significantly lower fiscal multipliers over time than non-defense spending, which can be explained using arguments from the related literature. The result is important for policymakers designing a fiscal stimulus package, since these packages often involve multiple spending categories. Moreover, academic research on the macroeconomic effects of fiscal policy should more explicitly take into account which category of government spending is used in the analysis. Studies that focus only on defense spending when estimating fiscal multipliers typically underestimate the total multiplier of government spending. Of course, this also holds for the multipliers estimated in chapter 2 .

Chapter 4 analyzes the effect of government spending shocks on specific sectors and across regions, with a specific application to EU Structural and Investment Funds. Just like for many other government spending programs, the sectoral effects and regional spillovers are often overlooked. The findings from this chapter indicate however that there can be substitution effects between sectors, but these only occur in more-developed regions. It is important for policymakers to take into account that even if there are positive overall effects, some sectors might still be negatively affected due to increased competition for production factors. Moreover, the findings suggest that it is necessary for policymakers to take into account regional spillover effects when deciding on policies that aim to stimulate specific regional economies. Even though the region that receives the stimulus might be positively affected, other regions can still experience negative supply-side driven spillovers. Academic research into the effects of government spending should pay more attention to possible effects across sectors and regions, to avoid misleading policy evaluations. The approach from this chapter could be used in more applications to study the sectoral and regional effects of government spending. 


\subsection{Strengths and weaknesses}

This thesis has shown that there are several aspects to take into account when empirically evaluating the short term effects of government spending. The conclusions point out that not taking into account these aspects might lead to misleading conclusions. Of course, there are many more underlying factors that play a role in the way government spending affects the macro-economy. It therefore remains difficult to make general claims on the effectiveness of government spending, both from a theoretical and empirical point of view.

In any empirical analysis, there might be specific conditions that weaken the external validity of the conclusions. As Nakamura and Steinsson (2018) point out, this external validity problem exists in virtually all macroeconomic research. If I take this thesis as an example, all chapters focus on types of government spending that are in some way specific for a particular country or group of countries. Chapters 2 and 3 use data on defense spending in the US. It is questionable to what extent general conclusions about changes to defense spending or defense spending news are also valid for other countries. In most other developed countries, military spending is much smaller both in absolute and relative terms, which implies that the interaction with the rest of the economy is probably less important, and therefore the impact on the economy might be smaller. Similarly, it is unclear to what extent the conclusions in chapter 4 based on an empirical study into the effects of EU Structural and Investment funds are also valid outside the EU. For instance, federal grants to states in the US are of a completely different nature. Grants to state governments are more shortterm oriented, because these contain contain mostly low-income support programs. Instead, EU funds support specific activities that promote long term growth, such as infrastructure projects and subsidies for innovative activities. Cross-country studies can help to make the research less sensitive to country-specific conditions, but that still does not solve the external validity problem completely.

Likewise, in theoretical studies that investigate the macroeconomic effects of government spending, the external validity can become problematic as well. The reason is that for the calibration of theoretical models, parameters from empirical analysis are used. But as just 
pointed out, these parameters might be based on studies that are only applicable under specific circumstances. It is therefore also in theoretical studies important to be aware of the underlying factors that might influence the short-term consequences of government spending. If a calibration study aims at providing general claims on the effectiveness of spending programs, then using bandwidths around parameters could be a solution.

Another problem that is encountered in this thesis is the endogeneity problem of government spending. Since government spending is inherently endogenous to macroeconomic variables like GDP, it is necessary in empirical studies to identify the exogenous variation in government spending. This exogenous variation is usually referred to as a government spending shock. In all chapters from this thesis, exogenous government spending shocks are identified. In chapter 2 government spending news shocks are identified using external information from a narrative in a time series analysis, while in chapters 3 and 4 shocks are identified internally by using the cross-sectional variation in a panel data set-up. When identifying government spending shocks, similar conditions as for instrumental variables (IV) estimation should be satisfied.

First of all, the shocks should be relevant, which means that the shocks should explain the variation in government spending reasonably well. This condition can be checked for all government spending shocks. As discussed in chapter 3, it seems that the estimated government spending shocks explain variation in federal government spending better han external instruments used in the existing literature. Secondly, the shocks should not suffer from the same endogeneity problem as the original government spending variable. This condition is often called the exclusion restriction in IV. However, this restriction is untestable. The exogeneity of the government spending shocks cannot be tested formally, because this would require estimating the correlation with the unobserved exogenous variation in macroeconomic variables ${ }^{1}$ It is important to notice that the exogeneity of the government spending shocks does not depend on the model or data used, but on the underlying argumentation. The exogeneity claim should be credible. For example, in chapter 2, the exogenous govern-

\footnotetext{
${ }^{1}$ Formally, in an IV set-up, the exclusion restriction requires that the instrument is uncorrelated to the errors in the second stage. These errors are unobserved.
} 
ment spending news shocks are based on the narrative by Ramey (2011). This narrative has been constructed very carefully to ensure that only news related to exogenous changes in defense spending is included. Also, the claim in chapters 3 and 4 that exogenous regional fiscal shocks can be identified by using the cross-sectional variation in fiscal grants to lowerlevel governments is formally not testable. The exogeneity claim relies fully on the argument that it is plausible that changes in central government spending at the level of the state or region is unaffected by the local economic conditions. In the empirical literature, this aspect deserves more attention.

\subsection{Future research}

There are many possible areas research for future research into the short-term macroeconomic consequences of government spending. As discussed before, it is important to identify more underlying factors that play a role in the way government spending affects the macro-economy. Knowing about these factors is both important in empirical studies and in theoretical studies, to avoid misleading general conclusions, and to improve the quality of policy evaluations.

There are many factors that could be explored further, such as the persistence of fiscal shocks, the interplay between fiscal and monetary policy and the role of government debt. But is also worth to explore the factors that are studied in this thesis even further. For example, the anticipation horizon in chapter 2 has only been analyzed to the extent of the inside lag, but it would also be interesting to analyze the role of the outside lag. The outside lag has been studied extensively for taxation, for example by Mertens and Ravn (2012), but not for spending. It should be noted that in the defense spending application in chapter 2 , the outside lag does not play an important role. But there could be other spending categories where it does play a role. It would therefore be interesting to see how the interaction of the category of spending and the anticipation horizon affects the macroeconomic consequences of government spending.

In fact, there is much more to explore with regard to categories of spending as analyzed 
in chapter 3. Defense spending has gained a lot of attention in the literature, but there are more categories of spending to consider in more detail. The argument has often been that defense spending is the 'most exogenous' category of government spending, because it reacts to foreign political events. There are definitely more external events that trigger specific parts of government spending. For example, the recent Covid-19 pandemic has shown that governments all over the world were forced to increase spending. In fact there are many external events that one could think of, which trigger a specific category of government spending. It is therefore promising that recently, empirical research is focusing on other categories such as infrastructure spending (Ramey, 2020). In line with the recent Covid19 pandemic, I would recommend to study even more categories of spending, including social security payments and business support, while ensuring that the effectiveness can be compared across categories and countries. Cross-country event studies could also be in an interesting avenue for future research.

Understanding the impact of the underlying factors can help to provide a clearer and more complete picture of the macroeconomic effects of government spending. The underlying factors that are analyzed in academic research should therefore also be taken into account in policy evaluations. Nevertheless, more research is needed both from a theoretical and empirical point of view to understand why the factors are important. For example, chapter 2 shows that government spending news only has expansionary effects when the anticipation horizon is sufficiently long. It remains however difficult to explain what exactly drives this effect. Future research could focus on trying to understand more about how agents form expectations based on government spending news. Similarly, there is much unknown about the exact transmission of government spending shocks in the economy. The conclusions in chapter 3 and 4 point out that interactions between agents on the 'receiving side' of spending are very important. It would be interesting to use a network analysis to study how government spending transmits from the direct receivers of spending, such as government contractors, to the rest of the economy. Understanding more about these connections helps to predict better possible spillover effects between sectors and sub-national regions. 
5.3. FUTURE RESEARCH 


\section{Valorisation addendum}


Nowadays, it is obvious that the government plays an important role in the economy. Not only is the government heavily involved in the provision of public goods and income redistribution, it also provides society with an insurance against economic downturns through anti-cyclical fiscal policy. It remains however important to investigate whether the positive effects of short-term anti-cyclical policy outweigh the possible negative effects, and whether no unintended 'side' effects occur. It makes sense that macro-economists pay close attention to the functioning of the government, not only in the long run, but also in the short run. Since the main macroeconomic theories disagree about the income effects of government spending in the short-run, empirical research is necessary. The findings from empirical research can help policymakers to make the right decisions, when the aim is to stimulate the economy during an economic slowdown or a recession. The main findings in this thesis can be regarded as examples of practical advise from empirical research for policymakers.

The problem for empirical research is that government spending and other macroeconomic variables are simultaneously affected by the same external factors. Anti-cyclical spending packages are usually initiated in an economic downturn. This implies that policymakers endogenously react to external economic factors, which creates two-way causality. Government spending is an endogenous variable in the system of macroeconomic variables, and it is therefore difficult to estimate causal effects of changes in government spending. This thesis uses econometric techniques to identify the exogenous part of government spending. The exogenous part is the component of government spending that does not react endogenously to movements in the business cycle. The aim of this thesis is to provide an empirical investigation into the underlying factors that play a role in the short-term macroeconomic consequences of government spending. Three factors are analyzed: the anticipation horizon, categories of spending and the determinants of sectoral and regional spillover effects.

Jointly, the chapters from this thesis do not only provide methodological guidance how to assess several underlying factors for government spending, but the results also provide policymakers with practical guidance. Chapter 2 shows that the effect of government spending news depends on the length of the anticipation horizon. This finding is relevant for 
both policymakers and academics. It appears that for news about policy changes where the anticipation horizon is longer, more positive effects are found than for news with a short anticipation horizon. This result implies that when policymakers want to provide an economic stimulus, the anticipation horizon should be sufficiently long for economic agents to anticipate on the policy change. Since the financial crisis in 2008, there is renewed interest from policymakers into the effectiveness of fiscal stimulus packages, because of the low interest rate. The empirical results indicate that a stimulus that involves a sudden change in policy does probably more harm than good. But this result also shows that academic research should take into account more explicitly the role of the anticipation horizon in models.

Chapter 3 proposes a novel methodology to study the effects of government spending at sub-national regions or states. The method relies on the notion that part of the spending allocated to regions is allocated independently of the regional economic conditions. With this method, it is possible to isolate the exogenous part of spending at the regional level. In chapter 3, it is shown that this method can even be applied to different categories of spending. The main advantage of this method is that it allows to compare different categories of spending in a unified framework, which does not depend on specific instruments or proxies that have to be identified for all categories. The method can be useful for future studies that want to predict or evaluate the effects of different government spending categories.

Comparing the effectiveness of different government spending categories is very important for policymakers. It is necessary to decide on the right policy mix in a fiscal stimulus package during economic downturns. According to the findings in chapter 3, defense spending results in smaller positive economic effects than the same increase in non-defense spending. In practice this means that increasing defense spending in economic downturns to stimulate the economy has less effect than increasing other categories of spending. Furthermore, empirical research into the effectiveness of government spending that only uses defense spending, typically underestimates the true effect of government spending. This is a valid concern, because defense spending is often used in empirical macroeconomic literature, since it is regarded as one of the most exogenous categories of spending. The results in chapter 3 however indicate 
that only focusing on defense spending leads to a misleading calculation of the multiplier effect of government spending.

Many empirical studies that investigate the role of government spending use data from the US. One should however be careful when trying to extrapolate these results to other countries. There can be a serious external validity problem, because several underlying factors are different in the US than in other countries. For example, the role of defense spending in the US economy is much larger than in many other developed countries. Therefore, it is important to apply methods that have been used for US data also for other countries, and to provide cross-country studies whenever applicable. This is of course not always possible, because the methods are not always suitable for applications in other countries. Fortunately, the method developed in chapter 3 can be applied in other countries. In chapter 4 this method is applied to EU Structural and Investment Funds. The results show that the economic effects of these funds are quite limited, but there are several unintended policy consequences, such as negative effects in some sectors, and regional spillover effects. Policymakers should be aware of these unintended consequences that play a role in the short run. For example, the results indicate that in developed regions, an increase in EU funds stimulates the construction sector, while the service sector experiences a negative effect. Moreover, in academic research, more attention should be paid to sectoral effects, and regional spillovers, because it seems that interactions between economic agents on the 'receiving side' of spending are important.

The conclusions from this thesis are relevant for policymakers, and for academic and non-academic researchers. Especially if the research is used for policy recommendations or evaluations. It is important to understand the underlying factors that play a role in the shortterm macroeconomic consequences of government spending. Ignoring these factors possibly causes misleading policy recommendations or evaluations, which can have severe economic effects on specific parts of the economy and the macro economy as a whole. It is therefore crucial that results of academic research about the effectiveness of government spending are clearly communicated, also on non-academic platforms, to reach a wide audience. With this thesis, I have contributed to this debate, but definitely more research should be done. 


\section{Bibliography}

Acemoglu, D., Carvalho, V., Ozdaglar, A., and Tahbaz-Salehi, A. (2012). The network origins of aggregate fluctuations. Econometrica, 80 (5):1977 - 2016.

Adelino, M., Cunha, I., and Ferreira, M. (2017). The economic effects of public financing: Evidence from municipal bond ratings. The Review of Financial Studies, 20 (9):3223 3268.

Aiyagari, R., Christiano, L., and Eichenbaum, M. (1992). Output, employment and interest rate effects of government consumption. Journal of Monetary Economics, 30:73 - 86.

Alesina, A., Barbiero, O., Favero, C., Giavazzi, F., and Paradisi, M. (2017). The effects of fiscal consolidations: theory and evidence. NBER Working Paper, No. 23385.

Alesina, A., Favero, C., and Giavazzi, F. (2018). What do we know about the effects of austerity? Working Paper, Harvard University.

Auclert, A., Rognlie, M., and Straub, L. (2018). The intertemporal Keynesian cross. NBER Working Paper, No. 25020.

Auerbach, A., Gorodnichenko, J., and Murphy, D. (2019). Local fiscal multipliers and fiscal spillovers in the United States. NBER Working Paper, 25457.

Barro, R. and Redlick, C. (2011). Macroeconomic effects from government purchases and taxes. Quarterly Journal of Economics, 126:51 - 102. 
Barsky, R. and Sims, E. (2011). News shocks and business cycles. Journal of Monetary Economics, 58:273-289.

Bartik, T. (1991). Who Benefits from State and Local Economic Development Policies?. W.E. Upjohn Institute for Employment Research, Michigan.

Basile, R., Capello, R., and Caragliu, A. (2012). Technological interdependence and regional growth in Europe: Proximity and synergy in knowledge spillovers. Regional Science, 91 (4):697- 722 .

Baxter, M. and King, R. (1993). Fiscal policy in general equilibrium. The American Economic Review, 83 (3):315-334.

Beaudry, P. and Portier, F. (2006). Stock prices, news and economic fluctuations. The American Economic Review, 96 (4):1293-1307.

Beaudry, P. and Portier, F. (2014). News-driven business cycles: Insights and challenges. Journal of Economic Literature, 52 (4):993-1074.

Becker, S., Egger, P., and Von Ehrlich, M. (2010). Going NUTS: The effect of EU structural funds on regional performance. Journal of Public Economics, 94:578 - 590.

Becker, S., Egger, P., and Von Ehrlich, M. (2012). Too much of a good thing? On the growth effects of the EUs regional policy. European Economic Review, 56:648 - 668.

Becker, S., Egger, P., and Von Ehrlich, M. (2018). Effects of EU regional policy: 1989-2013. regional science and urban economic. Regional Science and Urban Economics, 69:143152.

Belloni, A. and Chernozhukov, V. (2013). Least squares after model selection in highdimensional sparse models. Bernoulli, 19 (2):521-547.

Ben Zeev, N. and Pappa, E. (2017). Chronicle of a war foretold: The macroeconomic effects of anticipated defence spending shocks. The Economic Journal, 127:1-30. 
Bénétrix, A. and Lane, P. (2010). Fiscal shocks and the sectoral composition of output. Open Economic Review, 21:335 - 350.

Biolsi, C. (2015). Local effects of a military spending shock: Evidence from shipbuilding in the 1930s. Working Paper, University of Houston.

Blanchard, O. and Perotti, R. (2002). An empirical characterization of the dynamic effects of changes in government spending and taxes on output. Quarterly Journal of Economics, 117 (4):1329-1368.

Chernozhukov, V., Chetverikov, D., Demirer, M., Duflo, E., Hansen, C., Newey, W., and Robins, J. (2018). Double/debiased machine learning for treatment and structural parameters. The Econometrics Journal, 21:C1-C68.

Chodorow-Reich, G. (2019). Geographic cross-sectional fiscal spending multipliers, what have we learned? American Economic Journal: Economic Policy, 11 (2):1 - 34.

Chodorow-Reich, G., Feiveson, L., Liscow, Z., and Woolston, W. (2012). Does state fiscal relief during recessions increase employment? American Economic Journal: Economic Policy, 4 (3):118-145.

Clemens, J. and Miran, S. (2012). Fiscal policy multipliers on subnational government spending. American Economic Journal: Economic Policy, 4 (2):46-68.

Coibion, O., Gorodnichenko, Y., and Ropele, T. (2018). Inflation expectations and firm decisions: New causal evidence. NBER Working Paper, No. 25412.

Conti-Brown, P. and Skeel, D. (2012). When States Go Broke: The Origins, Context, and Solutions for the American States in Fiscal Crisis. Cambridge University Press.

Dupor, B. and Guerrero, R. (2017). Local and aggregate fiscal policy multipliers. Journal of Monetary Economics, 92:16-30.

Dupor, B. and McCrory, P. (2017). A cup runneth over: Fiscal policy spillovers from the 2009 recovery act. The Economic Journal, 128 (611):1476-1508. 
Ellahie, A. and Ricco, G. (2017). Government purchases reloaded: Informational insufficiency and heterogeneity in fiscal vars. Journal of Monetary Economics, 90:13-27.

Esposti, R. and Bussoletti, S. (2018). Impact of Objective 1 Funds on regional growth convergence in the European Union: A panel-data approach. Regional Studies, 42 (2):159 $-173$.

Farhi, E. and Werning, I. (2017). Fiscal unions. American Economic Review, 107 (12):3788 -3834 .

Fève, P. and Pietruni, M. (2016). Noisy fiscal policy. European Economic Review, 85:414-436.

FFIS (2016). Summary of state matching and MOE requirements. Special Analysis 16-03, Federal Funds Information for States, Washington DC.

FFIS (2018). Grants 101: An introduction to federal grants for state and local governments. Primer Update, Federal Funds Information for States, Washington DC.

Fishback, P. and Kachanovskaya, V. (2015). The multiplier for federal spending in the states during the Great Depression. The Journal of Economic History, 75 (1):125-162.

Forni, M., Gambetti, L., and Sala, L. (2013). No news in business cycles. The Economic Journal, 124:1168-1191.

Fragetta, M., Gasteiger, E., and Richard, J. (2014). Fiscal foresight, limited information and the effects of government spending shocks. Oxford Bulletin of Economics and Statistics, $75(5): 667-692$.

Gabaix, X. (2011). The granular origins of aggregate fluctuations. Econometrica, 79 (3):733772.

Galí, J., David López-Salido, J., and Vallés, J. (2007). Understanding the effects of government spending on consumption. Journal of the European Economic Association, 45(1):227 -270 . 
Gamkar, S. and Oates, W. (1996). Asymmetries in the responses ot increases and decreases in intergovernmental grants: Some empirical findings. National Tax Journal, 49 (4):501-512.

Gonçalves, S. (2011). The moving blocks bootstrap for panel linear regression models with individual fixed effects. Econometric Theory, 27 (5):1048-1082.

Gordon, N. (2004). Do federal grants boost school spending? Evidence from Title I. Journal of Public Economics, 88:1771-1792.

Hausman, J. (2016). Fiscal policy and economic recovery: The case of the 1936 Veterans? Bonus. American Economic Review, 106 (4):1100-1143.

Ilzetzki, E., Mendoza, E., and Vgh, C. (2013). How big (small?) are fiscal multipliers? Journal of Monetary Economics, 60 (2):239-254.

Jaimovich, N. and Rebelo, S. (2009). Can news about the future drive the business cycle? The American Economic Review, 99 (4):1097-1118.

Jordà, O. (2005). Estimation and inference of impulse responses by local projections. American Economic Review, 95 (1):161-182.

Klarner, C. (2013). State partisan balance data, 1937 - 2011. Harvard University.

Knight, B. (2002). Endogenous federal grants and crowd-out of state-government spending: Theory and evidence from the Federal Highway Aid Program. American Economic Review, $92(1): 71-92$.

Kock, A. and Callot, L. (2015). Oracle inequalities for high dimensional vector autoregressions. Journal of Econometrics, 186 (2):325-344.

Leduc, S. and Wilson, D. (2013). Roads to prosperity or bridges to nowhere? Theory and evidence on the impact of public infrastructure investment. NBER Macroeconomics Annual 2012, pages 89-142. 
Leeper, E., Richter, A., and Walker, T. (2012). Quantitative effects of fiscal foresight. American Economic Journal: Economic Policy, 4 (2):115-144.

Leeper, E., Traum, N., and Walker, T. (2017). Clearing up the fiscal multiplier morass. American Economic Review, 107 (8):2409-2454.

Leeper, E., Walker, T., and Yang, S. (2010). Government investment and fiscal stimulus. Journal of Monetary Economics, 57:1000-1012.

Leeper, E., Walker, T., and Yang, S. (2013). Fiscal foresight and information flows. Econometrica, 81 (3):1115-1145.

Lewbel, A. (2019). The identification zoo: Meanings of identification in econometrics. Journal of Economic Literature, 57 (4):853-903.

Marglin, S. and Spiegler, P. (2013). Unpacking the multiplier: Making sense of recent assessments of fiscal stimulus policy. Social Research, 80 (3):819 - 854.

Mauro, P., Romeu, P., Binder, A., and Zaman, A. (2015). A modern history of fiscal prudence and profligacy. Journal of Monetary Economics, 76:55 - 70 .

Mertens, K. and Ravn, M. (2012). Empirical evidence on the aggregate effects of anticipated and unanticipated us tax policy shocks. American Economic Journal: Economic Policy, $4(2): 145-181$.

Mertens, K. and Ravn, M. (2013). The dynamic effects of personal and corporate income tax changes in the united states. American Economic Review, 103 (4):1212-1247.

Miller, R. (2007). Funding Extended Conflicts: Korea, Vietnam and the War on Terror. Praeger Security International, Westport, London.

Mohl, P. and Hagen, T. (2010). Do EU structural funds promote regional growth? New evidence from various panel data approaches. Regional Science and Urban Economics, 40:353-365. 
Mountford, A. and Uhlig, H. (2009). What are the effects of fiscal policy shocks? Journal of Applied Econometrics, 24 (6):960-992.

Nakamura, E. and Steinsson, J. (2014). Fiscal stimulus in a monetary union: Evidence from US regions. American Economic Review, 104 (3):753-792.

Nakamura, E. and Steinsson, J. (2018). Identification in macroeconomics. Journal of Economic Perspectives, 32 (3):59 - 86.

Nesbit, T. and Kreft, S. (2009). Federal grants, earmarked revenues, and budget crowd-out: State highway funding. Public Budgeting 83 Finance, 29 (2):94-110.

Pellegrini, G., Terribile, F., Tarola, O., Muccigrosso, T., and Busillo, F. (2012). Measuring the effects of european regional policy on economic growth: A regression discontinuity approach. Papers in Regional Science, 92 (1):217-234.

Puigcerver-Peñalver, M. (2007). The impact of structural funds policy on European regions' growth. a theoretical and empirical approach. The European Journal of Comparative Economics, 4 (2):179-208.

Ramey, V. (2011). Identifying government spending shocks: It's all in the timing. Quarterly Journal of Economics, 126 (1):1-50.

Ramey, V. (2015). Macroeconomic shocks and their propagation. Handbook of Macroeconomics, vol. 2:71-162.

Ramey, V. (2019). Ten years after the financial crisis: What have we learned from the renaissance in fiscal research? Journal of Economic Perspectives, 33 (2):89-114.

Ramey, V. (2020). The macroeconomic consequences of infrastructure investment. Working Paper, University of California/ NBER.

Ramey, V. and Shapiro, M. (1998). Costly capital reallocation and the effects of government spending. Carnegie-Rochester Conference Series on Public Policy, 48:145-194. 
Ramey, V. and Zubairy, S. (2018). Government spending multipliers in good times and in bad: Evidence from US historical data. Journal of Political Economy, 126 (2):850-901.

Ricco, G. (2015). A new identificvaiton of fiscal shocks based on the information flow. ECB Working Paper 1813.

Ricco, G., Callegari, G., and Cimadomo, J. (2016). Signals from the government: Policy disagreement and the transmission of fiscal shocks. Journal of Monetary Economics, 82:107-118.

Romer, C. and Romer, D. (2010). The macroeconomic effects of tax changes: Estimates based on a new measure of fiscal shocks. American Economic Review, 100 (3):763-801.

Schmitt-Grohé and Uribe, M. (2012). What's news in business cycles? Econometrica, 80 (6):2733-2764.

Shoag, D. (2016). The impact of government spending shocks: Evidence on the multiplier from state pension plan returns. Working paper, Harvard University.

Sims, E. and Wolff, J. (2018). The output and welfare effects of government spending shocks over the business cycle. International Economic Review, 59 (3):1403-1435.

Stock, J. and Watson, M. (2012). Disentangling the channels of the 2007-09 recession. Brookings Papers on Economic Activity, pages 81-156.

Stock, J. and Watson, M. (2018). Identification and estimation of dynamic causal effects in macroeconomics using external instruments. The Economic Journal, 128:917-948.

Stock, J. and Yogo, M. (2005). Testing for weak instruments in linear IV regression. In Identification and Inference for Econometric Models: Essays in Honor of Thomas Rothenberg, pages 80-108. Cambridge: Cambridge University Press.

Suárez Serrato, J. and Wingender, P. (2016). Estimating local fiscal multipliers. NBER Working Paper, No. 22425. 
Thissen, M., Diodato, D., and Van Oort, F. (2013). Integration and convergence in regional europe: European regional trade flows from 2000 to 2010. mimeo, PBL Netherlands Environmental Assessment Agency.

Thissen, M., Los, B., and Lankhuizen, M. (2017). Construction of a time series of finegrained detailed NUTS2 regional input-output tables for the EU embedded in a global system of country tables. mimeo, PBL Netherlands Environmental Assessment Agency.

Tibshirani, R. and Taylor, J. (2012). Degrees of freedom in lasso problems. Annals of Statistics, 40 (2):1198-1232.

Van Gemert, T. and Lieb, L. (2020). Effects of government spending news: The role of the anticipation horizon. Maastricht University, Working Paper.

Van Gemert, T., Lieb, L., and Treibich, T. (2020). Local fiscal multipliers of different government spending categories. Maastricht University, Working Paper.

Wilson, D. (2012). Fiscal spending jobs multipliers: Evidence from the 2009 American Recovery and Reinvestment Act. American Economic Journal: Economic Policy, 4 (3):251-282.

Woodford, M. (2011). Simple analytics of the government expenditure multiplier. American Economic Journal: Macroeconomics, 3 (1):1 - 35.

Zou, H. and Hastie, T. (2005). Regularization and variable seleciton via the elastic net. Journal of the Royal Statistical Society B, 67 (2):301 - 320.

Zou, H. and Zhang, H. (2009). On the adaptive elastic-net with a diverging number of parameters. Annals of Statistics, 37 (4):1733 - 1751. 
BIBLIOGRAPHY 


\section{Summary}

This thesis investigates the role of government spending in the economy. A central problem is that government spending and other macroeconomic variables are simultaneously affected by the same external factors. Moreover, policymakers often react directly to downturns in the economy by increasing spending, creating two-way causality. It is therefore difficult to estimate causal effects of changes in government spending. As a solution, each chapter uses econometric techniques to identify the part of government spending that does not react to movements of the economy. The aim is to understand which underlying factors play a role in the way government spending affects the economy. Three factors are analyzed: the anticipation horizon, categories of spending and sectoral and regional spillover effects. The conclusions are relevant for policymakers, and provide guidance for academic research.

Chapter 2 focuses on the anticipation horizon of government spending news, which is the period between the announcement of a change in government spending and the effective implementation. The chapter investigates to what extent the response of macroeconomic variables to government spending news is affected by the length of the anticipation horizon. For the analysis, news announcements related to defense spending in the United States are used. The main finding is that news about an increase in government spending in the more distant future results in positive economic effects, whereas news with a shorter anticipation horizon creates negative effects. Therefore, it is important that policymakers take into account that if they aim to provide an economic stimulus, there should be enough time for households and firms to anticipate on the policy change. Also, academic research into the macroeconomic effects of government spending news should take into account the effect of the 
anticipation horizon explicitly, because when spending news shocks with short anticipation horizons dominate in the analysis, then the true effects are underestimated.

Chapter 3 studies the economic effects of different categories of government spending. Specifically, the chapter focuses on the effects of defense versus non-defense spending across states in the United States. The methodology developed in this chapter relies on the notion that part of federal spending to states is allocated independently of the state-level economic conditions, and that the spending decision lies outside of the control of the state. The main finding is that an increase in defense spending results in smaller positive effects than non-defense spending. This finding implies that related studies that focus only on defense spending typically underestimate the true effect of government spending in general. This result is relevant for policymakers, because stimulus packages often involve multiple spending categories. Non-defense spending appears to be more effective than defense spending.

Chapter 4 investigates sectoral and regional spillover effects of government spending, with a specific application to EU Structural and Investment Funds across NUTS-2 regions in EU member states. Unlike existing studies that evaluate the long-term effects of EU funds, this chapter studies the short run. It is important for policymakers to not only know whether the long-term objectives are achieved, but also whether unintended short-run policy consequences arise. The methodology is similar to chapter 3 . The results indicate that in general the effects of EU funds are rather limited, but there are several relevant conclusions. In line with the literature, this chapter finds a mild positive overall effect in less-developed regions, driven by the industrial and public sector. In more-developed regions, the overall effect is slightly negative. Although some sectors like the construction sector are stimulated, other sectors such as the services sector are negatively affected. The regional spillover effects are limited at the regional level, but some sectors experience spillovers, which are in general opposite to the direct effects. Thus, policymakers should be aware that there can be negative effects at the sectoral level, or between regions. Academic research into the effects of government spending should pay more attention to spillovers between sectors and regions in policy recommendations and evaluations. 


\section{Nederlandstalige Samenvatting}

Dit proefschrift onderzoekt de rol van overheidsbestedingen in de economie. Een belangrijk probleem is dat overheidsbestedingen en andere macro-economische variabelen gelijktijdig worden beïnvloed door dezelfde externe factoren. Bovendien reageren beleidsmakers vaak direct op een economische teruggang met hogere bestedingen. Het is daardoor moeilijk om het causaal effect van veranderingen in overheidsbestedingen in te schatten. Als oplossing hiervoor gebruiken alle hoofdstukken in dit proefschrift econometrische technieken om het deel van de overheidsbestedingen te identificeren dat niet reageert op de economische conjunctuur. Het doel is om te begrijpen welke onderliggende factoren een rol spelen bij de manier waarop overheidsbestedingen een effect hebben op de economie. Drie factoren worden nader onderzocht: de anticipatiehorizon, categorieën van overheidsbestedingen, en sectorale en regionale overloopeffecten. De conclusies hieromtrent zijn relevant voor beleidsmakers, en schetsen mogelijke richtingen voor toekomstig academisch onderzoek.

Hoofdstuk 2 concentreert zich op de anticipatiehorizon van nieuws over overheidsbestedingen, oftewel de periode tussen de bekendmaking van een verandering in bestedingen en daadwerkelijke implementatie. Het hoofdstuk onderzoekt tot op welke hoogte de reactie van macro-economische variabelen op nieuws over overheidsbestedingen wordt beïnvloed door de lengte van de anticipatiehorizon. Voor deze analyse wordt gebruikgemaakt van nieuws over defensie-uitgaven in de Verenigde Staten. De belangrijkste conclusie is dat nieuws over een toename in de defensie-uitgaven in de verdere toekomst positieve economische effecten heeft, terwijl nieuws met een kortere anticipatiehorizon negatieve effecten heeft. Daarom is het belangrijk dat indien beleidsmakers de economie willen stimuleren, rekening gehouden 
moet worden met het feit dat huishoudens en bedrijven voldoende tijd hebben om te kunnen anticiperen op de beleidsverandering. Verder dient academisch onderzoek over de macroeconomische effecten van overheidsbestedingen expliciet rekening te houden met de anticipatiehorizon, omdat indien nieuws over bestedingen met een korte anticipatiehorizon de analyse domineert, de werkelijke effecten worden onderschat.

Hoofdstuk 3 bestudeert de economische effecten van verschillende categorieën overheidsbestedingen. Dit hoofdstuk concentreert zich specifiek op de effecten van defensie-uitgaven versus niet-defensie-uitgaven in staten van de Verenigde Staten. De methodologie die wordt uiteengezet in dit hoofdstuk maakt gebruik van het inzicht dat een deel van de federale bestedingen in staten onafhankelijk wordt toegewezen, los van de economische situatie in de staat, en dat de beslissing over de toewijzing van de gelden buiten de invloed van de staat ligt. De belangrijkste bevinding is dat een toename in de defensie-uitgaven kleinere positieve effecten heeft dan andere uitgaven. Dit betekent in het algemeen dat verwante studies die zich uitsluitend concentreren op defensieuitgaven het werkelijke effect van overheidsbestedingen in het algemeen onderschatten. Voor beleidsmakers is deze conclusie tevens relevant, omdat stimuleringspakketten vaak bestaan uit meerdere categorieën overheidsuitgaven. Niet-defensie-uitgaven blijken effectiever te zijn dan defensie-uitgaven.

Hoofdstuk 4 onderzoekt de sectorale en regionale overloopeffecten van overheidsbestedingen, specifiek toegepast op Europese Structuur- en Investeringsfondsen in NUTS-2 regio's van EU-lidstaten. In tegenstelling tot bestaande studies die de langetermijneffecten van EU-fondsen onderzoeken, concentreert dit hoofdstuk zich op de korte termijneffecten. Het is belangrijk voor beleidsmakers om niet alleen te weten of de doelen voor de lange termijn worden behaald, maar ook of er geen ongewenste korte termijneffecten optreden. De methodologie is vergelijkbaar met hoofdstuk 3. De resultaten geven aan dat over het algemeen de effecten van EU-fondsen vrij beperkt zijn, maar er zijn enkele relevante conclusies te trekken. In lijn met de literatuur, worden ook in dit hoofdstuk milde positieve effecten op regionaal niveau gevonden in minder ontwikkelde regio's, veroorzaakt door de industriële en publieke sector. In beter ontwikkelde regio's is het effect op regionaal niveau enigszins negatief. 
Alhoewel sommige sectoren waaronder de bouwsector worden gestimuleerd, ondervinden andere sectoren zoals de dienstensector negatieve effecten. De regionale overloopeffecten zijn vrij beperkt op het regionale niveau, maar er zijn wel regionale overloopeffecten in sommige sectoren, en die zijn tegenovergesteld aan de directe effecten. Beleidsmakers dienen zich er dus bewust van te zijn dat negatieve effecten op sectoraal niveau of tussen regio's kunnen optreden. Academisch onderzoek naar de effecten van overheidsbestedingen dient meer aandacht te besteden aan overloopeffecten tussen sectoren en regio's in aanbevelingen voor nieuw beleid en evaluaties van bestaand beleid. 


\section{Curriculum Vitae}

Thomas van Gemert was born on March 9, 1993 in Weert in the Netherlands. In 2011, he started studying economics at Maastricht University. After completing the bachelor's degree Economics and Business Economics, including an exchange semester at Queen's University in Canada, he started the research master Economic and Financial Research in 2014. During his master's studies, he was research assistant for Dr. Lenard

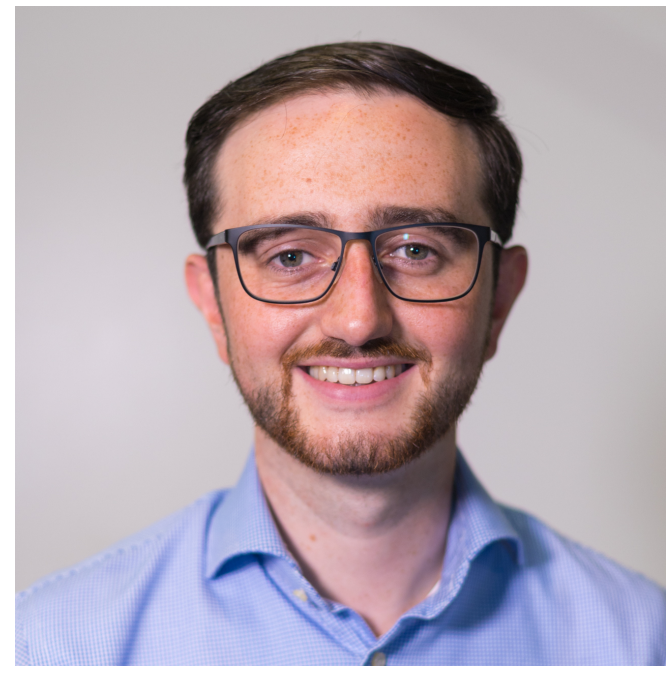
Lieb, and teaching assistant at the Economics Department. In 2016, he graduated cum laude from the research master and started a PhD track at the same university, supervised by Prof. Clemens Kool, Prof. Tom van Veen, Dr. Tania Treibich and Dr. Lenard Lieb. This dissertation contains his research.

Thomas has presented his research in various academic conferences, such as the International Conference on Computational and Financial Econometrics (London, 2017), the International Association of Applied Econometrics (Nicosia, 2019), the Netherlands Economist Day (Amsterdam, 2019), the Annual Belgian Macroeconomics Workshop (Ghent, 2019), and the (EC) $)^{2}$ Conference on Identification in Macroeconomics (Oxford, 2019).

During his $\mathrm{PhD}$ track, Thomas also engaged in many teaching activities, and acquired the University Teaching Qualification. He taught several undergraduate courses in microe- 
conomics, macroeconomics and international economics, and also coordinated a third-year bachelor course on the topic of globalisation.

In 2020, Thomas started working at Statistics Netherlands (CBS), in the team for International Trade in Goods Statistics. In this team, he works on the development and implementation of new methodologies for the production of trade statistics, in line with new European legislation for business statistics.

Thomas is also politically active. In 2017 he was elected in the municipal council of Weert. Since 2018, he has been chairman of the liberal policial party VVD in the council. 